Portland State University

PDXScholar

$1-1-2010$

\title{
Multi-Criteria Trucking Freeway Performance Measures for Congested Corridors
}

Nicole Marie Wheeler

Portland State University

Follow this and additional works at: https://pdxscholar.library.pdx.edu/open_access_etds Let us know how access to this document benefits you.

\section{Recommended Citation}

Wheeler, Nicole Marie, "Multi-Criteria Trucking Freeway Performance Measures for Congested Corridors" (2010). Dissertations and Theses. Paper 177.

https://doi.org/10.15760/etd.177

This Thesis is brought to you for free and open access. It has been accepted for inclusion in Dissertations and Theses by an authorized administrator of PDXScholar. Please contact us if we can make this document more accessible: pdxscholar@pdx.edu. 


\title{
Multi-Criteria Trucking Freeway \\ Performance Measures for Congested Corridors
}

by

Nicole Marie Wheeler

A thesis submitted in partial fulfillment of the requirements for the degree of

\author{
Master of Science \\ in \\ Civil And Environmental Engineering
}

Thesis Committee:

Miguel Figliozzi, Chair

Christopher Monsere

Ashley Haire

Portland State University

(C) 2010 


\begin{abstract}
This research focuses on the development of multi-criteria tools for measuring and analyzing the impacts of recurring and non-recurring congestion on freight corridors in the Portland Metropolitan Area. Unlike previous studies, this work employs several distinct data sources to analyze the impacts of congestion on Interstate 5 (I-5) in the Portland Metropolitan Area: global positioning system (GPS) data from commercial trucks and Oregon DOT corridor travel-time loop data and incident data. A new methodology and algorithms are developed to combine these data sources and to estimate the impacts of recurrent and non-recurrent congestion on freight movements' reliability and delays, costs, and emissions. The results suggest that traditional traffic sensor data tend to underestimate the impacts of congestion on commercial vehicles travel times and variability. This research also shows that congestion is not only detrimental for carriers and shippers costs but also for the planet due to major increases in GHG emissions and for the local community due to large increases in NOx, PM, and other harmful pollutants. The methodology developed throughout this work has the potential to provide useful freight operation and performance data for transportation decision makers to incorporate freight performance measures into the planning process.
\end{abstract}




\section{Dedication}

This thesis is dedicated to my amazing boyfriend who encouraged me throughout this process, my loving and supportive parents and sisters, and my favorite coffee shop-thank you Tom, mom, dad, Kelly, Ashley, and Corbett Coffee Plant!! 


\section{Acknowledgements}

Special thank you to Dr. Figliozzi for his guidance over this research and as my advisor during my time at Portland State University. Thank you to my committee members, Dr. Figliozzi, Dr. Monsere and Dr. Haire, for careful review and assistance with my final thesis. Thank you to Jeffrey Short from the American Transportation Research Institute for his help in acquiring and handling the GPS data. I gratefully acknowledge the Oregon Transportation, Research and Education Consortium (OTREC) and Federal Highway Administration for sponsoring this research. 


\section{Table of Contents}

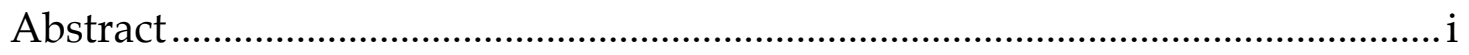

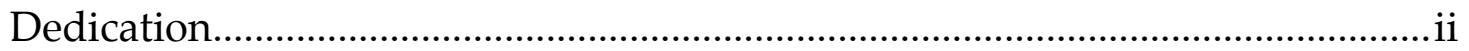

Acknowledgements......................................................................................ii

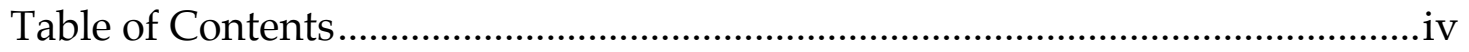

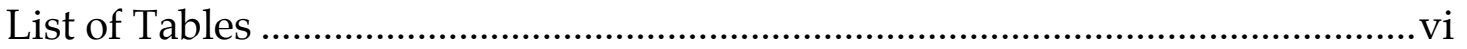

List of Figures................................................................................................

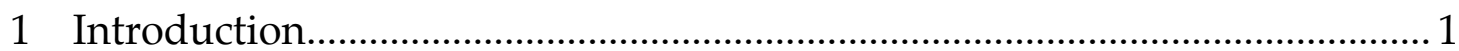

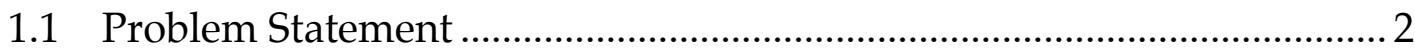

1.2 Research Objectives........................................................................ 3

1.3 Project Scope ................................................................................. 4

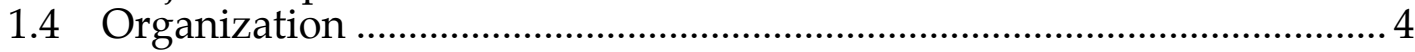

2 Background .................................................................................. 6

2.1 Developing Congestion and Mobility Performance Measures................ 6

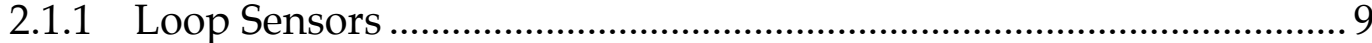

2.1.2 Weigh-In-Motion (WIM) and Truck Transponder Data.................. 10

2.1.3 Commercial Global Positioning System (GPS) Data ....................... 12

2.2 Monetary Performance Measures ............................................................ 13

2.2.1 Variations in Value of Time for Freight Vehicles ............................ 14

2.2.2 Monetizing Travel Time and Delay Using Value of Time .............. 15

2.2.3 Incorporating Travel Time Reliability in Travel Cost Calculations16

2.2.4 Monetizing Travel Time and Delay Using Operational Cost ......... 17

2.3 Environmental and Health Performance Measures ............................... 19

2.3.1 Importance of Quantifying Freight Emissions............................... 20

2.3.2 Emissions and Air Pollutants ............................................................. 20

2.3.3 Factors Contributing to Freight Emissions ................................... 23

2.3.4 Modeling Freight Vehicle Emissions ........................................... 27

2.4 Summary of Background Review ...................................................... 28

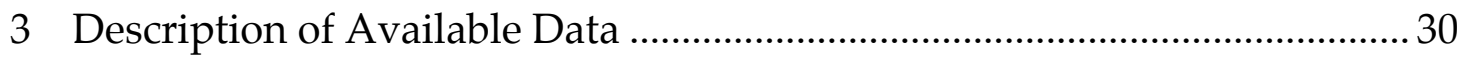

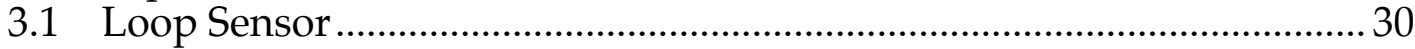

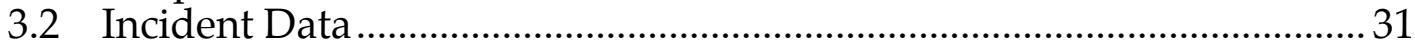

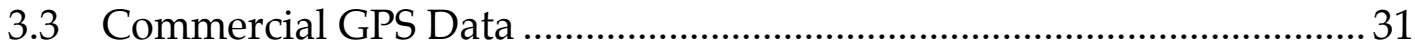

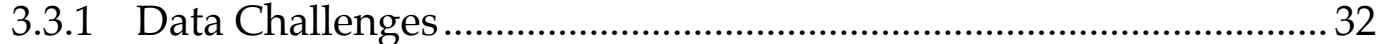

3.3.2 Truck Travel Types ....................................................................... 36

4 Methodology For Identifying Through Trucks........................................ 41

4.1 Filter Process 1: Truck ID Matching .................................................... 41

4.2 Filter Process 2: Comparison to Loop Sensor Average Travel Time .... 42

4.3 Methodology for Non-Recurring Congestion ....................................... 45

5 Recurring Congestion Results ................................................................. 49 


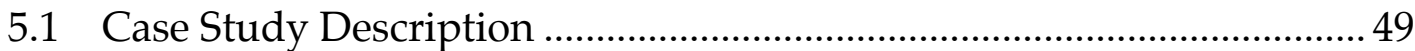

5.2 Travel Time, Delay and Reliability .............................................................5 51

5.3 The Cost of Recurring Congestion ..............................................................53

5.4 Recurring Congestion Emissions Estimation ...........................................5 57

5.5 Recurring Congestion Summary ..............................................................5

5.5.1 Adapting Methodology to Smaller Segments ........................................ 60

5.5.2 Integrating Loop Sensor Data and Commercial GPS Data ................64

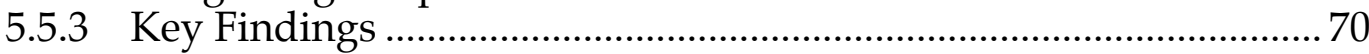

5.5.4 Applying Techniques for Deriving Multi-Criteria FPM in Practice 74

6 Non-Recurring Congestion Results ................................................................77

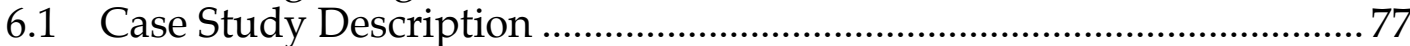

6.1.1 Impact of an Incident on Freight Movements...................................... 80

6.1.2 Effect of Including Partial Through/Local Trucks.............................. 81

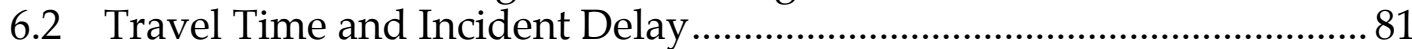

6.2.1 Impact of an Incident on Freight Movements ................................... 81

6.2.2 Effect of Including Partial Through / Local Trucks ................................ 87

6.3 The Cost of Non-Recurring Congestion.................................................... 90

6.4 Non-Recurring Congestion Emissions Estimation .................................... 93

6.5 Non-Recurring Congestion Summary ……………................................... 99

6.5.1 Summary of Key Findings ........................................................... 99

6.5.2 Applying Techniques for Deriving Multi-Criteria FPM in Practice 101

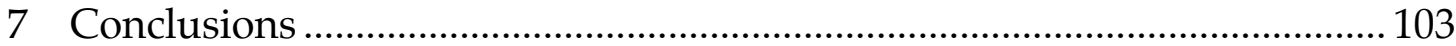

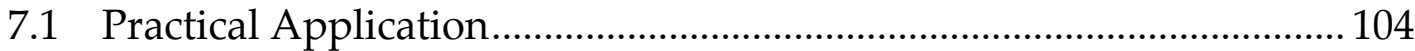

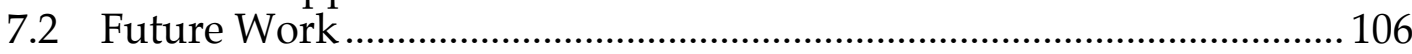

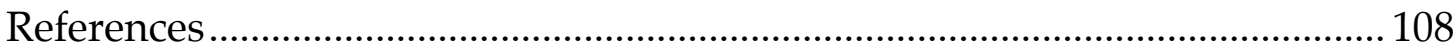

Appendix A: Cost Estimation Parameters for Recurring and Non-Recurring Congestion Analysis ...................................................................................... 112

Appendix B: MOVES2010 Emission Estimation Input Parameters for Recurring and Non-Recurring Congestion Analysis ......................................... 117 


\section{List of Tables}

Table 1: User-Defined Parameters for Recurring Congestion Case Study....... 50

Table 2: Percent increase in Multi-Criteria Performance Measures, above 52.05 mph free-flow conditions for All Day and PM Peak (3-6 PM) time periods. 72

Table 3: Percent increase by time of day in emission rates (g/mile), above emissions during $52.05 \mathrm{mph}$ free-flow conditions. Freight vehicle average speed and volume are shown by time of day. A limited amount of truck data was available for AM and PM off-peak periods, so free-flow conditions were assumed-this means in off peak periods a $0 \%$ increase would occur. 74

Table 4: User-Defined Parameters for Filter Process 1 for Non-Recurring Congestion Case Study 77

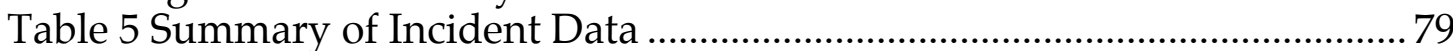

Table 6: Non-Recurring, Recurring and Free-Flow travel times through fivemile incident areas. 91

Table 7: Average impact of an incident; average percent increase in delay, cost and emission relative to free-flow, and recurring congestion conditions. Averages are based on data obtained for incidents C1-1, A1-2, B2-3 and A4-1 101 


\section{List of Figures}

Figure 1: Value of time for freight vehicles $(\$ / h r)$ derived from several

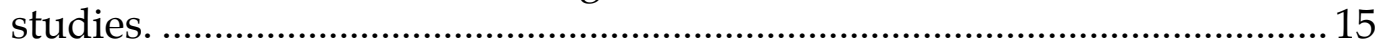

Figure 2: Operating costs involved in the trucking industry............................. 18

Figure 3: Emission-Speed Plot Taken from Barth \& Boriboonsomisin, 2009

(37); moderate speeds show minimum emission rates................................. 24

Figure 4: Map showing truck GPS data coverage provided by ATRIindividual readings on I-5 for August 2007 are shown (146,290 readings). An average of 126,000 readings occurred each month, with roughly 1,500,000 readings total for January through December 2007.

.34

Figure 5: Truck travel types, 1) Through, 2) Partial Through, 3) Partial Local, and 4) Local ......................................................................................... 36

Figure 6: GPS spot speeds for seven trucks (through, partial through, partial local, or local trucks) at I-5/I-84 Junction in Portland, OR. It is possible for the local readings to be improperly assigned to the freeway network, presenting a bias of slower speeds in the data set......................................... 39

Figure 7: Diagram showing user-defined parameters for Filter Process 1 (truck ID matching to find potential through trucks), and corresponding algorithm logic.

Figure 8: Diagram of parameters for Filter Process 1 used to study incident areas A, B and C............................................................................................. 46

Figure 9: Diagram parameters for Filter Process 1, used to study incident

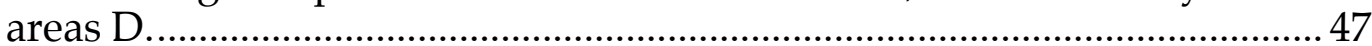

Figure 10: Map of loop sensor station locations along northbound I-5 recurring congestions study area...............................................................5 50

Figure 11: From top to bottom, a) Average corridor travel time results following Filter Process 2, showing aggregated loop sensor and through trucks travel time over one year (standard error of mean noted for multiple through truck readings in a time bin); b) Coefficient of variation in travel time (smoothed data by moving average of 3 time bins).............. 52

Figure 12: From top to bottom, a) Percent increase in freight vehicle cost of delay for northbound I-5 for three cost formulation types; b) Summary of general cost formulation types and percent increase in daily cost of delay for freight vehicles relative to $52.05 \mathrm{mph}$ free-flow travel time. 55

Figure 13: From top to bottom, a) Daily cost of delay per mile for freight vehicle traveling northbound I-5 for different cost scenarios; b) Cost scenario descriptions, parameters and formulations used. 56

Figure 14: Top to bottom: a) Percent increase in freight vehicle Greenhouse Gas (GHG), Mobile Source Air Toxic (MSAT), and Criteria Pollutant (CP) emissions in congestion relative to $52.05 \mathrm{mph}$ free-flow emission rates, and corresponding increases in freight vehicle-hours of delay per mile; b) Summary of daily freight vehicle emission rates above $52.05 \mathrm{mph}$ freeflow emission rates. 
Figure 15: Average corridor travel time results following Filter Process 2 at a five-mile segment of northbound I-5 near Corbett Ave., showing aggregated loop sensor and through trucks travel time over a threemonth period (with standard error of mean noted for multiple readings in a time bin) .................................................................................................... 62

Figure 16: Average corridor travel time results following Filter Process 2 at a five-mile segment of northbound I-5 near Morrison St., showing aggregated loop sensor and through trucks travel time over a threemonth period (with standard error of mean noted for multiple readings in a time bin).

Figure 17: Average corridor travel time results following Filter Process 2 at a five-mile segment of northbound I-5 near Terwilliger Blvd., showing aggregated loop sensor and through trucks travel time over a threemonth period (with standard error of mean noted for multiple readings in a time bin) 63

Figure 18: From top to bottom, a) average corridor travel time shown for dynamic and static aggregation of loop sensor data, alongside truck average corridor travel time (with standard error of the mean shown); $b$ ) percent increase in dynamic sensor travel time compared to static loop sensor travel time (positive values indicate dynamic travel time is longer-slower, negative values indicate dynamic travel time is shorterfaster). 66

Figure 19: Results from statistical analysis comparing differences in mean between truck average corridor travel time and static loop sensor travel time, dynamic loop sensor travel time, and travel time at $52.05 \mathrm{mph}$ freeflow conditions. Results indicate whether the truck average corridor travel time is statistically significantly different than the loop sensor and free-flow travel time for a given time bin, at a confidence level of $95 \%$. Also noted is whether or not truck data show travel time longer or shorter travel time in comparison. Data for dynamic loop sensor travel time were available only for the time binds listed above. 67

Figure 20: Percent increase in right lane travel time results compared to the travel time averaged from all lanes at five stations on northbound I-5. When values are positive, the right lane shows longer (slower) travel time; when values are negative, the right lane shows shorter (faster) travel time. 68

Figure 21: Diagrams of I-5 northbound incident areas A, B, C and D, showing incident locations........................................................................................ 80

Figure 22: From top to bottom, a) Incident area A northbound I-5 throughincident truck travel time results following Filter Process 2-June 8, 2007; b) Incident area A northbound I-5 through-incident truck travel time results following Filter Process 2-July 3, 2007. 83

Figure 23: From top to bottom, a) Incident area A northbound I-5 throughincident truck travel time results following Filter Process 2-August 14, 
2007; b) Incident area A northbound I-5 through-incident truck travel time results following Filter Process 2-August 24, 2007. .......................... 84

Figure 24: From top to bottom, a) Incident area B northbound I-5 throughincident truck travel time results following Filter Process 2-July 26, 2007; b) Incident area B northbound I-5 through-incident truck travel time results following Filter Process 2-August 2, 2007. 85

Figure 25: From top to bottom, a) Incident area $C$ northbound I-5 throughincident truck travel time results following Filter Process 2-June 12, 2007; b) Incident area C northbound I-5 through-incident truck travel time results following Filter Process 2-August 3, 2007. 86

Figure 26: From top to bottom, a) Incident area D northbound I-5 throughincident truck travel time results following Filter Process 2-December 12, 2008 (with standard error of mean noted for multiple readings in a time bin); b) Incident area D northbound I-5 partial through and partial local incident truck travel time results following Filter Process 2-December 12, 2008 (with standard error of mean noted for multiple readings in a time bin). 89

Figure 27: Percent increase in freight vehicle cost of incident delay for northbound I-5, relative to $52.05 \mathrm{mph}$ free-flow travel time and relative to recurring congestion travel times presented in Table 6 92

Figure 28: From top to bottom, cost of incident delay per mile for freight vehicle traveling northbound I-5 during incident periods C1-1, A1-2, B2-3 and A4-1, a) relative to free-flow travel time at $52.05 \mathrm{mph}$; b) relative to recurring congestion travel times presented in Table 6; c) cost scenario descriptions, parameters and formulations used for non-recurring analysis. 94

Figure 29: From top to bottom, percent increase in freight vehicle Greenhouse Gas (GHG emissions from freight vehicle traveling northbound I-5 during incident periods C1-1, A1-2, B2-3 and A4-1, a) relative to $52.05 \mathrm{mph}$ freeflow emission rates; b) relative to recurring congestion travel times presented in Table 6.

96

Figure 30: From top to bottom, percent increase in freight vehicle Mobile Source Air Toxic (MSAT) emissions from freight vehicle traveling northbound I-5 during incident periods C1-1, A1-2, B2-3 and A4-1, a) relative to $52.05 \mathrm{mph}$ free-flow emission rates; b) relative to recurring congestion travel times presented Table 6 . 97

Figure 31: From top to bottom, percent increase in freight vehicle Criteria Pollutant $(\mathrm{CP})$ emission emissions from freight vehicle traveling northbound I-5 during incident periods C1-1, A1-2, B2-3 and A4-1, a) relative to $52.05 \mathrm{mph}$ free-flow emission rates; b) relative to recurring congestion travel times presented in Table 6. 98

Figure 32: From top to bottom, a) truck count distribution at a northbound I-5 count station between Victory and OR 99W; b) average hourly northbound I-5 truck counts by time of day (average is was take from 8 count stations, each with 3 days of count data from spring of 2006)....... 115 
Figure 33: Freight vehicle value of time used in cost estimations of recurring and non-recurring congestion; value of time for the source year are shown alongside the 2010 adjusted prices. Costs were adjusted using the consumer price index (45).

116

Figure 34: Link and Link Drive Schedule travel time and speed distributions for recurring congestion analysis. For of-peak periods (where little through truck data was observed) $52.04 \mathrm{mph}$ free-flow conditions were assumed. . 123

Figure 35: Link and Link Drive Schedule travel time and speed distributions for non-recurring analysis; non-recurring and recurring congestion conditions provided for each incident areas and incident period studied. 124 


\section{Introduction}

Due to its geographic location, Oregon's economy is highly dependent on reliable freight transportation. Recent studies indicate that projected growth in freight and passenger traffic will significantly increase congestion and travel time delays. Further, it is predicted that congestion may result in loss of value added generation of as much as $\$ 1.7$ billion per year by 2025 in Oregon, and a "loss of 16,000 ongoing jobs" $(1,2)$. For the freight industry, delay and congestion not only negatively impact the businesses that rely on efficient and timely deliveries, but also increase emission levels and the cost of transporting goods. In order to improve the functionality of transportation networks and make efficient use of funds, it is crucial that public agencies develop the proper tools to assess transportation system performance.

Performance measures allow planners and engineers to monitor and evaluate the operation of a facility, transportation system, or particular project. Performance measures include travel time, speed, travel time reliability and others derived from these basic measures. Early on in the adoption process of performance-based metrics, passenger vehicles were the main focus, while freight traffic was not incorporated independently (3). Therefore, freight specific performance measures (FPMs) are not in wide use by public agencies. It is becoming increasingly important to continue to develop a system of performance measures that will capture the impact of congestion on different modes, the environment, and people living near a transportation network.

Recently, a body of research has emerged which employs new methods for collecting and analyzing data from the trucking industry and commercial 
vehicles in order to develop freight performance measures. This research is showing great promise for providing consideration of freight transportation within transportation improvement projects.

\subsection{Problem Statement}

Distinct from other studies, this work employs GPS data from commercial trucks, corridor travel time loop data (from Oregon DOT sensors), and incident data to study travel time on I-5 in the Portland Metropolitan area. Integrating the loop sensor data with the truck GPS data in the filtering algorithm allows for validation between the two data sets, and improves the filtering process to identify trucks that have experienced congested freeway conditions-by classifying truck types, trucks that have diverted from the freeway network to the local network between GPS readings are eliminated from the analysis. Unlike the loop sensor data, which may underestimate the impacts of congestion on trucks, the GPS data more accurately portray the roadway conditions experienced by trucks.

A methodology has been developed to combine these data sources and estimate the impacts of recurrent and non-recurrent congestion on freight movement speed, travel time and travel time reliability. This study seeks to distinguish trucks moving along a freeway network from those making local movements (such as for rests or refueling) in order to study freight performance with unbiased measures-these trucks traveling the corridor without stopping are referred to as through trucks. This work is the first to 
integrate the multiple data sets into filtering algorithms, and the first to identify through trucks within the freeway network from GPS data in order to remove bias from trucks traveling as lower speeds on the local network, or higher speeds on nearby frontage roads.

The freight performance measures are then monetized and used to estimate emissions through an urban corridor using standard methods-this research is a pioneer in using FPMs from through trucks to investigate the impact of congestion on freight cost and freight vehicle emissions through urban areas. The methodology developed and applied in this research provides multiple criteria for evaluating the performance of freight vehicles and accounts for the impact of congestion on freight industry profit, environmental quality and health of people near transportation facilities. The analysis of the commercial truck GPS data is a significant step not only in understanding the behavior of freight travel throughout the day, but also the impact caused by recurring congestion and incidents along the corridor on freight performance.

\section{$1.2 \quad$ Research Objectives}

The objective of this research is to study the impact of both recurring and nonrecurring congestion on the freight industry using multiple criteria to evaluate freight performance. In order to evaluate performance this research: (1) reviews current research and methodologies to study freight performance, cost and emissions to identify research gaps and appropriate techniques; (2) develops and applies a methodology to identify through trucks from GPS 
readings, and uses through truck data to generate travel time distributions over time; (3) compares findings to loop sensor data to observe trends and develop mobility performance measures; (4) applies standard methods to quantify performance measures in terms of freight industry costs; and (5) employs the MOVES2010 emission model to estimate freight vehicle emissions during congested periods.

\subsection{Project Scope}

This research will focus the recurring congestion study on truck data collected over a one-year period in 2007; the analysis will cover the northbound I-5 corridor surrounding the Portland metropolitan area. The non-recurring congestion study will focus on five incident periods and investigate five-mile segments surrounding each incident. Cost and emission estimations will be quantified at the corridor level, and for one-hour periods when incidents occurred.

\subsection{Organization}

This paper is organized as follows. Section 2 provides a review of performance measures in general, methods for monetizing these measures, and guidance for quantifying and monitoring the impact of congestion on the environment and public health. Section 3 discusses the data sources used in this research. Section 4 discusses the procedure to identify through trucks (trucks that have traveled a corridor without stopping for deliveries, rest periods or to refuel the vehicle). Section 5 discusses the recurring congestion case study used in this research. The results from the case study are discussed in terms of mobility and congestion performance measures, freight industry cost, and freight 
vehicle emissions. A summary of the results from the recurring congestion analysis is provided at the end of Section 5. Section 6 discusses the nonrecurring congestion case study used in this research. The results from the case study are discussed in terms of mobility and congestion performance measures, freight industry cost, and freight vehicle emissions. A summary of the results from the non-recurring congestion analysis is provided at the end of Section 6. Section 7 provides a summary of conclusions and recommendations from this research. Here, the research findings summarized and related to planning and engineering practices, as well as applications for use by carriers and truckers in the freight industry. 


\section{Background}

This section provides a review of performance measures in general, and the development of freight performance measures specifically related to the trucking industry. Here, the reader will find a description of data sources and methods used to determine congestion and mobility performance measures for freight vehicles, methods for monetizing these measures, and guidance for quantifying and monitoring the impact of congestion on the environment and public health.

\subsection{Developing Congestion and Mobility Performance Measures}

Performance can be defined as how well a system or project is meeting an intended goal or purpose $(4,5)$. Performance measures are an essential element of the planning process; they are quantifiable and help to inform and justify decisions made by government officials. Additionally, performance measures make it possible to prioritize system improvements so a region may target areas most in need of improvement, thereby making efficient use of funds. As new performance measures are developed, it is also expected that they are efficient (in terms of the data and analysis required), and easy to understand, because they are used in communication with the public $(4,5)$. In this way, performance measures increase accessibility and understanding of transportation issues within the public body of knowledge, as well as increase accountability of the decision makers.

Transportation asset management performance measures fall under a broad range of categories, including (5): preservation, accessibility, mobility, operations and maintenance, safety, environmental impacts, economic 
development, social impacts, security and project delivery. Because of the nature of the freight industry, performance measures falling under the mobility category provide the key to understanding how freight movements may be impacted by the current and future transportation network. Mobility can be defined as how easily a vehicle can travel between origin and destination (5). Inadequate system performance in mobility creates challenges for the freight industry, including increased difficulty in scheduling departure/arrival times, additional fees for late arrivals, and potential loss of time-sensitive goods, such as food.

Travel time- the time it takes a driver to travel between an origin and destination-is the most basic measure of roadway performance. Travel time information is easy to interpret, and is desired by the general traveling public, as well as freight carriers. Travel time data are most often collected using loop sensors embedded in the roadway. The network of loop sensors allows agencies to study corridor travel time under both recurring and non-recurring congestion conditions. Recurring congestion conditions can be defined as congestion present day-to-day, resulting from fluctuations in demand or roadway geometry. Non-recurring congestion conditions are associated with unexpected events that impact traffic flow, such as a collision, stalled vehicle, weather event or construction. While critical information can be gleaned from travel time data, the infrastructure installation and collection effort required to gather and analyze the information is costly. This limits how extensive the coverage can be. For some states, the cost is too great to implement a system of 
loop sensors to collect travel time data (6). As such, it is important to use readily available data sets with wider coverage area to further the development of performance measures.

There are several performance measures that can be calculated from travel time, with a bit of supplemental data and information about the corridor in question. In comparison to uncongested free-flow travel time conditions, delay is defined as the amount of additional time required to travel a corridor during congested conditions. Delay can be calculated in terms of intensity, (e.g., person-minutes/day, or vehicle-minutes/day of delay), or represented in terms of the extent of roadway (e.g., number of miles of congested roadway, or vehicle-miles under congested conditions).

Reliability of a system is defined as the variability in travel time, or delay (6). NCHRP Report 618 recommends the use of $90^{\text {th }}$ and $95^{\text {th }}$ percentile travel times for a given route or trip as the simplest indicator of travel time reliability-this measure allows users to understand how bad delay or travel time may be during heavy congestion (6). Other recommended measures of reliability include the Buffer Index (BI) and the Planning Time Index, which calculate an allotted trip time for drivers to account for variation caused by congestion.

Finally, speed is often used as a measure of performance, calculated from the travel time and distance of a given corridor or trip. State DOT's with freeway and arterial loop sensor networks will typically use speeds to graphically display the real-time performance of the roadway. The use of 
segment speed and visual displays via a DOT webpage help to convey general roadway conditions effectively.

Roadway loop sensors, weigh-in-motion data, and GPS data can be used to obtain travel time and speed information for freight trucks. However, with each data source there are advantages and challenges in using the data for the purpose of deriving freight performance measures for congestion and mobility (such as travel time, speed, and travel time reliability).

\subsubsection{Loop Sensors}

The use of archived loop sensor data has shown success in estimating freeway performance (e.g., travel time, speed, and vehicle count), can be used to study recurring and non-recurring congestion, and help to identify and study bottlenecks within regions $(7,8)$. However, loop sensors are limited in their ability to capture different vehicle types traveling along the freeway to provide disaggregate data by mode.

Research at the University of Washington has studied the reliability of loop detectors in providing accurate count and speed results by vehicle type, and the capability of loop detectors to differentiate between vehicles by incorporating video footage $(9,10)$. The findings show that there is promise in integrating single loop detectors with video footage to differentiate between general purpose vehicles and freight vehicles with reasonable accuracy in count and speed estimates, however, dual loop detectors were found to be less reliable and could not reasonably estimate between vehicle types during congestion (9). Sensitivity and hardware errors occurring when dual loop 
sensors are used to detect vehicle types are likely to result in discrepancies in count by lane, vehicle speeds, and proper differentiation of mode. Additionally, underlying logic within the algorithm and large fluctuations/variations in speed during congested periods may cause additional issues (9).

\subsubsection{Weigh-In-Motion (WIM) and Truck Transponder Data}

At weigh-in-motion (WIM) stations located along the interstate highways, freight vehicles equipped with electronic truck transponders are required to pass through the checkpoint, where vehicle weight, timestamp of visit, and other credentials are recorded. The driver is given an in-vehicle green light to continue, or a red light to pull off for further inspection. In the US, three main programs exist that utilize electronic transponders: (1) the Heavy Vehicle Electronic License Plate (HELP) program, (2) the North American Preclearance and Safety System (NORPASS) program, and (3) the Oregon Green Light program.

Recently, researchers have investigated the use of truck transponder data as a source for truck travel time information, which could then be used to develop freight performance measures. If a transponder-equipped vehicle can be tracked at two sequential stations, the timestamp at each can be used to generate information regarding the trip, which translates into freeway link performance (travel time, speed, reliability). However, there are challenges in working with truck transponder data. First, there are generally long distances between WIM stations and few locations, so a freight vehicle has opportunity 
to stop, rest, re-fuel or make deliveries before it is tracked at the next station. Algorithms must be incorporated to filter out trucks that have not traveled through the corridor without stopping, because their travel time information would present a bias in the data (slower travel time due to stopping/resting or delivery). Secondly, the number of trucks equipped with transponders is relatively low, and a large sample size must be required to accurately estimate link travel time based on the truck data (11).

Initial work at the University of Washington investigated the use of truck transponder data in providing link travel time information (12). Following this work, the researchers found that both GPS and truck transponder technologies have the potential to estimate link travel times; however, a large number of vehicle observations are required and must incorporate methods for determining which trucks have stopped for deliveries, resting, or refueling (13).

Recent work at Portland State University, under the sponsorship of the U.S. DOT University Transportation Centers Program, investigated the use of transponder-equipped trucks to make travel time estimations between weigh stations in rural Oregon (11). Similar to previous research, this work incorporated algorithms to identify trucks deviating from the freeway between WIM stations by matching unique truck ID's between stations, and using time thresholds and comparisons between trucks to identify those traveling through the corridor without stopping. This research was successful in developing an effective algorithm to identify through trucks, and deriving 
additional measures of performance by quantifying overweight vehicles, tonmiles on corridors, empty vehicles, the penetration of trucks with truck transponders, origin-destination estimations, and seasonal variability in various measures as well as travel time estimations (11).

The studies discussed above have been successful incorporating techniques and algorithms to mine truck transponder data to identify trucks that have traveled the freeway without stopping.

\subsubsection{Commercial Global Positioning System (GPS) Data}

At the national level, the Federal Highway Administration (FHWA) in partnership with the American Trucking Research Institute (ATRI) have looked at methodologies to utilize GPS technology to determine travel time reliability in freight corridors (14) and to identify freight bottlenecks (15). Most recently, FHWA and ATRI released an online freight performance measure tool, FPMweb, giving users access to aggregated operational truck speed information using GPS data from several hundred thousand unique trucks (16). Limitations associated with the approach of the earlier work, (14), were carefully examined by Schofield and Harrison (3). The main problems they observed were: (a) the accuracy of the GPS coordinates which in some cases may have an error of up to $1 / 4$ of a mile and (b) the low number of observations in areas with low traffic volume. In addition, a more severe limitation is that the data do not differentiate between vehicle stops due to congestion and stops due to refueling or mandatory driver rest periods. This presents a bias in 
the data set, where slow speeds may be representing local trips rather than congestion on the network.

Researchers at the University of Washington acquired GPS data from many vehicles (commercial trucks) having infrequent readings and used these to estimate link travel time, develop freight performance measures and study before and after conditions where roadway improvements were made $(13,17)$. The research team used spot speeds (the speed between two subsequent readings) to estimate measures of mobility. Although a significant amount of data cleaning was employed to remove erroneous data, the data were not filtered to identify truck type behaviors (e.g., identifying trucks that have not stopped along the corridor). The research indicated that spot speeds are best used for large quantities of data, over longer periods of time (17), however, the team was successful in showing benefit of a freeway improvement project by studying GPS data on a small scale before, after, and during construction.

\subsection{Monetary Performance Measures}

Projects may be ranked by system performance, but performance measures may also be monetized and ranked in order to show benefit and impact of a proposed project. Without accurate information regarding the operating costs or value of time for the freight industry, it is possible to underestimate the benefit of a given project or overestimate the benefit of financing strategies like congestion pricing (18). In this section, data sources and methods used to monetize performance measures are discussed. 


\subsubsection{Variations in Value of Time for Freight Vehicles}

Research has shown great variation in freight value of time across regions, roadway conditions, and carrier types. The value of time for freight vehicles derived in several studies is presented in Figure 1.

The NCHRP 431 report investigated variations in value of time for passenger vehicles and commercial trucks under hypothetical congested roadway scenarios. For both freight and passenger vehicles, time losses during congestion were valued at more than twice the value of time savings during uncongested conditions. This report recommends the use of travel time values for congested periods that are 2.5 times the value of time estimates during uncongested periods (19).

As shown in Figure 1, the value of time for freight vehicle derived in the NCHRP 431 is quite large in comparison to values of time derived in other studies. Although the researchers note a small number of respondents from the freight industry, and concerns of respondent comprehension of surveys as potential sources of discrepancy, it is also acknowledged that the need for carriers to adhere to strict schedules contributes to greater value of time (19). Additionally, the NCHRP 431 freight value of time presented in Figure 1 reflects value of time under congested conditions, which NCHRP 431 determined to be roughly 2.5 times greater than value of time during uncongested conditions.

Variations in freight value of time are also found by region. Figure 1, the shows that value of time estimates can vary over a wide range, based on 
research conducted by Minnesota, the Oregon DOT, and a national urban area average provided by Texas Transportation Institute (TTI) (20-22).

Kawamura (2000) investigated differences in value of time among operators and trucking industry segments. Findings from Kawamura show that not only do freight carriers have a higher value of time than passenger vehicles, but that there is also significant heterogeneity among carriers (23).

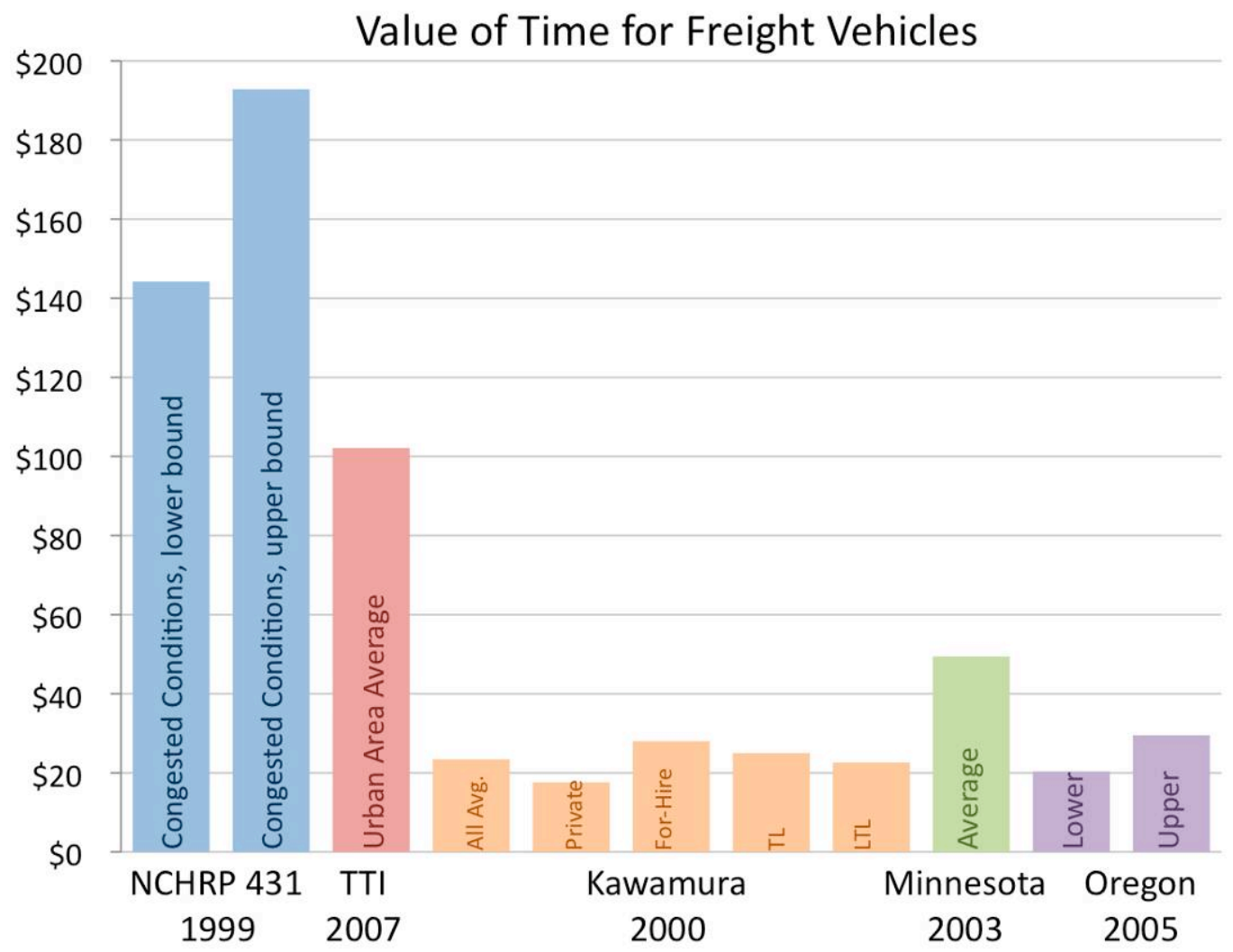

Figure 1: Value of time for freight vehicles $(\$ / \mathrm{hr})$ derived from several studies.

\subsubsection{Monetizing Travel Time and Delay Using Value of Time}

Utilizing the value of time derived from (23) it is possible to monetize measures of travel time and delay. TTI publishes the Urban Mobility Report, which evaluates procedures, processes, and data used for developing 
estimations of the cost of congestion (22). The following expression (Eq. 1) is the TTI formula to determine the annual cost of congestion for freight vehicles (22).

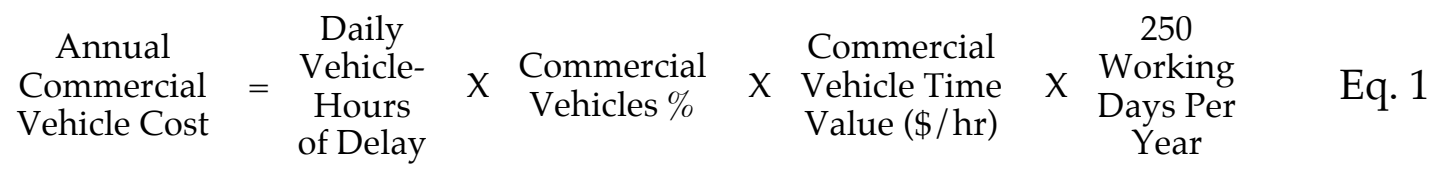

\subsubsection{Incorporating Travel Time Reliability in Travel Cost Calculations}

In addition to travel time and delay, travel time reliability (or variability) can be incorporated into travel cost calculations. Reliability of travel time is particularly important to time-sensitive shippers and time-definite delivery carriers. One of the simplest approaches to quantifying traveler cost takes the following form shown in Eq. 2 (24):

$$
\mathrm{U}_{\mathrm{c}} \quad=\quad \mathrm{a}_{1}{ }^{*} \mathrm{~T}+\mathrm{a}_{2}{ }^{*} \mathrm{~V}(\mathrm{~T})+\mathrm{a}_{3}{ }^{*} \mathrm{M}
$$

where:

$\mathrm{U}_{\mathrm{c}}=$ the traveler cost,

$\mathrm{T}=$ trip travel time,

$\mathrm{V}(\mathrm{T})=$ trip travel time variability,

$\mathrm{M}=$ cost of traveling, and

$\mathrm{a}_{1}, \mathrm{a}_{2}$ and $\mathrm{a}_{3}$ are parameters representing the dislike of travel time, variability, and travel cost, respectively.

For the variability term, Cohen uses a low- and high-end range for $\mathrm{a}_{2}$ of 0.3 and 1.3; parameters $a_{1}$ and $a_{3}$ were estimated to be 1 (24). Research has found that, by improving reliability (reducing variability) during congested peak 
periods, there is great potential to significantly reduce the cost of travel during congestion.

\subsubsection{Monetizing Travel Time and Delay Using Operational Cost}

Although the value of time has been widely incorporated into cost-benefit analysis, by examining marginal operating costs we can gain insight into decisions made by carriers and how the freight industry is impacted by the performance of the transportation system.

Studying aggregate marginal costs in the freight industry is a challenge because of the complexity in shipping processes between carriers, variation in fleet size, and differences in carrier types-data is difficult to obtain and often varying ranges of marginal costs are considered (18). Recent work by ATRI derived marginal operation costs for various carrier types by using survey methods. ATRI defined marginal costs as "those costs associated with operating a truck one mile or one hour in standard operating conditions" (18). Figure 2 presents a list of operating costs considered by ATRI, classified into driver and vehicle categories. 


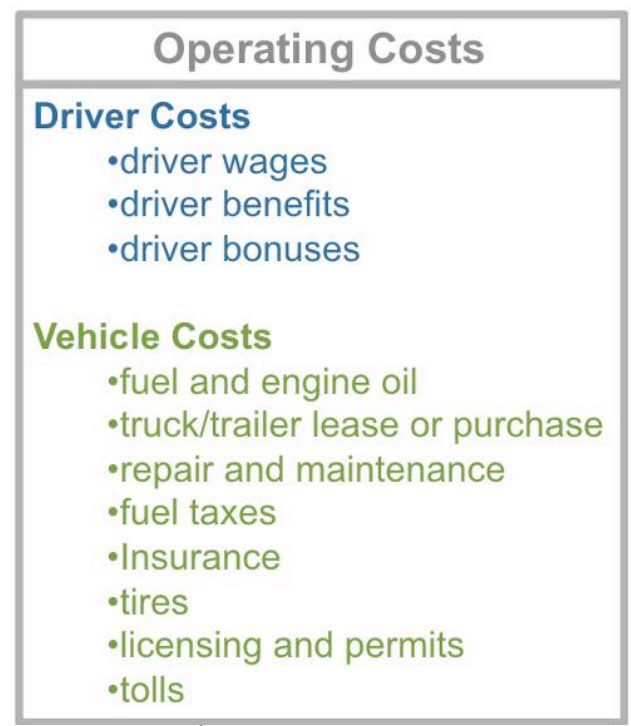

Figure 2: Operating costs involved in the trucking industry.

Marginal costs are used to analyze costs resulting from transportation related issues, since these are the costs that are impacted most by the roadway conditions-congestion will generally have a greater impact on marginal costs than fixed costs. For example, as congestion increases, freight vehicles spend more time on the road thereby consuming more fuel. Carriers will adjust shipping schedules and vehicle routing as a response to congestion to reduce the cost of fuel as much as possible. Additionally, fixed costs are less consistent across carrier types compared to marginal costs, decrease as the vehicle-miles traveled increases, and are often allocated differently between carriers making it more difficult to aggregate information. Therefore, examining only the marginal costs will provide a better understanding of decisions made by carriers and how the freight industry is impacted by the transportation system conditions in terms of cost. 
In a recent study, ATRI found the average marginal operating cost for the freight industry to be $\$ 1.78$ per mile and $\$ 83.68$ per hour (18). ATRI also found that specialized carrier types had the highest cost per mile followed by less than truckload, and truckload ${ }^{2}$ carrier types. Fuel, driver wages, and truck/trailer lease or purchase, were among the top cost items. As revealed in value of time studies, there are major differences among trucking industry sectors. ATRI also applied average cost values to investigate the annual cost impact of a network bottleneck on the trucking industry, using a three-step methodology; this research concluded that the truck congestion costs associated with a bottleneck case study resulted in $\$ 5.7$ million annually (25).

\subsection{Environmental and Health Performance Measures}

It is crucial to be able to accurately estimate emissions due to freight vehicles in transportation planning and engineering, in order to address concerns for public health, the air quality of the environment, and to adhere to current and emerging policies. This section introduces vehicle emissions and factors that influence the amount of emissions produced. The section ends with a discussion of how emissions can be estimated and quantified, and subsequently used as a link to understand the health impacts of transportation.

\footnotetext{
${ }^{1}$ Less than truckload (LTL) carriers haul a relatively small amount of freight, and may carry goods of different types in a given load. LTL carriers may visit multiple customers throughout the day to deliver or to pickup goods.

${ }^{2}$ Truckload (TL) carriers haul large amounts of the same type of goods. All good carried in one truckload will generally go to one customer.
} 


\subsubsection{Importance of Quantifying Freight Emissions}

The freight industry is a critical piece of our transportation system and national economy. The U.S. Department of Transportation found on average 58 million tons of freight shipments per day in 2007 (domestic, exports and imports) $-60 \%$ of which were transported by the trucking industry (26). The Federal Analysis Framework predicts the tons of goods moved by trucking will more than double 2007 values by the year 2035 (26). Assuming the status quo, this expected increase in freight transportation will have a direct impact on air quality over the next 25 years. Freight transportation constitutes $20 \%$ of the energy consumed by the transportation sector; for ground transportation (rail and trucks) this means that 35 billion gallons of diesel fuel are consumed each year, equating to 350 million metric tons of carbon dioxide (CO2) per year (27). Without continuing to make changes in policy, transportation operations, and technology, these rates will only become greater over time, as the freight industry grows to meet the expanding economy, demands of justin-time production, and increased usage of online shopping.

\subsubsection{Emissions and Air Pollutants}

Greenhouse Gases and the Environment: Greenhouse gases (GHG) are those that trap heat in the atmosphere and are largely responsible for changes in the global climate. Non-carbon GHG are methane $(\mathrm{CH} 4)$, nitrous oxide $(\mathrm{N} 2 \mathrm{O})$, hydrofluorocarbons (HFC's), perfluorocarbons (PCs) and sulfur hexafluoride (SF6); carbon dioxide (CO2) is the leading carbon GHG. Of the six main GHGs, the transportation sector contributes mostly to $\mathrm{CO} 2$ emissions and to a 
lesser degree, $\mathrm{N} 2 \mathrm{O}$ emissions (28). The remaining GHGs result mainly from agriculture and industrial activities.

Carbon dioxide is the most prevalent GHG. Although N2O emissions are much less than $\mathrm{CO} 2$ emissions, they are 300 times more powerful at trapping heat in the atmosphere compared to $\mathrm{CO} 2$, so it is important to monitor more than just carbon emissions. Each year, the EPA tracks the nations greenhouse gas inventory, which allows agencies, policy makers, and scientists to observe emission trends, monitor progress, and develop strategies to reduce GHG emissions in the future (29). There are several initiatives and policies aimed toward reducing $\mathrm{CO} 2$ emissions.

Mobile Source Air Toxics and our Health: In addition to the environmental concerns regarding GHGs, there is national concern over the health risks caused by mobile source air toxics (MSAT). MSAT are compounds emitted from mobile sources that present known or suspected health risks for humans (e.g., cancers, immune system damage, or respiratory problems).

The Clean Air Act Amendments established by Congress in 1990 required the EPA to regulate 188 MSAT. Over the past two decades, the EPA has compiled a list of several hundred compounds emitted from mobile sources and identified several compounds as significant contributors to health related issues (30). FHWA reviewed work by EPA and agreed upon seven compounds that have the greatest influence on health: acrolein, benzene, 1,3butadiene, diesel particulate matter plus diesel exhaust organic gases (diesel PM), formaldehyde, naphthalene, and polycyclic organic matter (31). 
Criteria Pollutants: The EPA has also identified six "criteria" pollutants, for which the agency has set National Ambient Air Quality (NAAQ) standards, including: ozone (O3), particulate matter (PM), nitrogen oxides $(\mathrm{NOx})$, lead $(\mathrm{Pb})$, sulfur dioxide $(\mathrm{SO} 2)$, and carbon monoxide $(\mathrm{CO})(32)$. Nitrogen dioxide (NO2) can be monitored independently from other highly reactive gases in the NOx group, as it stands as an indicator of the group. For diesel engines (used almost exclusively to power heavy-duty vehicles), very little $\mathrm{CO}$ emissions and hydrocarbons are produced, however, significant amounts of NOx and PM are produced (33).

Nitrous oxides, like NO2, form quickly from emissions of vehicles, and are linked with many adverse health effects-short term exposure to NO2 emissions from 30 minutes to 24 hours has shown increased airway inflammation in healthy persons, and increased respiratory symptoms in people with asthma (34). In addition to the health risks, NOx contribute to the increase of smog, which in turn reduces visibility. It is expected that recent NOx standards for passenger vehicles and heavy-duty engines in 2004 and 2007-2010 model years, respectively, will to contribute to decreases in NO2 concentrations in the future.

Particulate matter (PM) is also closely linked with respiratory health and visibility effects. PM are small bits of liquid or solid material suspended in air (or water). Ground freight transportation (rail and trucking) contributes to $30 \%$ of all PM emissions (27), and as indicated above, diesel PM has been identified as one of EPA's seven significant contributors to health risks 
resulting from MSAT. Fine and ultrafine particles (particle matter with diameter of 2.5 micrometers and smaller, PM2.5) contribute to smog/haze and can be inhaled deep into the lungs causing health problems.

To date, governmental regulation and vehicle technology improvements have received wide attention in reducing GHG emissions, MSAT and other pollutants by heavy-duty vehicles. Currently diesel vehicles are being regulated by EPA to reduce PM and NOx. As noted in recent work by University of California Riverside, little attention has been paid to the impact of traffic operations and various roadway conditions on freight emissions (33).

\subsubsection{Factors Contributing to Freight Emissions}

It is clear that transportation has a significant impact on air quality and consequently public health, and is responsible for a large portion of global air pollution. However, it is important to understand what factors contribute to emission of GHG, MSAT, and other air pollutants. For example, fuel consumption and $\mathrm{CO} 2$ emissions are directly related, but fuel consumption depends heavily on travel speed, road characteristics and vehicle characteristics (35). This section will present a review of factors contributing to freight emissions.

Speed and Acceleration: Using probe passenger vehicles equipped with GPS, loop sensor data and an emissions model, one study found that when congestion brings average vehicle speed below $45 \mathrm{mph}$, there is a negative net effect on emissions; vehicles spend more time on the road, and exhibit acceleration and deceleration patterns, which result in increases in $\mathrm{CO} 2$ 
emissions (36). Additionally, very high speeds (above $65 \mathrm{mph}$ ) also result in higher emission levels. The study makes recommendations for "traffic smoothing" and congestion mitigation to maintain steady speeds between 45 to $50 \mathrm{mph}$ and reduce $\mathrm{CO} 2$ emissions (36). The impact of speed on vehicle emission rates is illustrated in Figure 3, taken from Barth and Boriboonsomin; the researchers indicate that moderate speeds produce minimum emissions (37).

Similar results were found for heavy-duty vehicles at different operating modes. Higher emission profiles were shown for vehicles accelerating, with the highest emission rates from accelerations between 0 to $25 \mathrm{mph}$ than from accelerations between 0 to $50 \mathrm{mph}$ (38). Additionally, at steady state speeds of $25 \mathrm{mph}$, emission profiles for hydrocarbons (compounds consisting of hydrogen and carbon) and CO components were greater in comparison to hydrocarbon and CO emissions for higher steady state speeds of 50 and 60 $\mathrm{mph}$.

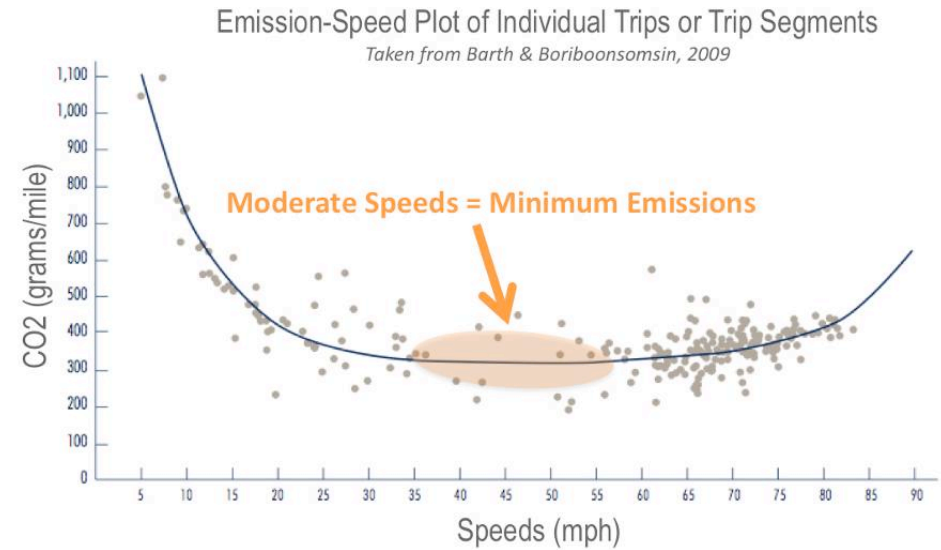

Figure 3: Emission-Speed Plot Taken from Barth \& Boriboonsomisin, 2009 (37); moderate speeds show minimum emission rates. 
More recent work has investigated heavy-duty vehicles using a state-ofthe-art Mobile Emission Laboratory (MEL). The study investigated emissions from heavy-duty vehicles on arterial and highway road classes, and found that at moderate speeds, emissions on the arterial road conditions were much higher than emissions at moderate speeds along the highway road conditions. These differences can be explained by more frequent and sharper accelerations on the arterial roadways, and supports the argument that it is not enough to use CO2 emission factors based solely on average speed, but should incorporate a measure of driving pattern (33). Additionally, tests performed at high speeds (greater than $65 \mathrm{mph}$ ) suggest that extrapolating from California Emissions Factor Model (EMFAC) curves for high speeds may underestimate $\mathrm{CO} 2$ emissions from heavy-duty vehicles.

MSAT have also been investigated, but to a lesser degree. Using the modeling tool CT-EMFAC, a recent study investigated MSAT sensitivity to changes in traffic volume, fleet composition and speed, concluding that MSAT emissions are more sensitive to speed changes than the other parameters evaluated (39). This study points to a need for further research and speciation of factors for MSAT (especially for diesel vehicles) in order to improve projectlevel MSAT emission estimates.

Vehicle Weight: Researchers have investigated the effect of vehicle weight on freight emissions, and in particular on the emission of NOx $(38,40)$. Gross vehicle weight was found to strongly effect emissions. Using data obtained from the West Virginia University Transortable Heavy Duty Emissions 
Testing Laboratories (TransLab), a linear relationship was found between NOx and heavy-duty diesel vehicle weight (40). Results for CO and PM emissions were not consistently affected by vehicle weight, although $\mathrm{CO}$ and PM showed increases in emissions during periods of acceleration (40). Using the 2002 simulation model Advanced Vehicle Simulator (ADVISOR), developed by the U.S. Department of Energy's National Renewable Energy Laboratory, researchers noted that increases in vehicle weight from 52,000 lbs to $80,000 \mathrm{lbs}$ resulted in approximately $40 \%$ greater increase in NOx grams per mile emissions during both acceleration periods and higher speed periods of vehicle operations (38). Both studies point to the importance of including a measure of weight within emissions models.

Recent work at the University of California Riverside supports the relationship between vehicle weight and emissions-as vehicle weight increases, quantity of emissions increases. By employing the Comprehensive Modal Emissions Model (CMEM) for a variety of vehicle weights, the researchers concluded that the emissions are lowest at moderate speeds and greatest at moderate average speeds. For a truck with no additional trailer weight, the optimum speed for minimizing emissions was found to be 23 $\mathrm{mph}$, while the optimum speed for a truck hauling $6400 \mathrm{lbs}$ of weight was found to be $45 \mathrm{mph}(33)$.

Roadway Grade: Though not a freight-specific study, research by Pierson et al. showed that NOx emissions were twice as high driving uphill at about $4 \%$ grade compared to driving on a level roadway (41). More recent work has 
investigated freight vehicles specifically (using the CMEM model) and found that a $1 \%$ increase in grade can increase heavy-duty vehicle $\mathrm{CO} 2$ emissions as much as $35 \%$ for grades between a $0 \%$ to $2 \%$ (33). Vehicles must travel a longer period of time on an uphill (because of reduced speeds caused by the grade), subsequently consuming more fuel and emitting more $\mathrm{CO} 2$. The reverse is true for downhill grade. By varying grades, the study also found increased linearity of the relationship between $\mathrm{CO} 2$ emissions and speed with increases in grade-these findings show that the speed corresponding to the minimum $\mathrm{CO} 2$ emissions is greater (faster) for downhill grades in comparison to flat terrain because less tractive effort is required to power a vehicle driving downhill (33).

\subsubsection{Modeling Freight Vehicle Emissions}

Utilizing freeway performance measures (e.g., speed over time), it is possible to quantify environmental and health performance measures related to tailpipe emissions, to provide transportation agencies the tools to link transportation performance to environmental and societal goals. In order to do this, planners and engineers often use a sequential three-step model process where outputs from one step become the input for the next. This process generally consists of the following models: (a) transportation demand-traffic models, (b) emissions rate models, and (c) pollution dispersion models.

There are a variety of models that can be used to estimate tailpipe vehicle emission rates. The MOVES2010 model can be used to estimate national, state, county, and project-level emissions for GHG, select MSAT, and criteria 
pollutants. Among models, there are some variations in the specific vehicle and roadway factors and assumptions. Several studies have investigated the impact of freight vehicle characteristics (e.g., speed, acceleration, weight) and the impact of roadway characteristics (e.g. grade, classification) on emission rates, but the degree to which these characteristics are incorporated into individual models may vary.

CMEM was developed at the University of California Riverside, and is intended for use with microscale transportation simulation models. Microscale transportation simulation models will typically produce detailed, second-bysecond trajectory outputs for location, speed, and acceleration, which can than be used as input for the CMEM model $(42,33,36)$. The CMEM model can account for various vehicle and roadway parameters, including vehicle type, size/weight, and grade. Given the necessary inputs, the CMEM model can predict second-by-second vehicle emissions, which are crucial for transportation policy purposes.

When vehicle activity information is combined with the emissions model, the output is the estimate of emissions (GHG, MSAT, or criteria pollutants) over time and space (43). After obtaining results from the emissions model, the outputs can then be used to study air quality and health effects using a dispersion model.

\subsection{Summary of Background Review}

The review presented here informed the research investigation. This section demonstrates an understanding of performance measures and concepts of 
using these measures to improve our transportation system. The review of literature related to freight performance measures highlights gaps in current research and determines challenges in using particular data sets. The methodologies presented for estimating the cost of congestion define procedures that can be used at a project or regional level to monetize performance measures. Finally the importance of quantifying freight emissions is discussed along with models that can be used to estimate emission rates from freight vehicles. 
3 Description of Available Data

This section discusses the data sources used in this research: loop sensor data, incident data, and commercial GPS data.

\subsection{Loop Sensor}

The Portland State University Intelligent Transportation Systems (ITS) lab has direct access to corridor loop data from Oregon DOT sensors. These sensors collect the count and speed of vehicles at more than 600 locations in the Portland region. The Portland Oregon Regional Transportation Archive Listing (PORTAL, see http://portal.its.pdx.edu) offers traffic data, performance measures, and analytical tools in a user-friendly interface.

The ODOT sensor stations consist of dual-loops in each lane and are typically located along the freeway mainline upstream of on ramps, and along the on ramps. The dual-loops allow for count and speed estimates per lane to be directly measured. PORTAL automatically calculates the speed estimate for a given station using a weighted average of speeds by vehicle count across all lanes present at the station. Additionally, travel time estimates are performed automatically in PORTAL using the traditional mid-point method. This method distinguishes influence areas (distance) midway between a station and nearest up/downstream detector stations, and divides this distance by the weighted station speed to produce travel time estimates through station influence areas.

In order to calculate the travel time through a corridor, the station travel times are added for a given time bin. Finally, the average speed through the corridor can be calculated by dividing the corridor travel time by the length of 
the corridor. It is important to note that weighted station average speeds cannot simply be averaged to produce a corridor average speed. This is due to the spatial nature of congestion through the corridor, where segments may experience congestion at different times. As discussed in the background section, past and current research projects at PSU have used the PORTAL archive to study recurrent congestion using historical data $(7,8)$.

\subsection{Incident Data}

In addition to the loop sensor data, PORTAL has also integrated incident data from the ODOT Advanced Transportation Management System (ATMS). These data provide the user with more information to discern whether the traffic behavior was recurring or non-recurring (caused by an incident, weather event or roadside construction). The incident database includes information on the type of incident (crash, stall, or random event), number of lanes affected, approximate start and end time, and approximate location of the incident, in addition to several other fields.

\subsection{Commercial GPS Data}

Most significantly, this work incorporates GPS data from a sample of commercial trucks along the I-5 corridor. The GPS devices are placed onboard trucks and report a unique truck identification (truck ID) number, date, time, and position (latitude/longitude) for each truck reading. GPS truck data were provided to this research project by the American Trucking Research Association (ATRI) as part of a research contract between Federal Highway Administration and Portland State University. 


\subsubsection{Data Challenges}

This work used data from January through December 2007 along the I-5 corridor in the Portland Metropolitan area. GPS data provide dynamic travel time information, and are capable of capturing the movement of vehiclesthese two characteristics make the data very useful when investigating freight vehicles traveling between different origins and destinations to make deliveries. Although GPS data provide more detailed information regarding the movement of a given vehicle in comparison to other data sources, there are challenges in working with the GPS data. Below is a summary of these challenges and considerations that must be made when working with GPS data from commercial vehicles and developing algorithms to mine the data.

1) Error in reading position: As indicated by Schofield and Harrison (3), the accuracy of the GPS coordinates may have an error of up to $1 / 4$ of a mile. This creates difficulty in properly assigning readings to road networks-time thresholds between readings can be used to assist in verifying whether or not a reading belongs to an assigned roadway. Additionally, a vehicle may appear to have suddenly changed direction if the error in position places a reading (occurring later in time) at a location prior to the first reading, when in reality the vehicle continued on the same path. By looking at the first and last readings covering a greater distance of travel, these sudden erroneous changes in direction are reduced. 
2) Erroneous spot speeds: Another error type occurs when the GPS reading happens to take place on a period of acceleration—very high speeds (e.g. greater than $100 \mathrm{mph}$ ) may result (17). Additionally, error in position (as discussed above) may also result in erroneous speed estimations between readings. By performing data cleaning, and/or by looking at the first and last readings covering a greater distance of travel, these errors are reduced.

3) Multiple trips by a given truck per day: Given the GPS data from all vehicles, it becomes necessary to identify individual trips made by a particular truck each day (i.e., travel between origin and destination points, or through a defined road segment). Depending on the operator or service type, the number of trips inside the study area will vary widely between trucks. The data set used for this research did not include detailed information regarding truck type, operator type, service type, vehicle contents, or the origin/destination of the vehicle. Given these details, filtering methods could incorporate the information into algorithms to aid in classifying trips and studying freight movement key origin and destination centers.

4) Data quantity: The data made available to this research provided a large number of individual readings surrounding I-5 in the Portland Metropolitan area. Figure 4 presents a map showing the coverage of individual GPS readings for the month of August 2007—an average of 126,000 readings were found each month, and roughly 1,500,000 
readings total for the year of 2007 . The shear size of the data set increases the data cleaning effort, pre-processing effort for input into the algorithms, and filter processing time in order to obtain truck travel time and other mobility performance measures.

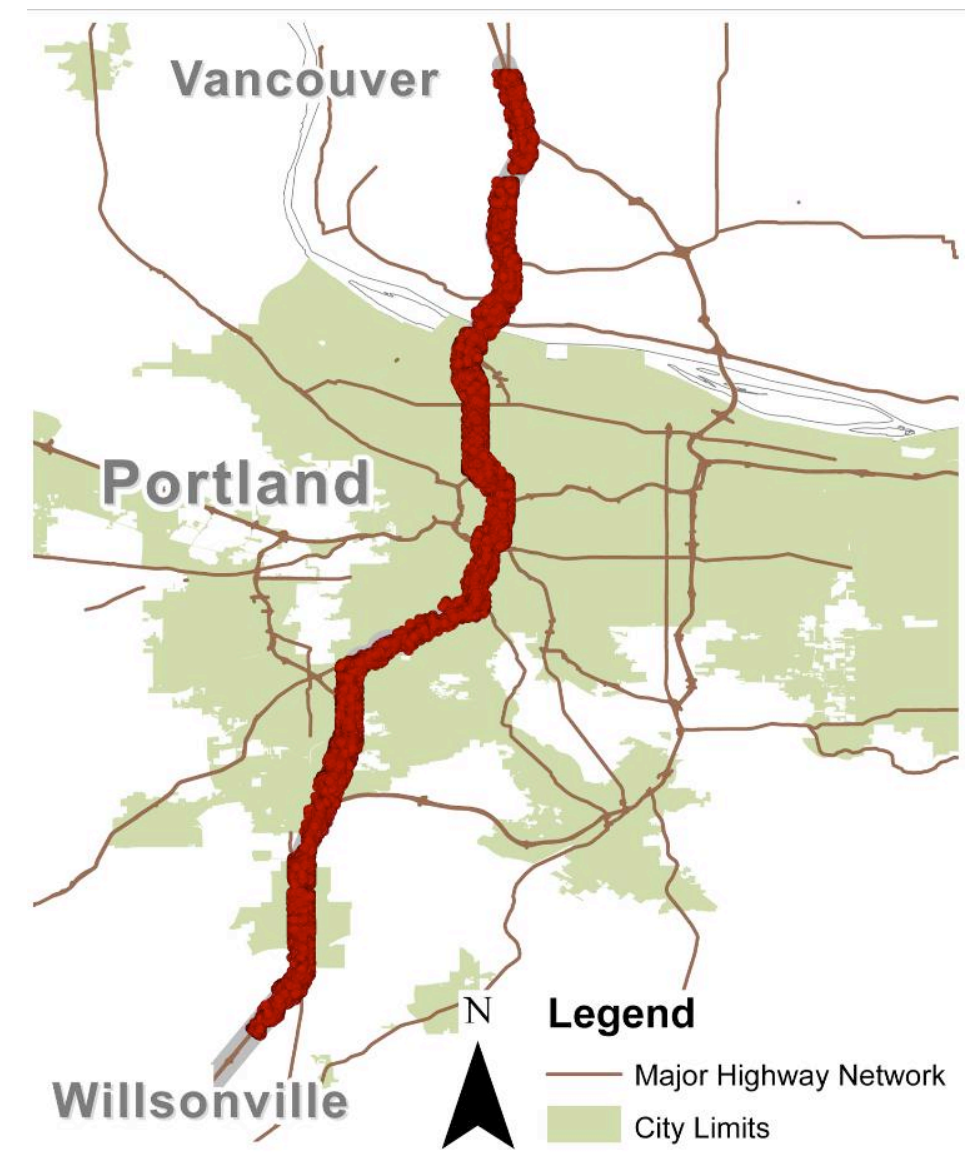

Figure 4: Map showing truck GPS data coverage provided by ATRI-individual readings on I-5 for August 2007 are shown (146,290 readings). An average of 126,000 readings occurred each month, with roughly 1,500,000 readings total for January through December 2007.

5) Reading frequency: The frequency of readings vary from truck to truck, meaning there is no common gap time between readings-even for a given truck, the frequency may vary. This is largely because a lower resolution of reading frequency is adequate for the trucking industry. The reading frequency creates challenges, because with larger 
time gaps between readings it is difficult to know what activity was taking place-techniques must be developed to discern, for instance, if a greater time between two readings translates to slower speeds resulting from freeway congestion, or if travel actually took place on a nearby local network where speeds are expected to be slower.

6) Different Truck Travel Types: Within the data set provided for this research, multiple truck travel types were discovered-some trucks travel the freeway network, while others use the local network while making deliveries. Additionally, it is possible for a truck to have readings on both the local and freeway network on a given trip, as they leave the freeway to make deliveries, refuel the vehicle, or rest. Highlighted in the literature review, previous research has not attempted to separate and classify readings by different truck travel types. By classifying truck travel types, it is possible to remove bias from trucks experiencing local (non-freeway) traffic conditions, and analyze only trucks that have experienced freeway network conditions. Section 3.3.2 will further discuss issues regarding truck travel types.

Filtering algorithms and data mining, such as those developed for this work (discussed in Section 4), are essential in order to manage the large quantity of GPS data and to provide accurate measures of performance. Data challenges and known sources of potential error indicated above should be considered throughout the development of filtering methodologies. 


\subsubsection{Truck Travel Types}

The truck travel types present in the data set can be grouped into two broad categories: through trucks and local trucks. Figure 5 illustrates a small local network and freeway network with different truck travel types presented.

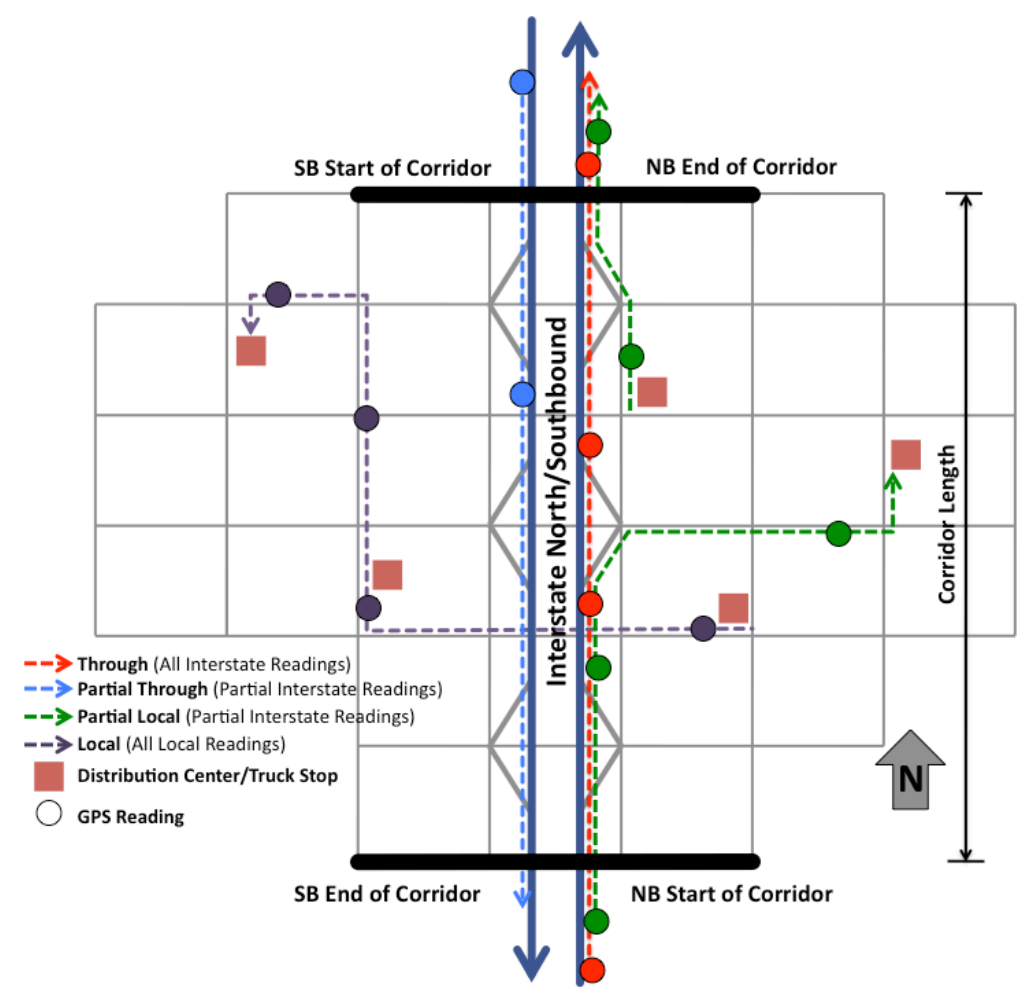

Figure 5: Truck travel types, 1) Through, 2) Partial Through, 3) Partial Local, and 4) Local

As shown in Figure 5, a through truck makes no stops on the freeway corridor and has at least one reading before and after the "start" and "end" of the corridor. Because they have traveled the freeway corridor without stopping, the travel time and speed obtained from the GPS data from through trucks will reflect the freeway corridor conditions experienced by the freight vehicles. 
As shown in Figure 5, a partial through truck is defined as a truck that has only one reading on either end of the corridor, and an intermediate reading somewhere between the start and end of the corridor. Partial through trucks may (or may not) have traveled the entire corridor. Without readings at both extremities of the corridor, it cannot be determined with certainty that the truck traveled the full length of the corridor, thereby experiencing all roadway conditions associated with the corridor at a given time of day. For instance, a partial through truck could have avoided a congested segment further downstream by leaving the freeway network, if readings are only available at the beginning of the corridor and midway through the corridor. The average speed between the available readings would reflect the segment traveled by the partial through truck (before it diverted to the local network), and would not represent the freeway conditions of the corridor. Here, the inclusion of partial through trucks speeds could present a bias of higher speeds through the corridor.

Similarly, partial local trucks have readings along the freeway corridor, but also readings on the local network (see Figure 5). As discussed previously, error in GPS position may cause local network readings to appear to be on the freeway network-this can contribute bias of slower travel time and speed estimates that do not represent freeway conditions, but rather a combination of freeway and local conditions. For instance, assume that for a given truck the first reading is taken near the start of the corridor, and the second reading is taken midway through the corridor after the truck has traveled the local 
network and stopped to deliver goods to a customer. A portion of the travel time between the first and second readings represents freeway travel conditions, but a portion of the travel time also represents local travel conditions. Without a reading between the two points, it is difficult to discern where the transition from freeway to local took place. However, it is clear the estimation of speed between the two points would not represent the corridor average speed, and could instead present a bias of slower speed, since local travel occurred.

Figure 5 shows that local trucks readings occur solely on the local network; these trucks may represent local or arterial street conditions rather than congested freeway conditions. The close proximity of the freeway and local streets, coupled with the error in position of GPS readings creates difficulty in assigning readings to the local network versus the freeway network. This is particularly of concern near interchanges, where vehicles transition between the freeway and local networks. Data from trucks traveling the local network to accessing customers or gas stations, or transitioning between the local and freeway networks may present bias of slower speeds, as they experience roadway conditions related to the local network.

Another example of bias from local trucks may occur where there are nearby frontage roads paralleling the interstate. Trucks could chose to travel a frontage road to avoid severe congestion on the freeway. Including data from local trucks that have traveled frontage roads could present a bias of higher speeds at times of day when the freeway network was severely congested. 
Figure 6 provides an example of the potential distorting effect of including local, or partial through/local truck GPS data in the aggregation of travel time and speed estimates along freeway corridors.

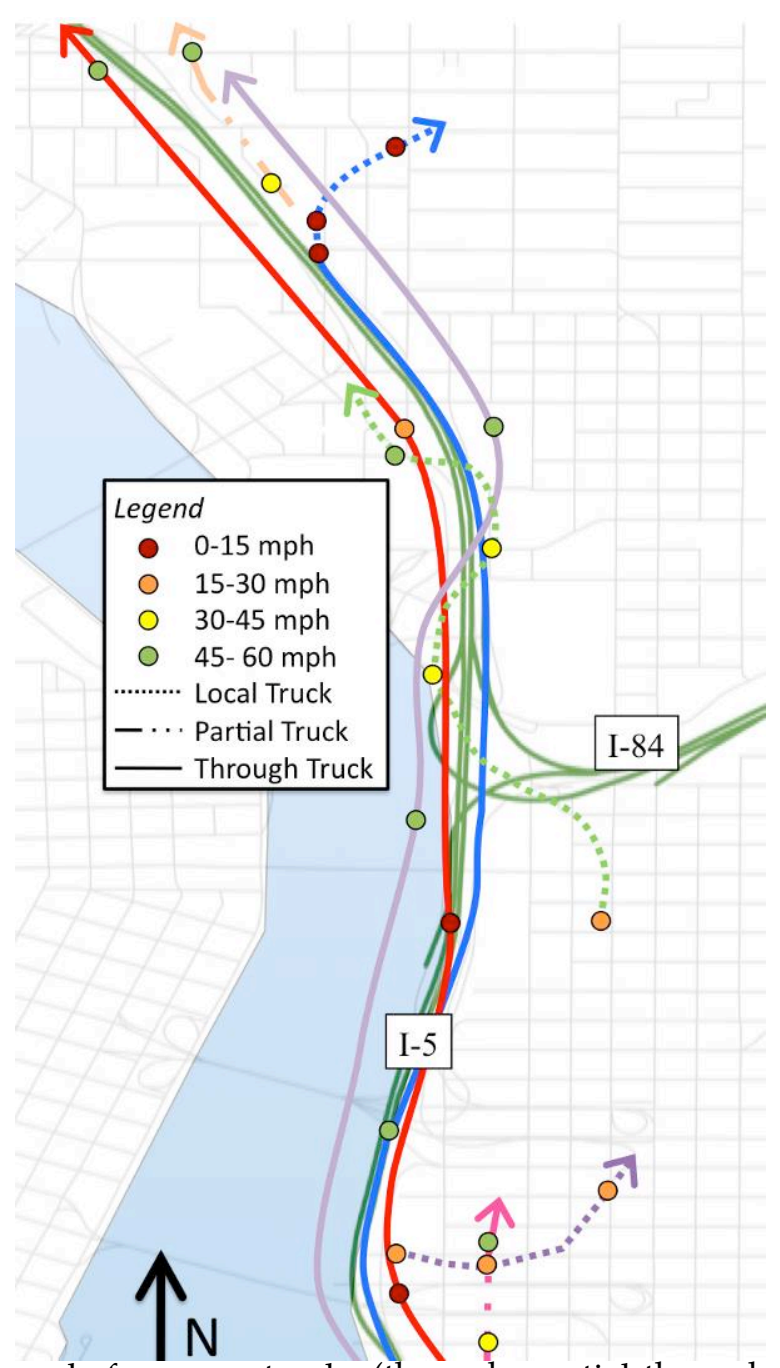

Figure 6: GPS spot speeds for seven trucks (through, partial through, partial local, or local trucks) at I-5/I-84 Junction in Portland, OR. It is possible for the local readings to be improperly assigned to the freeway network, presenting a bias of slower speeds in the data set.

Figure 6 shows GPS spot speeds for through, partial and local trucks at the junction of I-5 and I-84 in Portland, Oregon. Here the interstates are elevated, with local streets directly beneath the interstates and in close proximity to the 
interstate. Because of the close proximity of the local network to the interstate network and the accuracy of GPS units, it is possible for the local readings to be improperly assigned to the freeway network, presenting a bias of slower speeds in the data set. In addition, mixing freeway reads can also lead to bias, as one freeway (e.g. I-84) can be uncongested while the other is highly congested (e.g. I-5).

Unlike other studies, this research identifies through trucks to estimate the impact of congestion on freight movements throughout the day, thereby eliminating partial through, partial local and local truck data from the analysis. A methodology is developed to reduce speed estimation bias by separating through trucks from partial through, partial local, and local trucks. 
$4 \quad$ Methodology For Identifying Through Trucks

This section discusses the procedure to determine those unbiased trucks that are classified as through trucks. In order to identify through trucks that experienced congestion, two main filtering processes were implemented: 1) truck ID matching process to identify all potential through trucks and 2) comparison of GPS speeds to loop sensor average travel time by time period.

\subsection{Filter Process 1: Truck ID Matching}

Figure 7 presents a diagram of parameters necessary to identify through trucks. The extremities of the corridor are defined in Figure 7 as $\mathrm{m}_{\mathrm{s}}=$ start mile, and $m_{e}=$ end mile. Because it is unlikely that readings will occur exactly at mile $\mathrm{m}_{\mathrm{s}}$ or $\mathrm{m}_{\mathrm{e}}$, a buffer region surrounding the start and end mile are created:

Start buffer $=\mathrm{m}_{\mathrm{s}}+/-\mathrm{r}$,

End buffer $=m_{e}+/-r$, where: $\mathrm{r}=$ buffer radius in miles.

A time window $t_{c}$ is defined as the maximum threshold for a vehicle to clear the extremities of the corridor plus the buffer region. This assumes that one trip must be completed within time window $t_{c}$; otherwise it is assumed that the truck has made one or more local stops through the corridor. This parameter is set liberally to ensure that vehicles traveling less than free flow speed during congested periods are captured as potential through trucks. Similarly, time window $t_{b}$ is defined as the maximum threshold for a vehicle to clear the buffer region surrounding $\mathrm{m}_{\mathrm{s}}$ or $\mathrm{m}_{\mathrm{e}}$. 
Many of the trucks found in the data set have made multiple trips through the corridor, either on the same day or on another day in a given month. Because of this, the matching process must also incorporate rules to distinguish between multiple through trips made by the same truck ID. The logic for identifying potential through trucks is summarized in Figure 7.

\subsection{Filter Process 2: Comparison to Loop Sensor Average Travel Time} In the second step to identifying through trucks, the corridor travel times from each potential through truck (from Filter Process 1) are sorted by the "start" reading timestamp into time bins of fifteen-minute intervals. These times are then compared to the loop sensor average travel time at a fifteen-minute resolution for the time period of interest. A deviation index is calculated using the loop sensor data to determine if the through truck values deviate too greatly from the expected average given by loop sensors. The deviation index is calculated as follows:

For a fifteen-minute time bin $\mathrm{t}$ let,

$$
\begin{aligned}
& a_{t}=\text { loop sensor average travel time at time bin } t \\
& \sigma_{t}=\text { loop sensor day-to-day standard deviation in travel time at time bin } t
\end{aligned}
$$

For each truck trip $\mathrm{k}$ in fifteen-minute time bin $\mathrm{t}$ let,

$$
\mathrm{T}_{\mathrm{k}}=\text { the corridor average travel time for truck trip } \mathrm{k}
$$

Then the deviation index $g_{k}$ is defined as

$$
\mathrm{gk}=\mid \text { at }-\mathrm{Tk} \mid / \sigma \mathrm{t}
$$


Any $g_{k}>m * \sigma$ for all time bins is assumed to be too far from the expected average and it is excluded from subsequent analysis; $m$ is a user-defined parameter. 


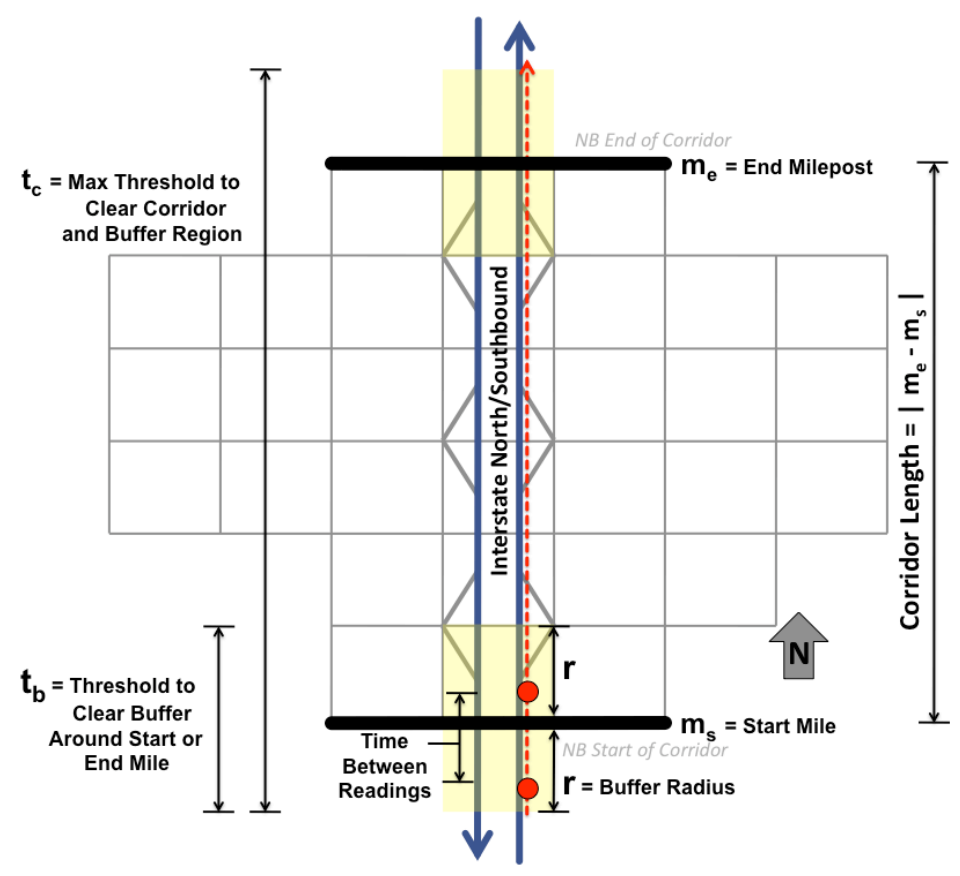

1. Use ArcGIS linear referencing tool (Locate Features Along Routes) to obtain milepost measures along an interstate for each GPS truck reading using latitude/longitude data

2. Determine the corridor extremities $\left(\mathrm{m}_{\mathrm{s}}\right.$ and $\left.\mathrm{m}_{\mathrm{e}}\right)$

3. Create a record of each reading falling within the start and end buffer ranges

4. For all readings which fall within the buffer ranges, distinguish individual trips by each truck using time thresholds and identify the "start" and "end" points of each trip

5. For each truck ID, match all "start" readings to a downstream "end" reading that occurs within a time $t_{c}$ and record as a single trip

6. Search the entire data set to find all intermediate readings for a truck ID that fall between the trip "start" and "end" readings (using timestamp and milepost data) to create a complete trip through the corridor

7. Adjust the "start" and "end" reading timestamp and milepost to begin at $\mathrm{m}_{\mathrm{s}}$ and $\mathrm{m}_{\mathrm{e}}$ using speeds obtained from the next closest reading

8. For each truck ID and trip, use adjusted "start" and "end" reading timestamp to obtain the travel time and speed through the corridor, and identify trip direction of travel using milepost data

Figure 7: Diagram showing user-defined parameters for Filter Process 1 (truck ID matching to find potential through trucks), and corresponding algorithm logic.

Because loop detection has the potential to underestimate the impact of congestion on the freight trucks, it is expected that in general loop sensor average travel times may be shorter than freight truck travel times. This 
important fact must be taken into account when setting the value of parameter $\mathrm{m}$ in order to exclude only trucks making stops from those traveling the entire corridor during congestion, without making stops.

\subsection{Methodology for Non-Recurring Congestion}

The methodology described above can be applied to study the effect of nonrecurring congestion caused by an incident. Instead of examining the entire corridor, attention is restricted to small roadway segments preceding incidents. The incident analysis required minor modifications to the procedure discussed above in order to identify through-incident trucks (trucks traveling through the incident without stopping)— two different approaches were used. Both approaches start by defining a five-mile incident area where throughincident trucks must travel without stopping for reasons un-related to congestion. Four incident areas were studied and are referred to as incident area $\mathrm{A}, \mathrm{B}, \mathrm{C}$ and $\mathrm{D}$. Twenty-two individual incidents occurring within these incident areas were studied, and are discussed further in a later section, along with descriptions of the incident areas.

The first approach (applied to study incident areas A, B, C), modified only the Filter Process 1 parameters $\left(\mathrm{m}_{\mathrm{e}}, \mathrm{m}_{\mathrm{s}}, \mathrm{r}, \mathrm{t}_{\mathrm{c}}, \mathrm{t}_{\mathrm{b}}\right)$ to investigate the incident areas. Figure 8 shows a diagram of the parameters used to study incident areas $\mathrm{A}, \mathrm{B}$, and $\mathrm{C}$. The diagram is similar to the diagram of parameters used for recurring congestion analysis (Figure 7), however, instead of creating a buffer surrounding the start and end miles, the buffer radius extends only to mileposts after (north of) the end mile, and before (south of) the start mile. 
This ensures a truck must travel the entire incident area to be considered a through-incident truck. A buffer radius of four-miles was used for the nonrecurring study of incident areas A, B, and C.

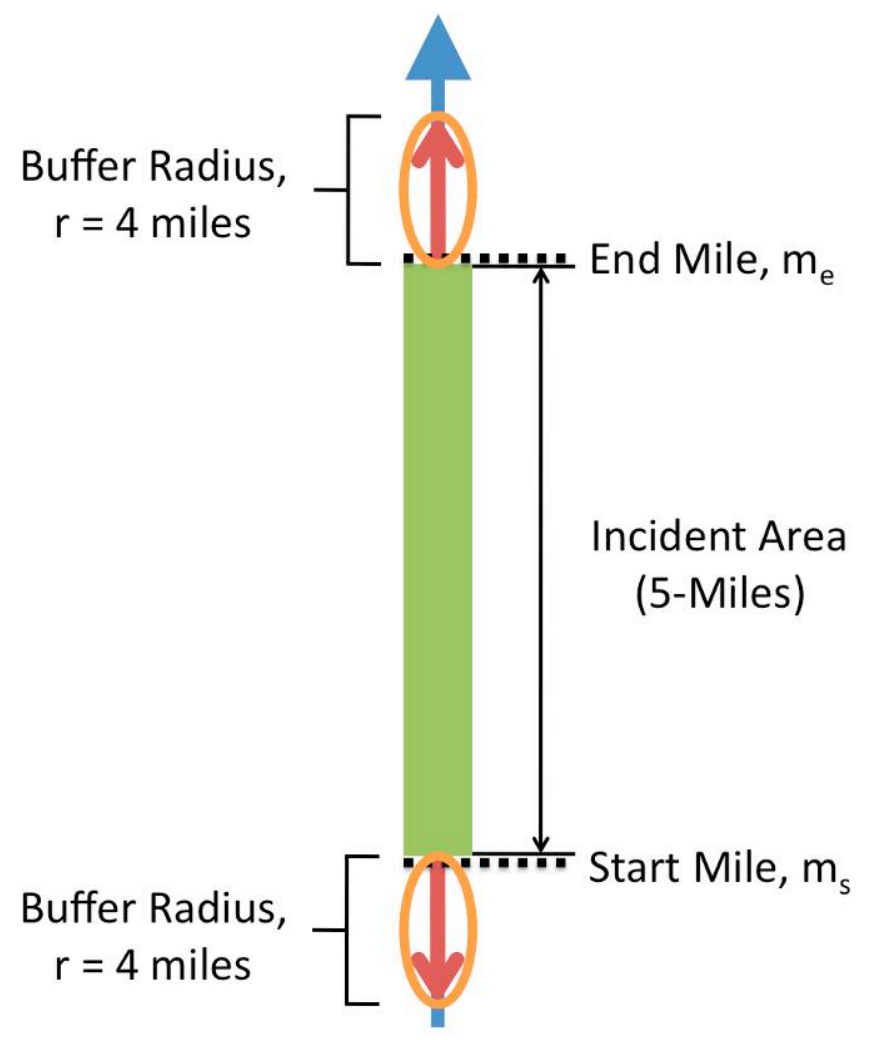

Figure 8: Diagram of parameters for Filter Process 1 used to study incident areas A, B and C.

The second approach (applied to study incident area D) differs from the first approach in that the buffer radius was extended to the extremities of the I-5 corridor in the Portland area (milepost 283.93 in Multnomah County, Oregon, and milepost 7.3 in Clark County, Washington); the buffer radius in the first approach was only four-miles. Because of the increased buffer radius, a further constraint to identifying through-incident trucks using the second 
approach was that at least one intermediate reading had to occur within the incident area.

The parameters, incident areas extents, and individual incidents occurring within each the incident area are defined and discussed further in a later section.

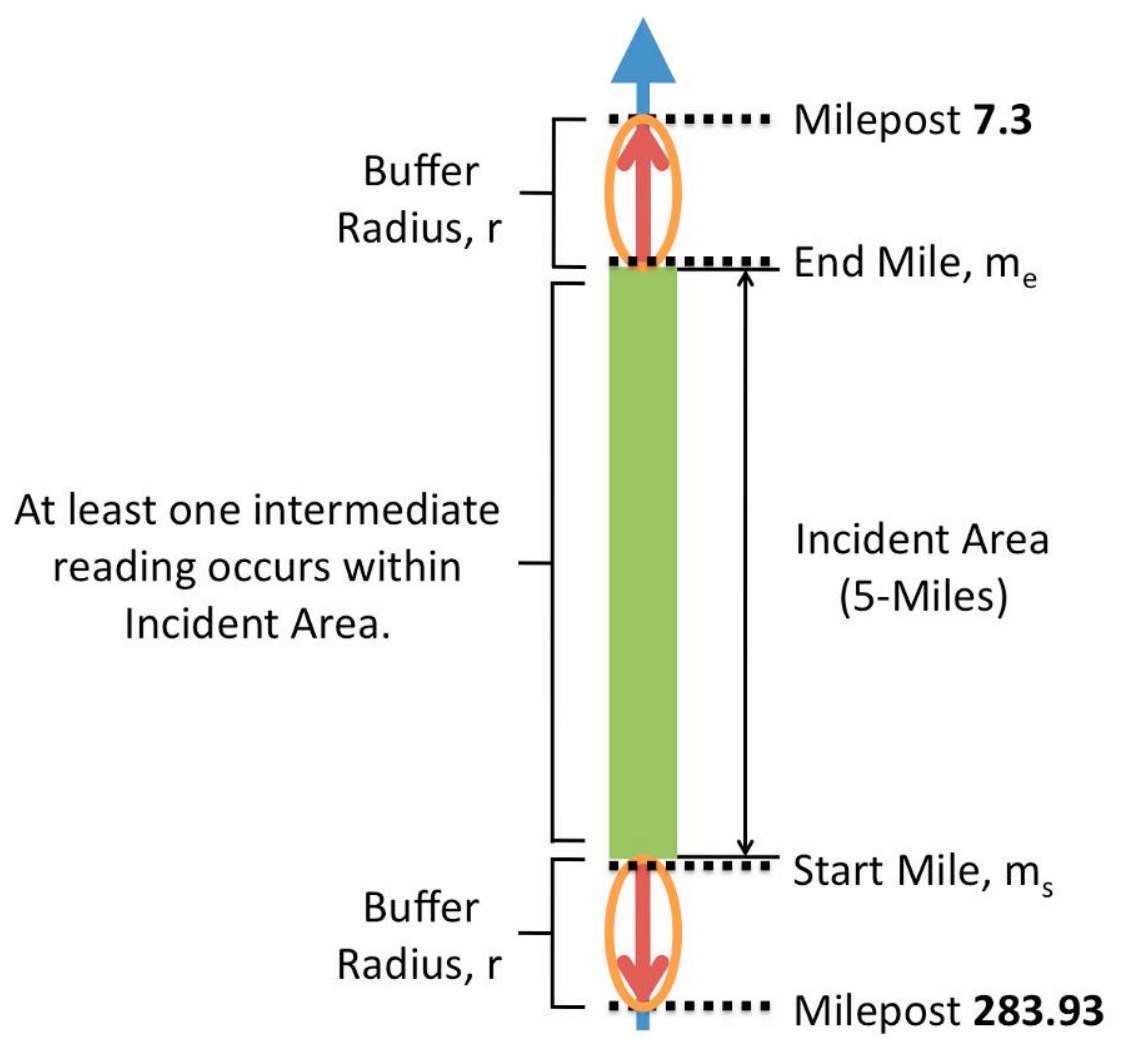

Figure 9: Diagram parameters for Filter Process 1, used to study incident areas D.

Following Filter Process 1, the through-incident truck average travel times were compared to loop sensor data collected from loop stations spanning the five-mile incident areas to further identify through-incident trucks (i.e., Filter Process 2). By evaluating those trucks that were certain to have passed 
through the incident areas without stopping, the fluctuation in travel time due to the incident can be observed without the effect of the local network. 


\section{$5 \quad$ Recurring Congestion Results}

Recurring congestion is the result of changes in demand throughout the day, and can occur at locations where the geometry of the roadway changes, creating a bottleneck (i.e., near interchanges, or lane drops). This section begins with a description of the recurring congestion case study used in this research. The recurring congestion study was designed to analyze corridor level congestion aggregated over a one-year period. The remainder of this section will present the results for the recurring congestion analysis. The results from are discussed first in terms of mobility and congestion performance measures (i.e., travel time, delay, reliability). Next, the cost of recurring congestion is presented, followed by the impact of recurring congestion on emission rates. Finally, a summary of the results from the recurring congestion analysis is presented.

\subsection{Case Study Description}

The recurring congestion case study presented in this work investigates a 31.75 mile segment of northbound I-5 from mile marker 283.93 in Multnomah County, Oregon, through mile marker 7.3 in Clark County, Washington. The study focused on weekdays during 2007 (January through December), and allowed for the analysis of the impact of congestion on corridor level travel time, cost and emissions. These results are presented in a later section.

Figure 10 presents a map of the northbound I-5 corridor, with loop sensor detector station locations listed. Because horizontal and vertical curves of a roadway typically affect the speed of freight trucks more so than passenger vehicles, the particular segment investigated in the case study offers some 
control for this effect, as this segment of I-5 is fairly flat and with few curves.

Table 1 presents the user-defined parameters used in Filter Process 1 for the recurring congestion analysis.

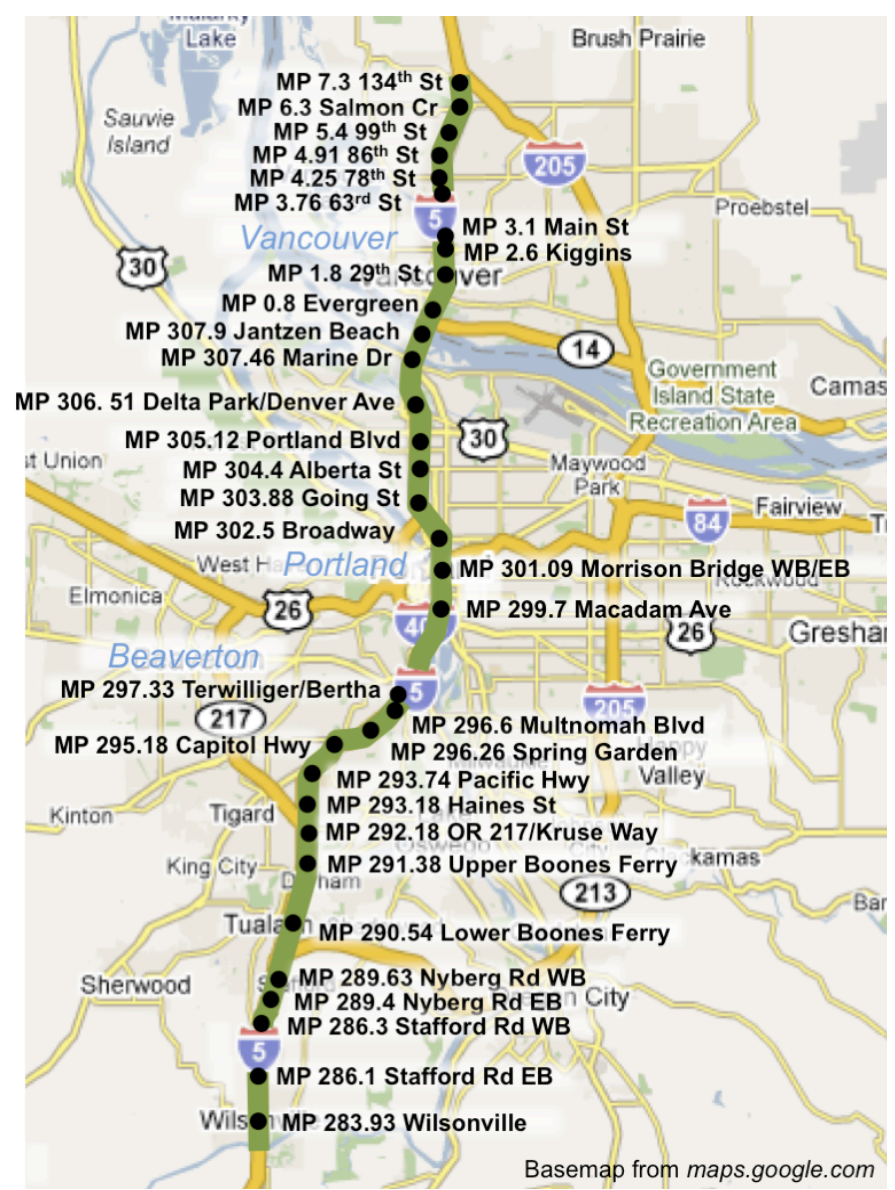

Figure 10: Map of loop sensor station locations along northbound I-5 recurring congestions study area.

Table 1: User-Defined Parameters for Recurring Congestion Case Study

\begin{tabular}{|c|c|c|c|}
\hline \multicolumn{2}{|l|}{ Parameter } & \multicolumn{2}{|c|}{ User-Defined Value for Case Study } \\
\hline Start of corridor, & & milepost 283.93 & Multnomah Co., OR \\
\hline End of Corridor, & $\mathrm{m}_{\mathrm{e}}$ & milepost 7.3 & Clark Co., WA \\
\hline Corridor Length, & & 31.75 mile & \\
\hline Buffer Radius, & $\mathrm{r}$ & 4 miles & \\
\hline $\begin{array}{l}\text { Corridor Travel } \\
\text { Time Threshold }\end{array}$ & $t_{c}$ & 3 hours & \\
\hline $\begin{array}{c}\text { Buffer Region } \\
\text { Threshold, }\end{array}$ & $t_{b}$ & 1 hour & \\
\hline
\end{tabular}




\subsection{Travel Time, Delay and Reliability}

Figure 11a presents the aggregated through truck corridor average weekday travel times for the year of 2007. The results show that in the PM peak hours from 3-6 PM, the travel time for through trucks is consistently greater than the travel time based on loop sensor data which suggests that in the PM peak period, loop sensor data may underestimate the impact of congestion for freight vehicles.

Figure 11a also presents the standard deviation of the mean for loop sensor data and standard error of the mean for through truck averages. The standard error for through truck averages indicates less reliable travel time during congested PM peak hours from 3-6 PM, as evident by greater standard error values. This means that in addition to longer travel time experienced during congested periods, there is a high degree of unpredictability in day-to-day corridor travel time. Figure $11 \mathrm{~b}$ presents the coefficient of variation in travel time for the through trucks and loop sensor data; data were smoothed using a moving average over three time bins. This figure confirms increased variability during congested periods for both loop sensor and through truck data. However, through truck data variability is considerably higher which greatly increases the difficulty of scheduling for carriers operations. It is clear that loop sensor data underestimate the impact of congestion freight travel time reliability. 
Through Truck vs PORTAL Corridor Average Travel Time *Results following filter process 2, showing Aggregated Data and Std Err

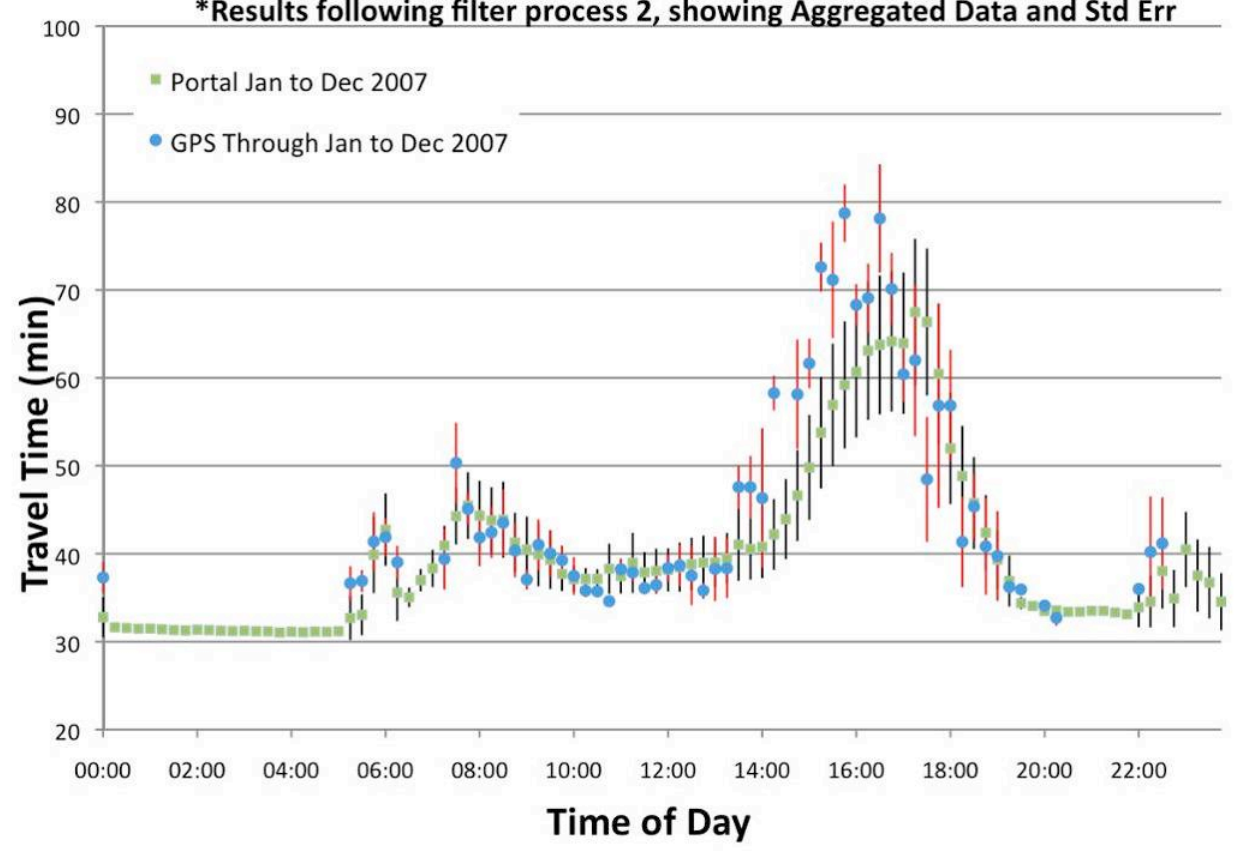

Through Truck vs PORTAL CV in Corridor Average Travel Time *Results following filter process 2, showing Aggregated Data, Smoothed

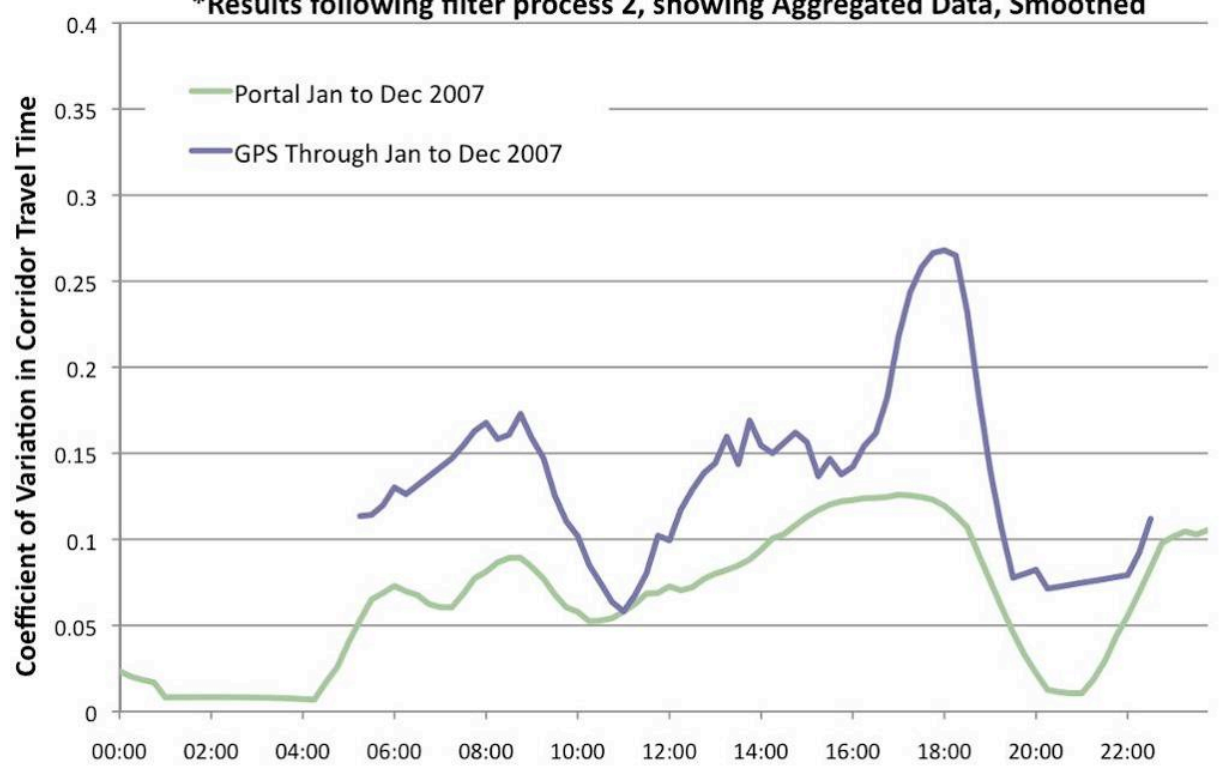

Time of Dav

Figure 11: From top to bottom, a) Average corridor travel time results following Filter Process 2 , showing aggregated loop sensor and through trucks travel time over one year (standard error of mean noted for multiple through truck readings in a time bin); b) Coefficient of variation in travel time (smoothed data by moving average of 3 time bins). 


\subsection{The Cost of Recurring Congestion}

The cost of congestion for freight vehicles traveling the northbound I-5 corridor was calculated using hourly travel time and speed distributions obtained from the recurring congestion analysis. The results were compared to costs during uncongested free-flow speeds; free-flow speed was assumed to be the accepted industry average operating speed $(52.05 \mathrm{mph})$ used by ATRI $(18,25)$. This is a conservative speed for cost calculations when compared to posted freeway speed limits. An hourly truck count distribution was estimated from 2006 Port of Portland disaggregated vehicle counts (44). Please refer to Appendix A for a more detailed description of data sources and assumptions made for deriving cost estimations.

In general there were three formulations for the cost estimates-these are summarized in Figure 12b. Formulation A multiplies the travel time (or delay) per mile by operating cost or value of time figures. Formulation B incorporates a term for travel time variability using 0.3 as a factor for dislike on variability (24), while formulation C uses 1.3 as a factor for dislike on variability (24)_formulations B and C provide low- and high-end estimates for the effect of variability on travel cost.

Different value of time and operating cost figures were applied to each formulation type described above to provide a range of cost per mile-these will be referred to as cost scenarios. Figure $13 \mathrm{~b}$ presents a description of the ten cost scenarios, and various parameters used to calculate daily cost per mile for the corridor analyzed. Values of time from the literature review were 
adjusted for inflation to reflect 2010 values using the consumer price index (45).

For each cost formulation, Figure 12 presents the percent increase (relative to $52.05 \mathrm{mph}$ free-flow conditions) in travel cost per mile for freight vehicles by time of day, and provides a summary of the daily cost per mile for freight vehicles traveling the northbound I-5 corridor. As shown, the daily percent increase in cost of delay per mile relative to costs at $52.05 \mathrm{mph}$ free-flow travel are as follows:

- $19 \%$ increase in cost per mile, without considering variability

- $22-31 \%$ increase in cost per mile, considering variability

Additionally, costs per mile peak at 2 PM. Here, the percent increase in cost of delay per mile relative to costs at $52.05 \mathrm{mph}$ free-flow travel are as follows:

- $95 \%$ increase in cost per mile, without considering variability

- $101-120 \%$ increase in cost mile, considering variability

These results point to the impact of travel time reliability throughout the day on the cost of freight operation. In the PM peak, where variability has shown to be the greatest, it is difficult for freight vehicles to adhere to arrive/departure schedules; just by reducing variability, the cost of congestion for freight vehicles traveling at 2 PM could be reduced by $25 \%$. 


\section{Percent Increase in Cost of Freight Vehicle-Hours of Delay Per Mile \\ Relative to $\mathbf{5 2 . 0 5} \mathbf{m p h}$ Free-Flow Travel Time}

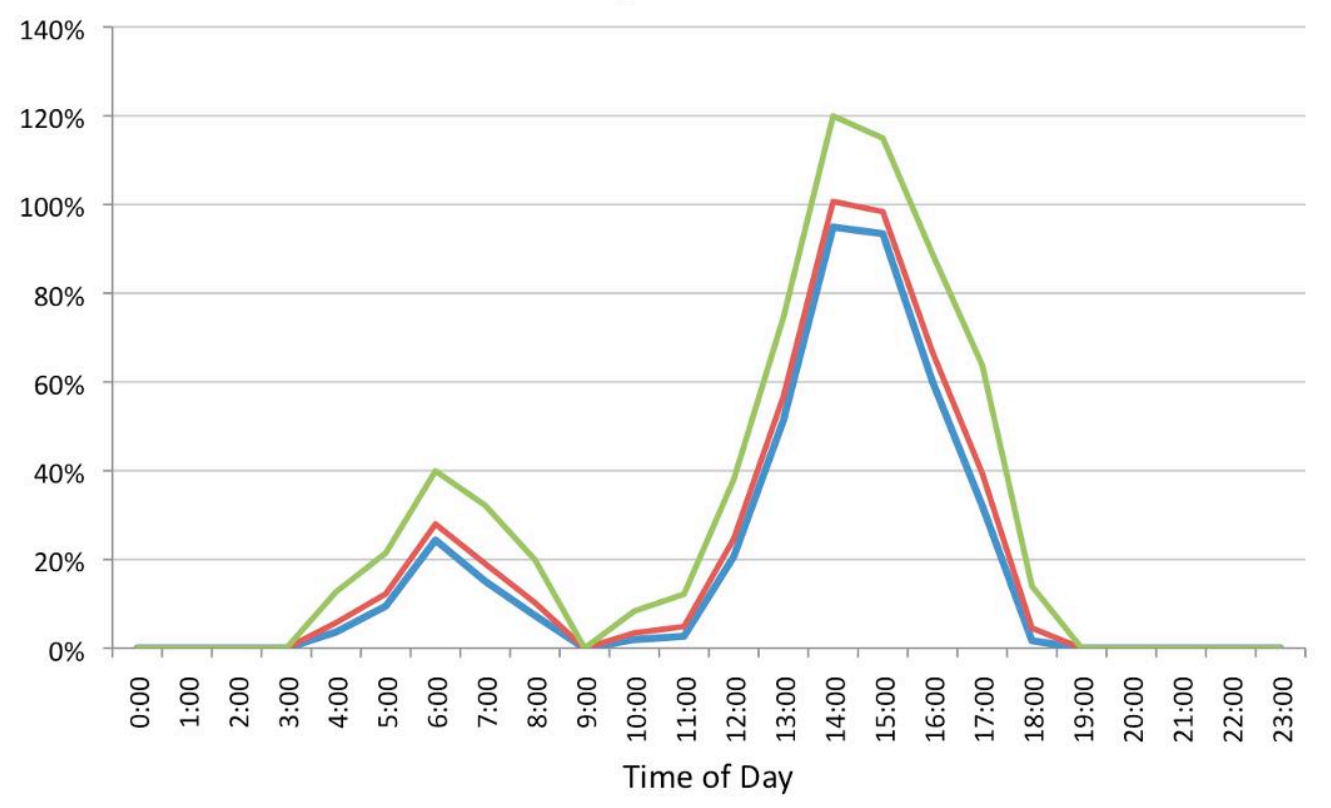

\begin{tabular}{|l|l|c|}
\hline \multicolumn{2}{|c|}{$\begin{array}{c}\text { General Formulation of } \\
\text { Cost Calculation }\end{array}$} & $\begin{array}{c}\text { Percent Increase in Daily Cost of } \\
\text { Freight Vehicle-Hours of Delay Per Mile } \\
\text { Relative to 52.05 mph Free-Flow Travel Time }\end{array}$ \\
\hline A & $\begin{array}{l}\text { Multiplies delay by operating CPH or VOT to } \\
\text { obtain costs. Reflects percent increases in } \\
\text { travel time by hour and daily travel time per } \\
\text { mile, relative to Free-Flow conditions. }\end{array}$ & $19 \%$ \\
B & $\begin{array}{l}\text { Incorporates Reliability (low-end). } \\
\text { C }\end{array}$ & $22 \%$ \\
Incorporates Reliability (high-end). & $31 \%$ \\
\hline
\end{tabular}

Figure 12: From top to bottom, a) Percent increase in freight vehicle cost of delay for northbound I-5 for three cost formulation types; b) Summary of general cost formulation types and percent increase in daily cost of delay for freight vehicles relative to $52.05 \mathrm{mph}$ free-flow travel time.

Ten cost scenarios were used to obtain a range of daily cost per mile for the northbound I-5 corridor and are presented in Figure 13; a summary of the lowest and highest cost scenarios are as follows:

- \$576 per mile, when looking at costs by operator type

- $\$ 2,551$ per mile, when considering regional value of time for Oregon with a 2.5 congestion markup, and incorporating the effect of variability 
Daily Cost of Freight Vehicle Travel Time Delay (\$/mile)

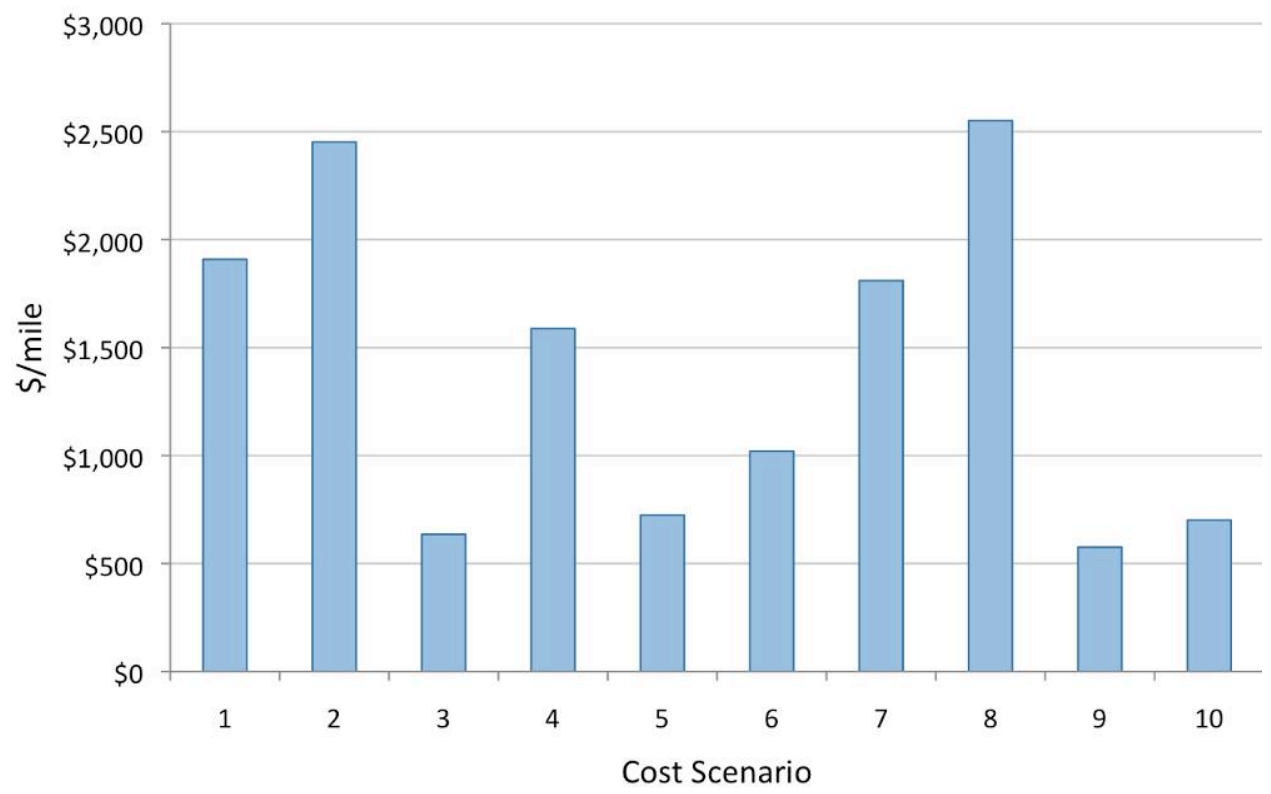

\begin{tabular}{|c|c|c|c|c|c|}
\hline $\begin{array}{c}\text { Cost } \\
\text { Scenario }\end{array}$ & $\begin{array}{l}\text { General Formulation of } \\
\text { Cost Calculation }\end{array}$ & $\begin{array}{l}\text { Factors/Parameters } \\
\text { Represented }\end{array}$ & $\begin{array}{c}\text { Cost Source for } \\
\text { Operating Cost Per Hour (CPH) or } \\
\text { Value of Time (VOT) }\end{array}$ & $\begin{array}{l}\text { Freight } \\
\text { CPH }\end{array}$ & $\begin{array}{l}\text { Factor of } \\
\text { dislike for } \\
\text { variability }\end{array}$ \\
\hline 1 & A: ATRI, 2010 & Marginal Operating Cost & ATRI, 2010 & $\begin{array}{l}\$ 83.26 \\
{ }^{*} \text { Freight } \\
\text { VOT }(\$ / h r)\end{array}$ & \\
\hline 2 & A: TTI, 2009 & National/Urban & TTI, 2009 & \$ 107.46 & \\
\hline 3 & A : TTI, 2009 & Regional & ODOT, 2005 Avg Truck & 27.85 & \\
\hline 4 & A : TTI, 2009 & Regional + Congestion & ODOT, 2005 Avg Truck X 2.5 (NCHRP) & 69.61 & \\
\hline 5 & B : TTI, 2009 + Cohen, 1999 & Regional + Reliabilty & ODOT, 2005 Avg Truck & 27.85 & 0.3 (low-end) \\
\hline 6 & C : TTI, $2009+$ Cohen, 1999 & Regional + Reliabilty & ODOT, 2005 Avg Truck & 27.85 & 1.3 (high-end) \\
\hline 7 & B : TTI, 2009 + Cohen, 1999 & Regional + Congestion + Reliability & ODOT, 2005 Avg Truck X 2.5 (NCHRP) & 69.61 & 0.3 (low-end) \\
\hline 8 & C : TTI, $2009+$ Cohen, 1999 & Regional + Congestion + Reliability & ODOT, 2005 Avg Truck X 2.5 (NCHRP) & 69.61 & 1.3 (high-end) \\
\hline 9 & A : TTI, 2009 & Differnce in Operator Type & Kawamura, 2000 Private Carriers & 23.05 & \\
\hline 9 & A: TTI, 2009 & Differnce in Operator Type & Kawamura, 2000 For-Hire Carriers & 36.67 & \\
\hline 10 & A: TTI, 2009 & Differnce in Service Type & Kawamura, 2000 Avg All Carriers & 30.64 & \\
\hline 10 & A : TTI, 2009 & Differnce in Service Type & Kawamura, 2000 Truck Load & 32.74 & \\
\hline 10 & A: TTI, 2009 & Differnce in Service Type & Kawamura, 2000 Less-Than Truck Load & 29.60 & \\
\hline
\end{tabular}

${ }^{\star}$ Freight Value of Time (VOT) have been adjusted for inlation and reflect 2010 prices

${ }^{\star} \mathrm{A}, \mathrm{B}$, and $\mathrm{C}$ refer the general formulation:

A : Uses CPH or VOT to obtain costs

B : Incorporates Reliability (low-end estimation)

C : Incorporates Reliability (high-end estimation)

Figure 13: From top to bottom, a) Daily cost of delay per mile for freight vehicle traveling northbound I-5 for different cost scenarios; b) Cost scenario descriptions, parameters and formulations used.

The wide range of cost results shows the importance using value of time and operating cost per hour parameters that provide realistic industry cost estimates during congested conditions. Values of time used in cost calculations should represent regional characteristics as much as possible, and should reflect the impact of congestion on the value of time. This work 
incorporated Oregon-specific value of time, and for several cost scenarios used value of time with a 2.5 congestion markup to reflect congested value of time.

Additionally, the effect of variability on total travel cost should be considered within the cost formulation, as this has shown to have a heavy impact on travel cost and is particularly valuable to the freight industry. Because of lack of good count data on the breakdown of carrier characteristics, it was not possible to separate costs by operator or service type with reasonable accuracy. However, it is understood that there are documented differences between carriers. If reliable data become available in the future, a breakdown of annual costs by operator or service type may provide valuable information for carriers.

\subsection{Recurring Congestion Emissions Estimation}

The average daily freight vehicle emissions per mile along the northbound I-5 corridor were estimated using the EPA's MOVES2010 model. Please refer to Appendix B for a more detailed explanation of user-defined parameters for MOVES2010 and assumptions made during the emissions estimation resulting non-recurring congestion conditions.

Figure $14 \mathrm{~b}$ presents the increase in freight vehicle GHG, MSAT and criteria pollutant emission rates (grams/mile) during congestion relative to emissions rates during $52.05 \mathrm{mph}$ free-flow conditions-an additional graph shows the percent increase in freight vehicle-hours of delay per mile throughout the day. The various emission types (GHG, MSAT, criteria pollutants) show increases in grams/mile of pollutant emitted, as there are increases in delay. However, 
the degree to which the emissions increase varies between each emission type. For this reason, it is important to consider emissions from GHG, MSAT, and criteria pollutant groups in order to understand the impact of congestion on the environment, and public health. For example $\mathrm{CO} 2$ emissions do not represent the same impact or amount of pollutant emitted over time in comparison to other pollutant types (e.g., 1,3-butadiene or PM 10).

As shown in Figure 14b, there is an $80-120 \%$ increase in freight vehicle emission rates during the PM peak period, which corresponds to an $85-95 \%$ increase in freight vehicle-hours per mile; i.e. congestion and delay during peak hours are highly correlated to increased emissions.

Environmental concerns are largely centered on carbon dioxide (CO2), as it is the prominent GHG. Figure 14b shows that on a daily basis, an additional 24,099 grams per mile are emitted from freight vehicles as the result of congestions (a nearly 50\% increase with respect to emissions during free-flow conditions).

Other gases, such as oxides of nitrogen (NOx), present concerns for public health as they are linked to respiratory problems. Particulate matter (PM10) and ultrafine particulate matter (PM2.5) are linked to ailments such as cancer and heart problems. Due to recurrent congestion, a daily increase of $65 \%$ in NOx emissions, $13 \%$ of PM emissions, and $49 \%$ of SO2 emissions was found on the northbound I-5 corridor. 


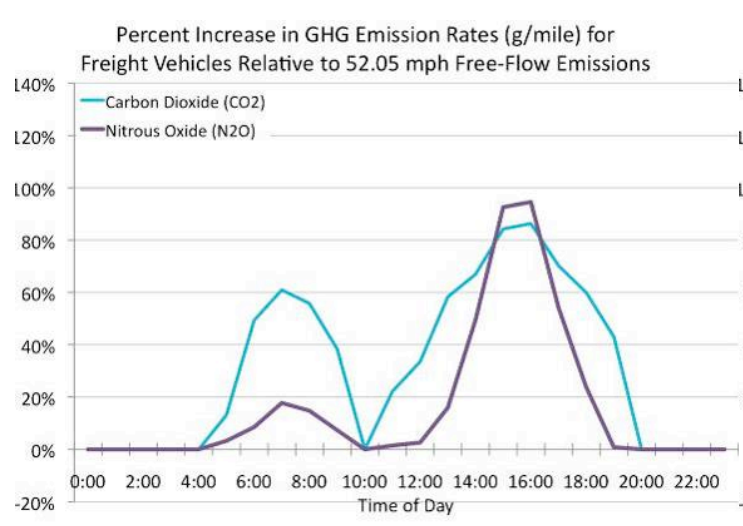

Percent Increase in MSAT Emission Rates ( $\mathrm{g} / \mathrm{mile}$ ) for Freight Vehicles Relative to $52.05 \mathrm{mph}$ Free-Flow Emissions
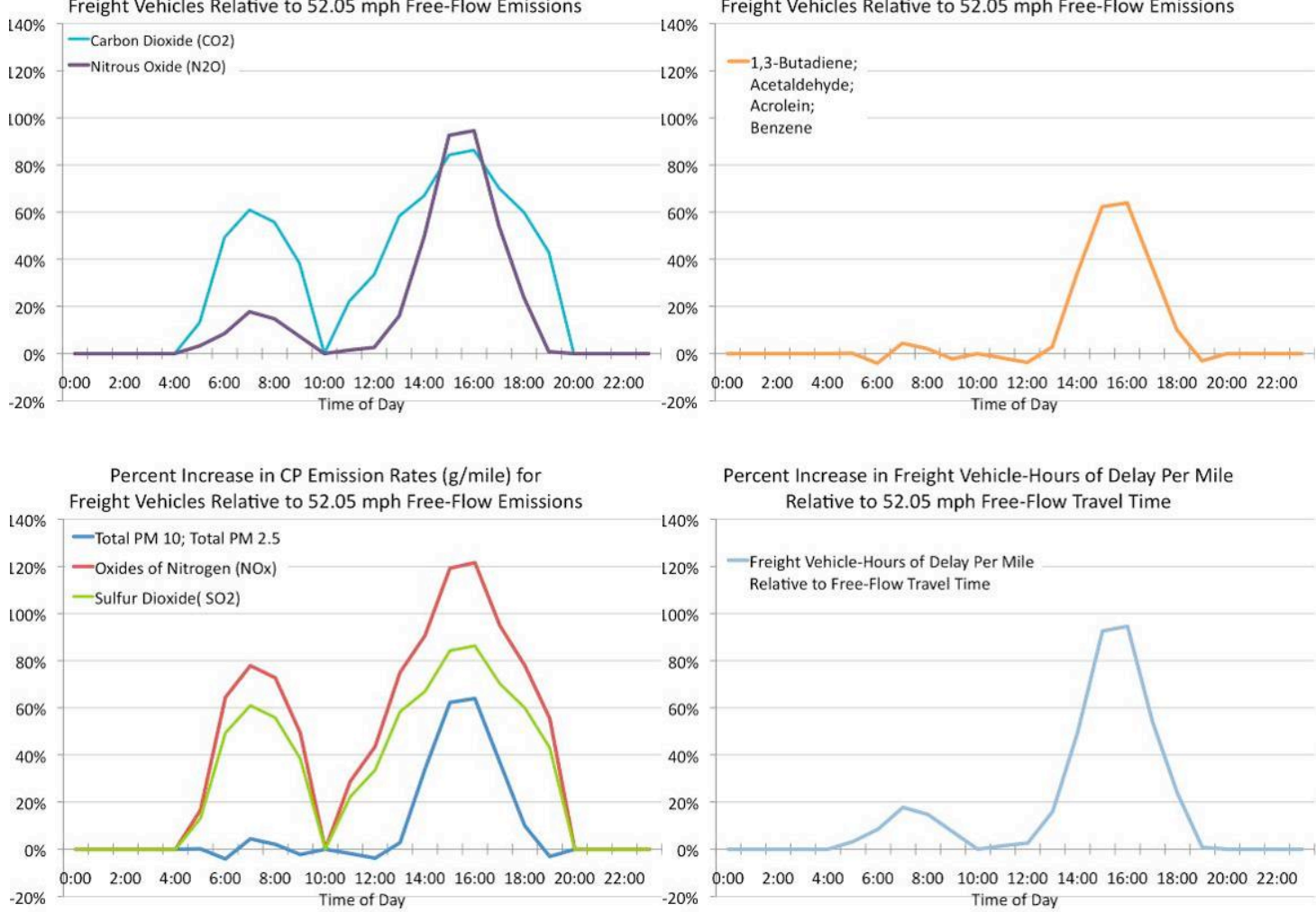

\begin{tabular}{|c|c|c|c|}
\hline \multicolumn{2}{|c|}{ Pollutant } & $\begin{array}{c}\text { Daily Freight Vehicle Emission Rates (g/mile) } \\
\text { Above } 52.05 \text { mph Free-Flow } \\
\text { Emission Rates }\end{array}$ & $\begin{array}{c}\text { Daily Percent Increase in Total } \\
\text { Freight Vehicle Emission Rates (g/mile) } \\
\text { Relative to } 52.05 \text { mph Free-Flow } \\
\text { Emission Rates }\end{array}$ \\
\hline \multirow{2}{*}{ GHG } & $\begin{array}{c}\text { Carbon Dioxide }\left(\mathrm{CO}_{2}\right) \\
\text { Nitrous Oxide }\left(\mathrm{N}_{2} \mathrm{O}\right)\end{array}$ & $\begin{array}{c}24099.96 \\
0.03\end{array}$ & $49.49 \%$ \\
\hline \multirow{3}{*}{ MSAT } & $1,3-$ Butadiene & & $25.80 \%$ \\
\hline & Acetaldehyde & 0.02 & $13.43 \%$ \\
\hline \multirow{4}{*}{ CP } & Acrolein & & $13.43 \%$ \\
& Benzene & 3.78 & $65.75 \%$ \\
& PM10 - Total & 138.55 & $49.51 \%$ \\
\hline
\end{tabular}

Figure 14: Top to bottom: a) Percent increase in freight vehicle Greenhouse Gas (GHG), Mobile Source Air Toxic (MSAT), and Criteria Pollutant (CP) emissions in congestion relative to $52.05 \mathrm{mph}$ free-flow emission rates, and corresponding increases in freight vehicle-hours of delay per mile; b) Summary of daily freight vehicle emission rates above $52.05 \mathrm{mph}$ free-flow emission rates.

\subsection{Recurring Congestion Summary}

This section provides an example of how the recurring congestion analysis can

be applied to study smaller roadway segments in order to capture 
performance measure spatially through an urban corridor. Next, a summary of integrating loop sensor and GPS data sources is discussed. Finally, the section ends with a synopsis of the results from the recurring congestion analysis and relates the findings and methods used to engineering, planning and freight industry practice.

\subsubsection{Adapting Methodology to Smaller Segments}

It is possible to adapt the methods described in the recurring congestion analysis to investigate smaller segments in order to study bottlenecks or to investigate the spatial nature of congestion. A cursory study of three five-mile segments was performed in order to provide an example of the capabilities of the methodology defined in Section 4 and applied to study recurring congestion.

The three five-mile segments studied were on northbound I-5 near Corbett Ave., Morrison St., and Terwilliger Blvd-data were averaged over a threemonth period (June through August 2007). Figure 15 through Figure 17 present the truck average travel time through each five-mile segment, with loop sensor data covering each segment shown; standard error of the through truck travel time mean are shown with error bars.

It should be noted that because the data were aggregated over a small period of time, many time bins provide an average for only a small number of trucks (e.g., two or three). Additionally, many of the time bins with very large standard error were found to have trucks crossing the segment at the time of an incident (this is discussed further in Section 6 regarding non-recurring 
congestion). Despite the limited data, the through truck data at each segment follow similar trends compared to the loop sensor data-AM peaks occur around $8 \mathrm{AM}$ and PM peaks occur around 6 PM. As evident by the loop sensor data at each segment, the travel time profile varies throughout the data from one study area to the next-for instance, the five-mile segments near Corbett Ave. and Terwilliger Blvd. have greater travel time on average in AM peak, while the five-mile segment near Morrison St. has greater travel time in the PM peak. Studying through truck data over a greater aggregation period would more clearly capture this spatial nature of congestion, although trends still emerge for the aggregation period shown.

The through truck date for each station reveals in general, greater travel time in comparison to loop sensor data in the PM peak, as well as increases in travel time variability (as indicated by standard error of the mean) in the PM peak. In off peak periods the through truck data are found surrounding the average loop sensor data. Again this indicates that in the PM peak, loop sensor data may underestimate the impact of congestion for freight vehicles.

By studying smaller segments end-to-end throughout the corridor, additional information can be gleaned regarding system performance. Particularly, the data could be used to help identify key bottlenecks for the freight industry, and allow agency to prioritize segments and bottlenecks throughout the corridor to make the most efficient use of improvement dollars. The analysis of the three five-mile segments presented here 
demonstrates the adaptability of the methodology and techniques defined in this research to study the impact of congestion on freight movements.

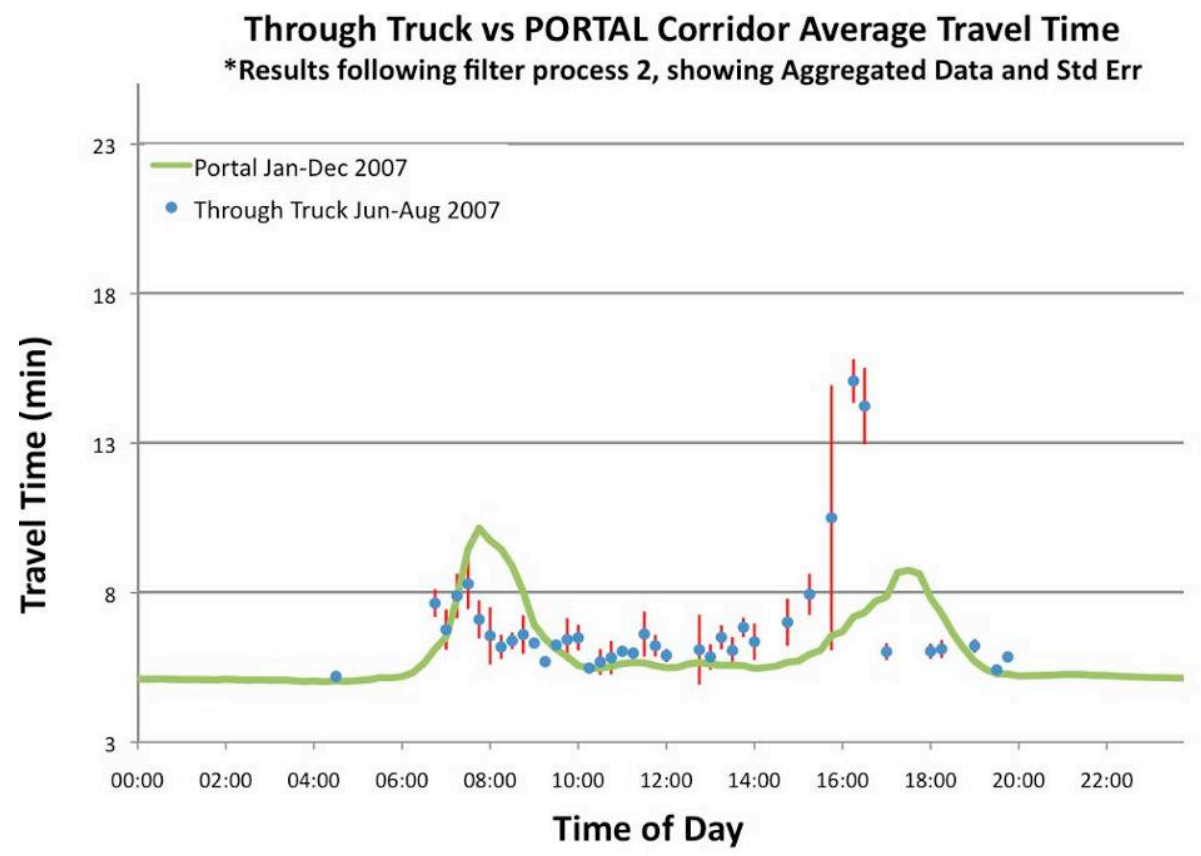

Figure 15: Average corridor travel time results following Filter Process 2 at a five-mile segment of northbound I-5 near Corbett Ave., showing aggregated loop sensor and through trucks travel time over a three-month period (with standard error of mean noted for multiple readings in a time bin) 


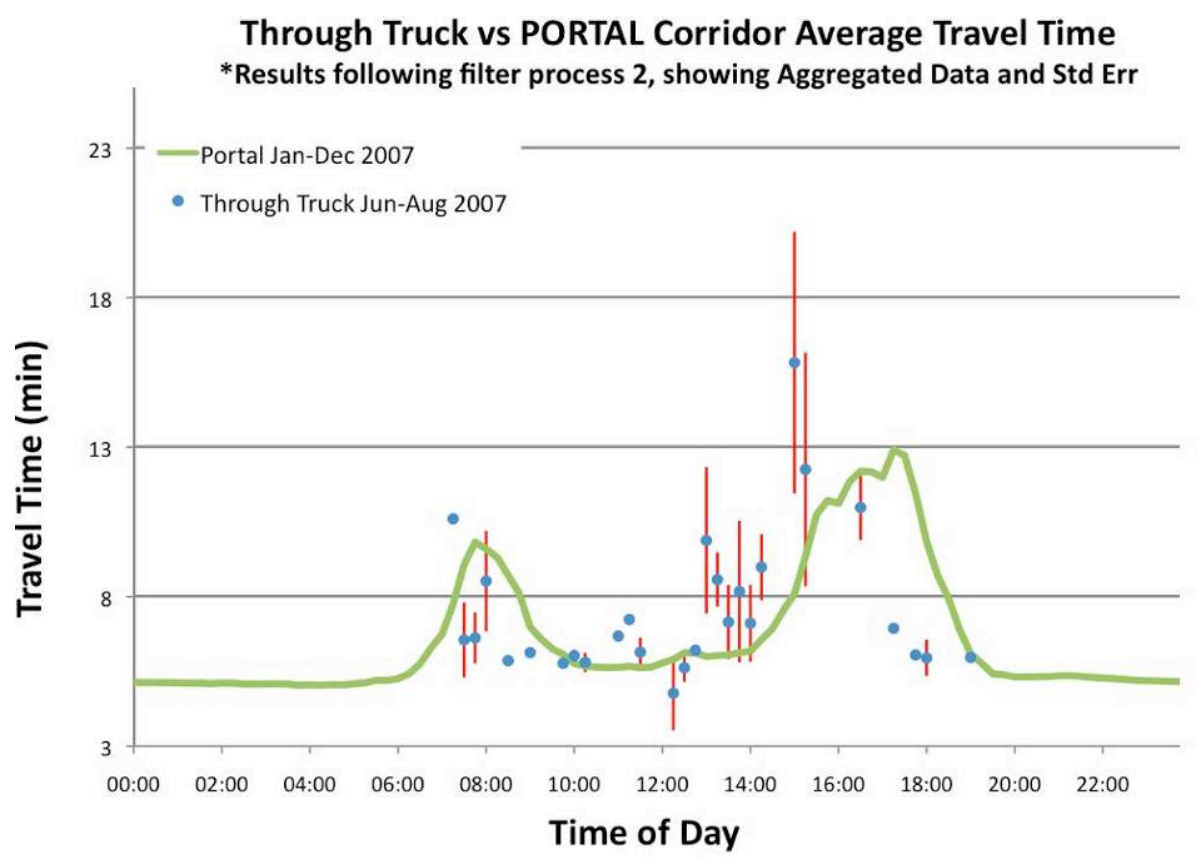

Figure 16: Average corridor travel time results following Filter Process 2 at a five-mile segment of northbound I-5 near Morrison St., showing aggregated loop sensor and through trucks travel time over a three-month period (with standard error of mean noted for multiple readings in a time bin)

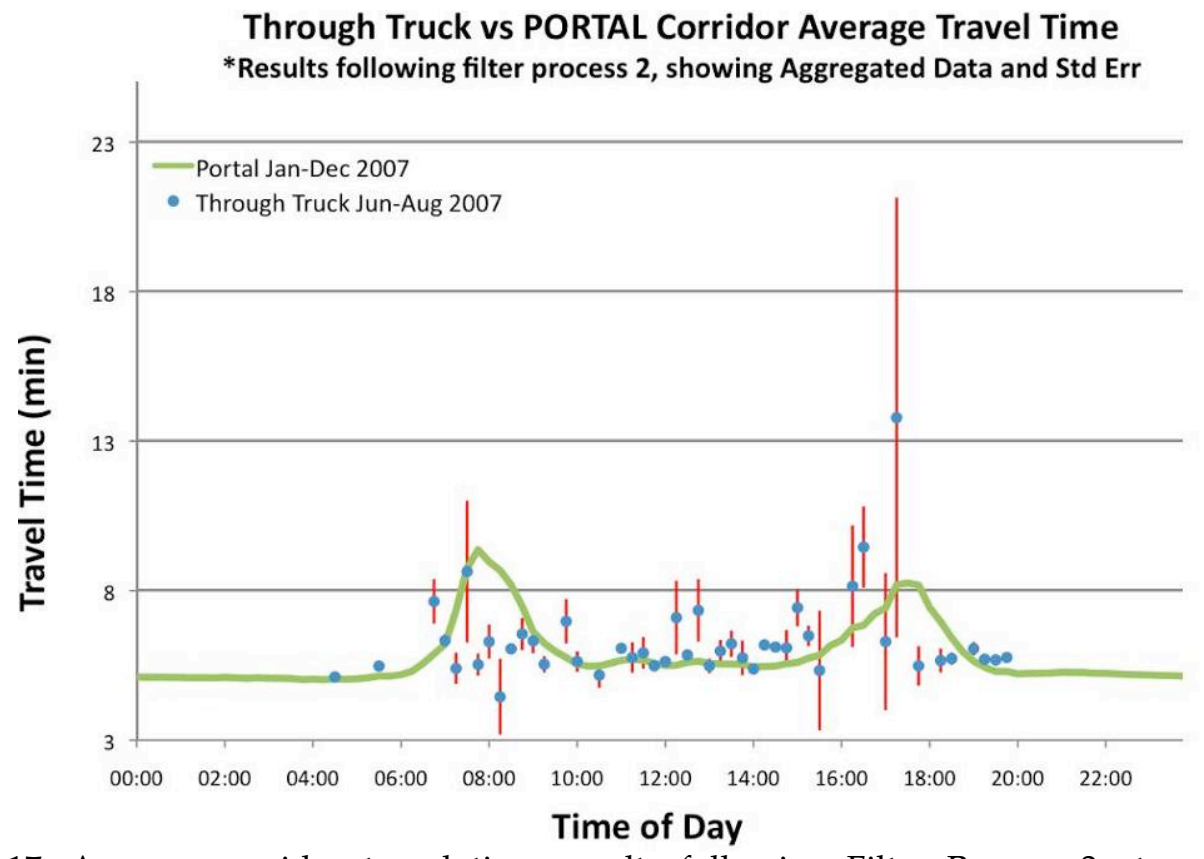

Figure 17: Average corridor travel time results following Filter Process 2 at a five-mile segment of northbound I-5 near Terwilliger Blvd., showing aggregated loop sensor and through trucks travel time over a three-month period (with standard error of mean noted for multiple readings in a time bin) 


\subsubsection{Integrating Loop Sensor Data and Commercial GPS Data}

The loop sensor data used for this research was intended to provide a basis of comparison for the truck GPS data. The loop sensor data were aggregated in such a way as to provide a static view of travel time through the corridor at a given time (i.e., travel time at each station for a given time bin were added to obtain a corridor travel time). In reality, congestion changes over time and space throughout the corridor. Particularly, over a long corridor it is possible to cross multiple time bins. For the northbound I- 5 corridor studied in this research, a worst case scenario of speeds at roughly $30 \mathrm{mph}$ through the entire corridor would result in a travel time of about one hour, and include travel time data crossing four different time bins; one every fifteen minutes.

In order to study the potential error present in aggregating loop sensor data in a static way (as done with this research) versus a dynamic way (which may compare more closely to the dynamic truck GPS data), a separate analysis was performed. Figure 18a presents the static loop sensor travel time alongside dynamic loop sensor travel time from 1-8 PM. As the data approach the PM peak (about $6 \mathrm{PM}$ ), the dynamic loop sensor travel time data have longer travel time, while following the PM peak (between 6 and 8 PM), the dynamic loop sensor data show short travel time in comparison to the static loop sensor data. As shown in Figure 18b the differences appear to be small when approaching the PM peak (less than 10\%), but following the PM peak, the difference is greater (less than 25\%). 
Despite the shifting of the travel time values when using dynamic loop sensor data Figure 18a still shows through truck average travel time consistently greater than both static and dynamic loop sensor travel time between 3-6 PM. A statistical analysis was performed to determine for which time bins the truck average travel time were statistically significantly different than static loop sensor travel time, dynamic loop sensor travel time, and freeflow travel time (see Figure 19).

The results from statistical analysis show that for several time bins between 3-6 PM both the static and dynamic loop sensor data are statistically significantly shorter in comparison to through truck average travel time (i.e., through truck travel times are significantly longer). This confirms that despite subtle differences between the static and dynamic loop sensor travel times, the impact of congestion on freight vehicles remains underestimated by both dynamic and static loop sensor travel times for most PM peak time bins. In comparison to free-flow travel time, truck average travel time begin to show statistically significant longer travel times as early as 1:30 PM, with the majority of time bins showing longer travel time until 6:30 PM. 


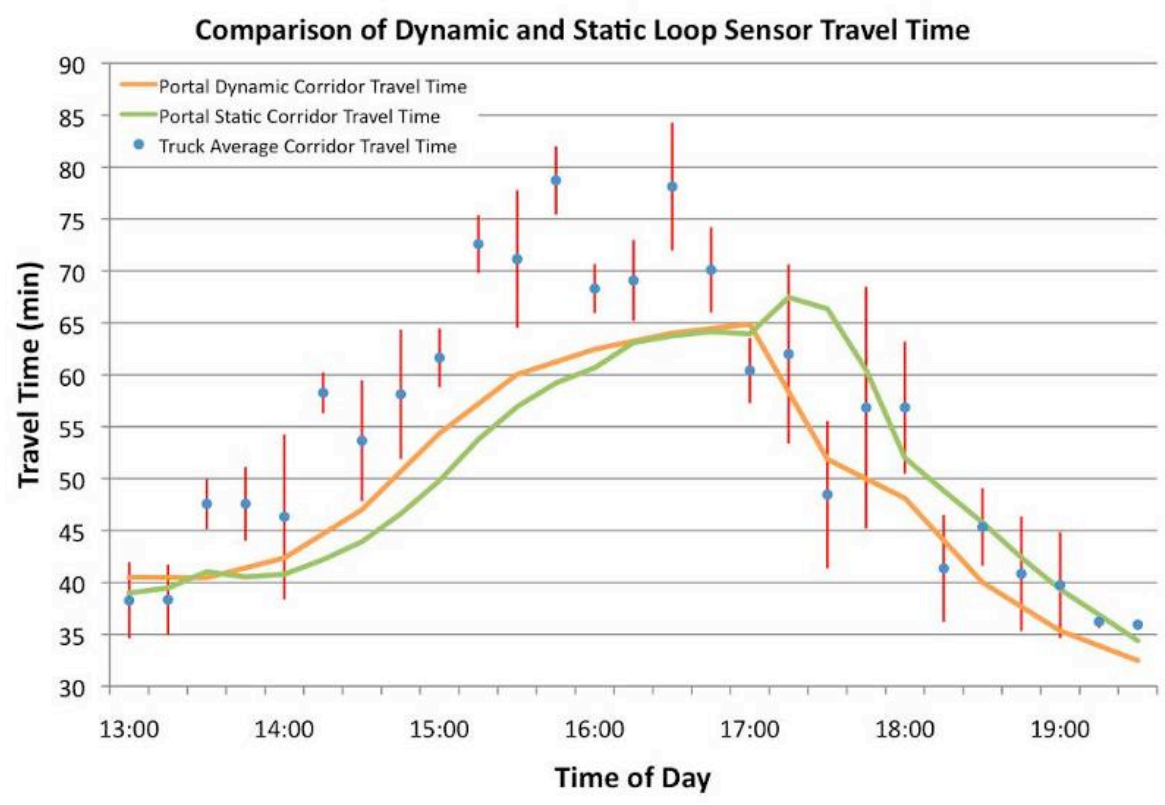

Percent Increase in Dynamic Loop Sensor Travel Time Compared to Static Loop Sensor Travel Time

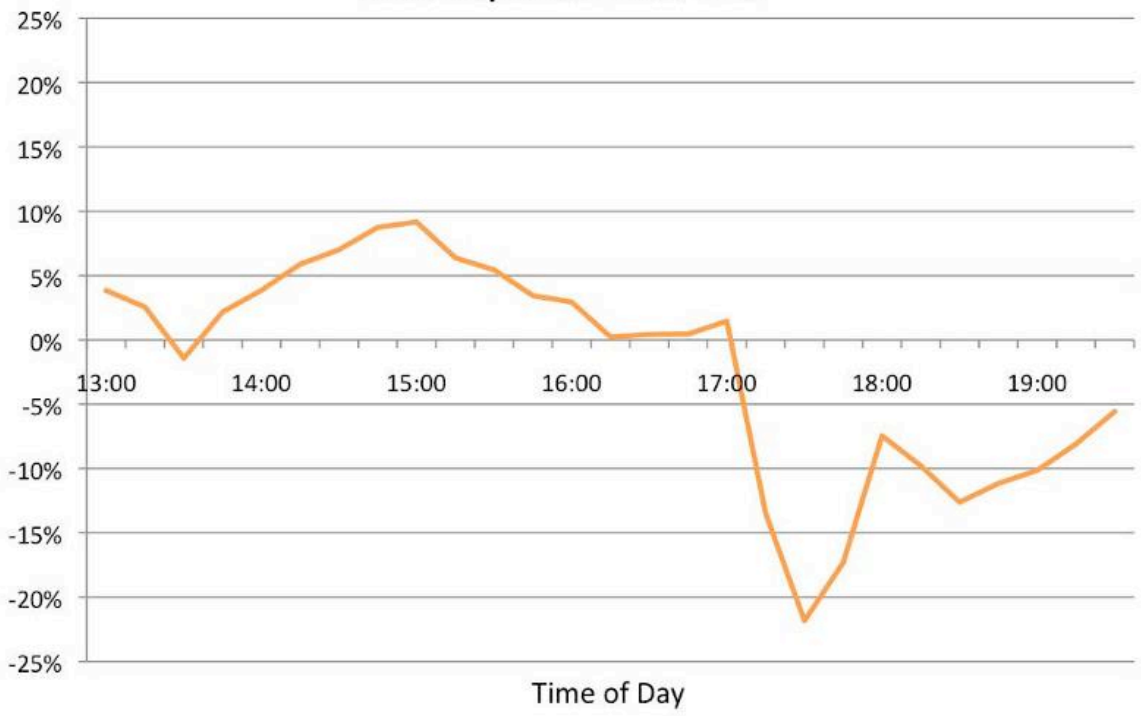

Figure 18: From top to bottom, a) average corridor travel time shown for dynamic and static aggregation of loop sensor data, alongside truck average corridor travel time (with standard error of the mean shown); b) percent increase in dynamic sensor travel time compared to static loop sensor travel time (positive values indicate dynamic travel time is longer-slower, negative values indicate dynamic travel time is shorter-faster). 


\begin{tabular}{|c|c|c|c|c|c|c|}
\hline \multirow[b]{2}{*}{ Time Bin } & \multicolumn{2}{|c|}{$\begin{array}{l}\text { Static Loop Sensor } \\
\text { Travel Time }\end{array}$} & \multicolumn{2}{|c|}{$\begin{array}{c}\text { Dynamic Loop Sensor } \\
\text { Travel Time }\end{array}$} & \multicolumn{2}{|c|}{$\begin{array}{c}52.05 \mathrm{mph} \text { Free-Flow } \\
\text { Travel Time }\end{array}$} \\
\hline & $\begin{array}{c}\text { Are } \\
\text { Differences } \\
\text { in Means } \\
\text { Statistically } \\
\text { Significant? }\end{array}$ & $\begin{array}{l}\text { Are Truck } \\
\text { Travel } \\
\text { Times } \\
\text { Longer or } \\
\text { Shorter? }\end{array}$ & $\begin{array}{c}\text { Are } \\
\text { Differences } \\
\text { in Means } \\
\text { Statistically } \\
\text { Significant? }\end{array}$ & $\begin{array}{l}\text { Are Truck } \\
\text { Travel } \\
\text { Times } \\
\text { Longer or } \\
\text { Shorter? }\end{array}$ & \begin{tabular}{c|c} 
Are \\
Differences \\
in Means \\
Statistically \\
Significant?
\end{tabular} & $\begin{array}{c}\text { Are Truck } \\
\text { Travel } \\
\text { Times } \\
\text { Longer or } \\
\text { Shorter? }\end{array}$ \\
\hline 00:00:00 & Yes & Longer & & & No & \\
\hline $05: 15: 00$ & Yes & Longer & & & No & \\
\hline 05:30:00 & Yes & Longer & & & No & \\
\hline 05:45:00 & No & & & & No & \\
\hline 06:00:00 & No & & & & Yes & Longer \\
\hline $06: 15: 00$ & No & & & & No & \\
\hline 07:15:00 & No & & & & No & \\
\hline 07:30:00 & No & & & & Yes & Longer \\
\hline $07: 45: 00$ & No & & & & Yes & Longer \\
\hline 08:00:00 & No & & & & No & \\
\hline $08: 15: 00$ & No & & & & Yes & Longer \\
\hline 08:30:00 & No & & & & No & \\
\hline $08: 45: 00$ & No & & & & No & \\
\hline 09:00:00 & Yes & Shorter & & & No & \\
\hline 09:15:00 & No & & & & No & \\
\hline 09:30:00 & No & & & & No & \\
\hline 09:45:00 & No & & & & No & \\
\hline $10: 00: 00$ & No & & & & No & \\
\hline $10: 15: 00$ & No & & & & No & \\
\hline $10: 30: 00$ & Yes & Shorter & & & No & \\
\hline $10: 45: 00$ & Yes & Shorter & & & Yes & Shorter \\
\hline 11:00:00 & No & & & & No & \\
\hline 11:15:00 & No & & & & No & \\
\hline 11:30:00 & Yes & Shorter & & & No & \\
\hline $11: 45: 00$ & No & & & & No & \\
\hline $12: 00: 00$ & No & & & & No & \\
\hline $12: 15: 00$ & No & & & & No & \\
\hline $12: 30: 00$ & No & & & & No & \\
\hline $12: 45: 00$ & Yes & Shorter & & & No & \\
\hline $13: 00: 00$ & No & & No & & No & \\
\hline $13: 15: 00$ & No & & & & No & \\
\hline $13: 30: 00$ & Yes & Longer & Yes & Longer & Yes & Longer \\
\hline $13: 45: 00$ & Yes & Longer & & & Yes & Longer \\
\hline $14: 00: 00$ & No & & No & & No & \\
\hline $14: 15: 00$ & Yes & Longer & & & Yes & Longer \\
\hline $14: 30: 00$ & No & & No & & Yes & Longer \\
\hline $14: 45: 00$ & No & & & & Yes & Longer \\
\hline $15: 00: 00$ & Yes & Longer & Yes & Longer & Yes & Longer \\
\hline $15: 15: 00$ & Yes & Longer & & & Yes & Longer \\
\hline $15: 30: 00$ & Yes & Longer & No & & Yes & Longer \\
\hline $15: 45: 00$ & Yes & Longer & & & Yes & Longer \\
\hline $16: 00: 00$ & Yes & Longer & Yes & Longer & Yes & Longer \\
\hline $16: 15: 00$ & No & & & & Yes & Longer \\
\hline $16: 30: 00$ & Yes & Longer & Yes & Longer & Yes & Longer \\
\hline $16: 45: 00$ & No & & & & Yes & Longer \\
\hline $17: 00: 00$ & No & & No & & Yes & Longer \\
\hline $17: 15: 00$ & No & & & & Yes & Longer \\
\hline $17: 30: 00$ & Yes & Shorter & No & & No & \\
\hline $17: 45: 00$ & No & & & & No & \\
\hline 18:00:00 & No & & No & & Yes & Longer \\
\hline $18: 15: 00$ & No & & & & No & \\
\hline $18: 30: 00$ & No & & No & & Yes & Longer \\
\hline $18: 45: 00$ & No & & & & No & \\
\hline 19:00:00 & No & & No & & No & \\
\hline 19:15:00 & No & & & & No & \\
\hline 19:30:00 & Yes & Longer & Yes & Longer & Yes & Shorter \\
\hline 20:00:00 & No & & & & Yes & Shorter \\
\hline $20: 15: 00$ & No & & & & Yes & Shorter \\
\hline 22:00:00 & Yes & Longer & & & Yes & Shorter \\
\hline $22: 15: 00$ & No & & & & No & \\
\hline 22:30:00 & No & & & & No & \\
\hline
\end{tabular}

Figure 19: Results from statistical analysis comparing differences in mean between truck average corridor travel time and static loop sensor travel time, dynamic loop sensor travel time, and travel time at $52.05 \mathrm{mph}$ free-flow conditions. Results indicate whether the truck average corridor travel time is statistically significantly different than the loop sensor and free-flow travel time for a given time bin, at a confidence level of $95 \%$. Also noted is whether or not truck data show travel time longer or shorter travel time in comparison. Data for dynamic loop sensor travel time were available only for the time binds listed above. 
Another potential source of error in using the loop sensor data obtained for this research is that it represents an average of all lanes. An additional analysis was performed to test the potential error resulting from using average corridor travel time from all lanes versus average corridor travel time from the right lane only. Figure 20 presents a comparison at five stations between the travel time given by right lane and the travel time given by the average of all lanes (which was used for this research). The figure indicates the percent increase in right lane travel time relative to the all lane average travel time; positive values indicate the right lane is slower at that station, while negative values indicate the right lane was faster.

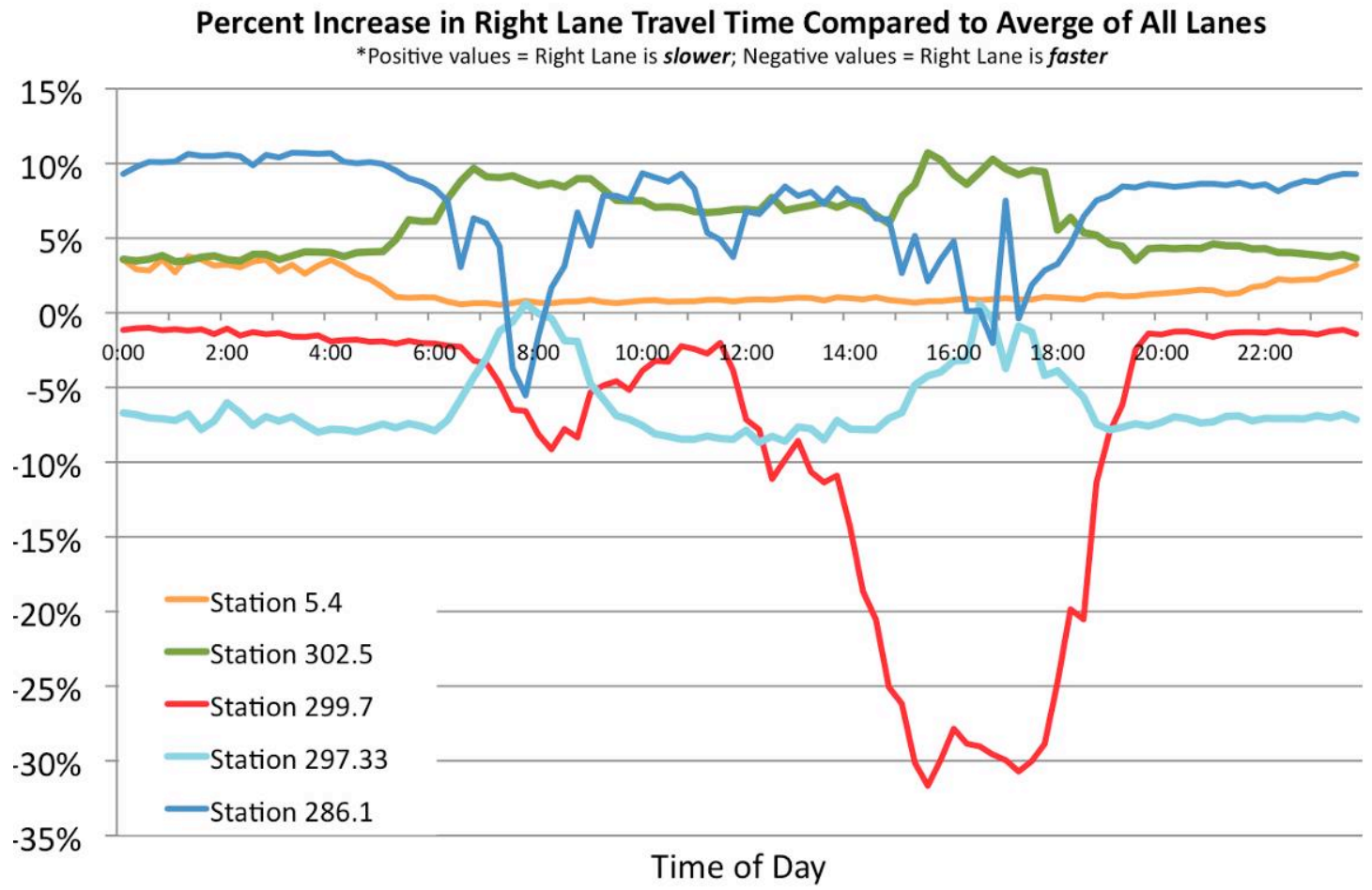

Figure 20: Percent increase in right lane travel time results compared to the travel time averaged from all lanes at five stations on northbound I-5. When values are positive, the right lane shows longer (slower) travel time; when values are negative, the right lane shows shorter (faster) travel time. 
Two of these stations (station 5.4, and station 286.1) show that the right lane is slower (by not more than about 10\%), but when approaching congested periods, the percent difference approaches $0 \%$-meaning that in congestion all lanes would be similar in travel time. The right lane at station 297.33 also approaches a $0 \%$ difference in peak periods, but in off-peak has a faster travel time than the average of the lanes. The right lane at station 302.5 shows slower travel time for the right lane, but the right lane becomes increasing slower during the PM peak-this may be the result of a key access point further downstream, so vehicles being to queue up early to be in the correct lane.

Right lane data from station 299.7 appears to be an outlier, showing faster travel time for the right lane, which becomes increasing faster during congested periods. Additionally, the percent difference (reaching $-35 \%$ in the PM peak) is much greater than the maximum percent difference at other stations (reaching $+/-10 \%$ ).

In general the right lane comparison shows differences at each station, but in peak periods, the difference in right lane and average of all lanes becomes less-the "all lane" average seems appropriate to provide loop sensor data. Because of the variations in right lane data at stations representing the start, end and middle of the corridor (the five stations tested), the right lane data at stations does not seem to be consistently slower, particularly in the off peak period (i.e., the use of all lane average travel time does not appear to be a source of error). Additionally, two right lanes tested showed faster travel time 
in off peak (station 297.33 and 299.7), so the average lane estimate may be more conservative to use at those stations.

\subsubsection{Key Findings}

Travel Time, Delay and Reliability

- Loop sensor data were found to underestimate the impact of PM peak congestion on freight vehicles, as indicated by consistently longer freight vehicle average corridor travel times from 3-6 PM.

- The PM peak period was found to have greater variability in freight vehicle travel time, as indicated by higher standard error values and greater coefficient of variation between 3-6 PM.

- In comparison to loop sensor coefficient of variation, there is greater variability in freight vehicle travel time, indicating that loop sensor data may underestimate the impact of variability on freight vehicles.

\section{The Cost of Recurring Congestion}

- A 95\% increase in cost per mile was found for cost formulation A (does not consider variability).

- $101 \%$ and $120 \%$ increase in cost mile, were found for cost formulations B and C, respectively (considers variability with lowand high-end parameters of dislike on variability).

- Costs scenarios ranged from \$576 per mile (when looking at costs by operator type) to $\$ 2,551$ per mile (when considering regional 
value of time for Oregon with a 2.5 congestion markup, and incorporating the effect of variability).

- In order to provide a more accurate representation, value of time and operating cost figures should reflect regional characteristics. The NCHRP 431 also recommends that a congestion factor be applied to values of time used in cost scenarios in order to represent congested value of time.

- Because of a lack of accurate data by operator and service, it is not recommended to use value of time by carrier characteristics. If more accurate data become available, quantifying cost by carrier characteristics may provide valuable information to carriers.

\section{Recurring Congestion Emission Estimation}

- As there are increases in delay, there are corresponding increases in GHG, MSAT, and criteria pollutants emission rates for through trucks in comparison to emissions during free-flow travel.

- An additional $24,099 \mathrm{~g} /$ mile of CO2 are emitted by freight vehicles daily (a 50\% daily increase above free-flow emissions).

- An additional $138 \mathrm{~g} /$ mile of NOx are emitted by freight vehicles daily (a 65\% daily increase above free-flow emissions).

- An additional 3.78 g/mile each of PM 10 and PM 2.5 are emitted by freight vehicles daily (a 13\% daily increase above free-flow emissions). 
- The percent increase in congested emission rates relative to freeflow emissions, and quantity of pollutants emitted varies between pollutant types. For this reason, a variety of pollutants should be modeled, particularly emission types that are known to have the greatest impact on the environment and health related issues.

Table 2 presents a summary of the multi-criteria freight performance measures for the recurring congestion analysis, showing percent increase in delay (vehicle-hours per mile), cost per mile, and emissions (grams per mile) relative to free-flow conditions. The results are presented in terms of daily increases (all day), and increases over the PM peak period (3-6 PM). As shown in the table, the impacts of congestion on freight vehicle delay, cost and emissions are greater through the PM peak period-if only the daily impacts are quantified, the impact of congestion is not as pronounced, and therefore PM peak period characteristics should be analyzed independently.

Table 2: Percent increase in Multi-Criteria Performance Measures, above $52.05 \mathrm{mph}$ free-flow conditions for All Day and PM Peak (3-6 PM) time periods.

\begin{tabular}{|c|c|c|c|c|c|c|c|c|c|c|}
\hline $\begin{array}{c}\text { Time } \\
\text { Period }\end{array}$ & Delay & \multicolumn{2}{|c|}{$\begin{array}{c}\text { Cost } \\
\text { Formulations }\end{array}$} & $\begin{array}{c}\text { MSAT } \\
\text { Emissions }\end{array}$ & \multicolumn{2}{c|}{$\begin{array}{c}\text { GHG } \\
\text { Emissions }\end{array}$} & \multicolumn{3}{c|}{$\begin{array}{c}\text { CP } \\
\text { Emissions }\end{array}$} \\
\hline & A & B & C & $\begin{array}{c}\text { 1,3-Butadiene } \\
\text { Acetaldehyde } \\
\text { Acrolei } \\
\text { Benzene }\end{array}$ & CO2 & N2O & $\begin{array}{c}\text { PM 10 } \\
\& 2.5\end{array}$ & NOx & SO2 \\
\hline $\begin{array}{c}\text { All } \\
\text { Day }\end{array}$ & $19 \%$ & $19 \%$ & $22 \%$ & $\begin{array}{c}31 \\
\%\end{array}$ & $13 \%$ & $50 \%$ & $26 \%$ & $13 \%$ & $66 \%$ & $50 \%$ \\
\hline $\begin{array}{c}\text { PM } \\
\text { Peak }\end{array}$ & $72 \%$ & $72 \%$ & $78 \%$ & $\begin{array}{c}99 \\
\%\end{array}$ & $43 \%$ & $75 \%$ & $66 \%$ & $43 \%$ & $103 \%$ & $75 \%$ \\
\hline
\end{tabular}

Table 3 presents the percent increase in various emission types over the course of the day, relative to free-flow emissions. Because only a small amount of data was available for off peak periods (00:00-4:00, and 20:00-23:00), free-flow 
conditions were assumed in the off peak (i.e., an increase of $0 \%$ ). As shown, the impact of congestion on freight vehicle emission varies between emission types, and is impacted by fluctuations in average speed and volume. 
Table 3: Percent increase by time of day in emission rates (g/mile), above emissions during $52.05 \mathrm{mph}$ free-flow conditions. Freight vehicle average speed and volume are shown by time of day. A limited amount of truck data was available for AM and PM off-peak periods, so free-flow conditions were assumed-this means in off peak periods a $0 \%$ increase would occur.

\begin{tabular}{|c|c|c|c|c|c|c|c|c|}
\hline $\begin{array}{c}\text { Time } \\
\text { Period }\end{array}$ & $\begin{array}{c}\text { Average } \\
\text { Speed } \\
\text { (Freight) }\end{array}$ & $\begin{array}{c}\text { Volume } \\
\text { (Freight) }\end{array}$ & $\begin{array}{c}\text { MSAT } \\
\text { Emissions }\end{array}$ & \multicolumn{2}{|c|}{$\begin{array}{c}\text { GHG } \\
\text { Emissions }\end{array}$} & \multicolumn{3}{|c|}{$\begin{array}{c}\text { CP } \\
\text { Emissions }\end{array}$} \\
\hline $\mathrm{mph}$ & $\begin{array}{c}\text { vehicles/ } \\
\text { hr }\end{array}$ & $\begin{array}{c}\text { 1,3-Butadiene } \\
\text { Acetaldehyde } \\
\text { Acrolei } \\
\text { Benzene }\end{array}$ & CO2 & N2O & $\begin{array}{c}\text { PM 10 } \\
\& 2.5\end{array}$ & NOx & SO2 \\
\hline $5: 00$ & 50 & 180 & $0 \%$ & $13 \%$ & $3 \%$ & $8 \%$ & $17 \%$ & $13 \%$ \\
\hline $\mathbf{6 : 0 0}$ & 48 & 267 & $-4 \%$ & $49 \%$ & $8 \%$ & $28 \%$ & $64 \%$ & $49 \%$ \\
\hline $\mathbf{7 : 0 0}$ & 42 & 322 & $4 \%$ & $61 \%$ & $18 \%$ & $38 \%$ & $78 \%$ & $61 \%$ \\
\hline $\mathbf{8 : 0 0}$ & 45 & 333 & $2 \%$ & $56 \%$ & $15 \%$ & $34 \%$ & $73 \%$ & $56 \%$ \\
\hline $\mathbf{9 : 0 0}$ & 48 & 428 & $-2 \%$ & $38 \%$ & $7 \%$ & $22 \%$ & $49 \%$ & $38 \%$ \\
\hline $\mathbf{1 0 : 0 0}$ & 52 & 462 & $0 \%$ & $0 \%$ & $0 \%$ & $0 \%$ & $0 \%$ & $0 \%$ \\
\hline $\mathbf{1 1 : 0 0}$ & 51 & 465 & $-2 \%$ & $22 \%$ & $1 \%$ & $11 \%$ & $29 \%$ & $22 \%$ \\
\hline $\mathbf{1 2 : 0 0}$ & 50 & 439 & $-4 \%$ & $34 \%$ & $3 \%$ & $17 \%$ & $44 \%$ & $34 \%$ \\
\hline $\mathbf{1 3 : 0 0}$ & 43 & 399 & $3 \%$ & $58 \%$ & $16 \%$ & $36 \%$ & $75 \%$ & $58 \%$ \\
\hline $\mathbf{1 4 : 0 0}$ & 34 & 382 & $34 \%$ & $67 \%$ & $49 \%$ & $56 \%$ & $91 \%$ & $67 \%$ \\
\hline $\mathbf{1 5 : 0 0}$ & 27 & 289 & $62 \%$ & $84 \%$ & $93 \%$ & $78 \%$ & $119 \%$ & $84 \%$ \\
\hline $\mathbf{1 6 : 0 0}$ & 27 & 242 & $64 \%$ & $86 \%$ & $95 \%$ & $80 \%$ & $122 \%$ & $86 \%$ \\
\hline $\mathbf{1 7 : 0 0}$ & 33 & 197 & $37 \%$ & $70 \%$ & $54 \%$ & $61 \%$ & $95 \%$ & $70 \%$ \\
\hline $\mathbf{1 8 : 0 0}$ & 40 & 232 & $10 \%$ & $60 \%$ & $24 \%$ & $41 \%$ & $78 \%$ & $60 \%$ \\
\hline $\mathbf{1 9 : 0 0}$ & 51 & 219 & $-3 \%$ & $43 \%$ & $1 \%$ & $19 \%$ & $55 \%$ & $43 \%$ \\
\hline
\end{tabular}

\subsubsection{Applying Techniques for Deriving Multi-Criteria FPM in Practice} The findings from the recurring congestion analysis are of value to both public agencies (Port of Portland, METRO, City of Portland), and the freight industry. The methods used to study freight vehicles in congestion and results from the analysis can be used to inform decisions made at a project or regional planning level, and from a carrier perspective, decisions made in routing and scheduling of freight deliveries.

From a planning and engineering perspective, the methodology developed to identify through trucks and produce corridor level multi-criteria 
performance measures will allow for the consideration of the freight industry in transportation improvement projects. This is a significant step in being able to study and address the needs of all users of the transportation system. Current methods used to study freeway performance largely rely on loop sensor data and do not incorporate freight independently; as shown through this research, it is possible for loop sensor data to underestimate the impact of congestion on freight vehicles.

The methodology used in this research can be modified to identify and study bottlenecks throughout the corridor (i.e., by studying smaller segments). Using the multi-criteria performance measures (e.g., delay, cost and emissions), comparisons can be made between a list of identified bottlenecks, and then used to prioritize the locations most in need of transportation funds. Being able to quantify the impact of congestion on freight vehicles creates transparency in the transportation planning process, holding agencies accountable to the public for the decisions that are made.

Additionally, the research presented here can help inform decisions made regarding congestion management strategies, and infrastructure improvements, such as ramp metering, variable speed limit signs, congestion pricing, tolling, and truck-only-lanes. Here the multi-criteria performance measures would allow decision makers to study the benefit to the freight industry of such improvements or strategies by using performance data that reflect the current impact of congestion on freight vehicles. For instance, decision makers could study the benefit of ramp meters or variable speed limit 
signs in managing congestion during peak hour in order to maintain an optimal speed that minimizes delay, variability, industry cost, and freight vehicle emissions. Finding a balance between these criteria using transportation infrastructure and intelligent transportation systems will provide the greatest overall system benefit.

From a freight industry perspective, the methodology developed to identify through trucks and produce corridor level multi-criteria performance measures will allow carriers to improve routing and scheduling logistics. By applying the techniques presented in this research, region wide freight performance measures could be developed on interstates throughout the Portland Metropolitan area.

Freight carriers could then use the multi-criteria performance measures to identify periods of time when travel time delay and variability increase on a given freeway-examining the region wide system of freeways, carriers would be able to identify the optimal route for a given time of day that would reduce travel time delay and improve reliability. By modifying scheduling and routing in this way, carriers would have see a reduction in transportation costs, and improvement in reliability, allowing carriers to more easily adhere to strict scheduling. Additionally, being able to schedule deliveries with more accuracy (by choosing routes with less variability), carriers can eliminate built in buffer time; this time could be allocated to make additional deliveries and increase profit for the carrier. 


\section{$6 \quad$ Non-Recurring Congestion Results}

Non-recurring congestion occurs as the result of an unexpected event (i.e., traffic incident, weather event or construction). This section begins with a description of the non-recurring congestion case study designed to analyze congestion during several incident periods. Additionally, one incident period was further studied to investigate the effect of including partial through and partial local truck types in the analysis of freight movements. The remainder of this section will present the results for the non-recurring congestion analysis. Non-recurring congestion results are discussed first in terms of mobility and congestion performance measures (i.e., travel time and delay). Next, four incident periods are used to estimate the cost and emission rates resulting from incidents.

\subsection{Case Study Description}

The non-recurring congestion analysis studied trucks passing through fivemile segments (incident areas) where incidents occurred on northbound I-5; four incident areas were studied (referred to as A, B, C and D). The Filter Process 1 parameters for each incident area are summarized in Table 4.

Table 4: User-Defined Parameters for Filter Process 1 for Non-Recurring Congestion Case Study

\begin{tabular}{|l|c|c|c|c|c|c|}
\hline \multicolumn{1}{|c|}{$\begin{array}{c}\text { Incident Area } \\
\text { Label }\end{array}$} & $\mathbf{m}_{\mathbf{s}}$ & $\mathbf{m}_{\mathbf{e}}$ & $\begin{array}{c}\text { Five-Mile } \\
\text { Incident } \\
\text { Area }\end{array}$ & $\begin{array}{c}\mathbf{r} \\
\text { (miles) }\end{array}$ & $\begin{array}{c}\mathbf{t}_{\mathbf{c}} \\
(\mathbf{m i n})\end{array}$ & $\begin{array}{c}\mathbf{b}_{\mathbf{c}} \\
(\mathbf{m i n})\end{array}$ \\
\hline A, Corbett Ave. & 293 & 298 & $293-298$ & 4 & 75 & 25 \\
B, Morrison St. & 295 & 300 & $295-300$ & 4 & 75 & 25 \\
C, Terwilliger Blvd. & 292 & 297 & $292-297$ & 4 & 75 & 25 \\
D, Going St. & 299 & 304 & $299-304$ & $16 \& 13$ & 75 & 25 \\
\hline
\end{tabular}


Many incidents occurred within each incident area, spanning different times of day. This analysis focused mainly on incidents that occurred during the summer months (June through August 2007), where the weather was clear with no rain. However, one incident day in December 2008 was studied, which had a small amount of rain throughout the day. The incidents are summarized in Table 5. The incident label shown in Table 5 refers to the incident area, the incident day studied, and the sequence of incidents on a given day. For instance, incidents B2-1, B2-2 and B2-3 all occur at incident area B on the second day studied at this incident area (as given by B2), and the numbers following the dash (1,2 and 3$)$ correspond to the order of the incidents on that day.

In addition to incidents occurring within the incident areas (those shown in Table 5), it was noticed that loop sensor and GPS data often captured the impact of incidents occurring downstream of the incident area. For this reason, figures presented later within this section will note and refer to downstream incidents that occurred within two miles of the incident areas. Figure 21 presents diagrams of incident areas $A, B, C$ and $D$, noting the milepost ranges of each incident area, and the location of incidents. 
Table 5 Summary of Incident Data

\begin{tabular}{|c|c|c|c|c|c|c|c|}
\hline $\begin{array}{c}\text { Incident } \\
\text { Label }\end{array}$ & Date & $\begin{array}{l}\text { Milepost } \\
\text { Location }\end{array}$ & $\begin{array}{l}\text { Start } \\
\text { Time }\end{array}$ & $\begin{array}{c}\text { Duratio } \\
\mathrm{n} \text { (min) }\end{array}$ & Type & Weather & $\begin{array}{c}\text { Affected } \\
\text { Lanes }\end{array}$ \\
\hline A1-1 & $6 / 8 / 07$ & 298 & $7: 06: 12$ & 58 & Debris & Clear & 0 \\
\hline A1-2 & $6 / 8 / 07$ & 297 & $7: 46: 17$ & 58 & Stall & Clear & 2 \\
\hline A2-1 & $7 / 3 / 07$ & 297 & $6: 29: 17$ & 58 & Stall & Clear & 0 \\
\hline A2-2 & $7 / 3 / 07$ & 297 & 14:57:39 & 57 & Stall & Clear & 0 \\
\hline A2-3 & $7 / 3 / 07$ & 298 & $16: 54: 52$ & 57 & Stall & Clear & 0 \\
\hline A3-1 & $8 / 14 / 07$ & 295 & 10:45:34 & 56 & Stall & Clear & 0 \\
\hline A3-2 & $8 / 14 / 07$ & 296 & 13:30:50 & 56 & Debris & Clear & 1 \\
\hline A3-3 & $8 / 14 / 07$ & 295 & $15: 24: 26$ & 56 & Stall & Clear & 0 \\
\hline A4-1 & $8 / 24 / 07$ & 297 & $16: 08: 49$ & 56 & Stall & Clear & 0 \\
\hline B1-1 & $7 / 26 / 07$ & 298 & 15:04:07 & 57 & Stall & Clear & 1 \\
\hline B2-1 & $8 / 2 / 07$ & 297 & $7: 25: 35$ & 56 & Stall & Clear & 0 \\
\hline B2-2 & $8 / 2 / 07$ & 297 & $13: 16: 34$ & 56 & Stall & Clear & 0 \\
\hline B2-3 & $8 / 2 / 07$ & 300 & $15: 04: 20$ & 56 & Stall & Clear & 1 \\
\hline B2-4 & $8 / 2 / 07$ & 299 & $16: 24: 59$ & 56 & Stall & Clear & 1 \\
\hline C1-1 & $6 / 12 / 07$ & 297 & $6: 37: 39$ & 58 & Debris & Clear & 0 \\
\hline C1-2 & $6 / 12 / 07$ & 297 & $8: 37: 37$ & 65 & Stall & Clear & 0 \\
\hline $\mathrm{C} 1-3$ & $6 / 12 / 07$ & 297 & $16: 02: 32$ & 58 & Crash & Clear & 2 \\
\hline C2-1 & $8 / 3 / 07$ & 296 & 9:33:07 & 77 & Crash & Clear & 2 \\
\hline C2-2 & $8 / 3 / 07$ & 295 & 13:33:31 & 56 & Stall & Clear & 0 \\
\hline $\mathrm{C} 2-3$ & $8 / 3 / 07$ & 295 & $17: 43: 22$ & 56 & Stall & Clear & 1 \\
\hline D1-1 & $12 / 12 / 08$ & 303 & $3: 46: 13$ & 102 & Crash & $\begin{array}{c}\text { Minimal } \\
\text { Rain }\end{array}$ & 2 \\
\hline D1-2 & $12 / 12 / 08$ & 304 & $12: 02: 50$ & 56 & Crash & $\begin{array}{c}\text { Minimal } \\
\text { Rain }\end{array}$ & 2 \\
\hline
\end{tabular}



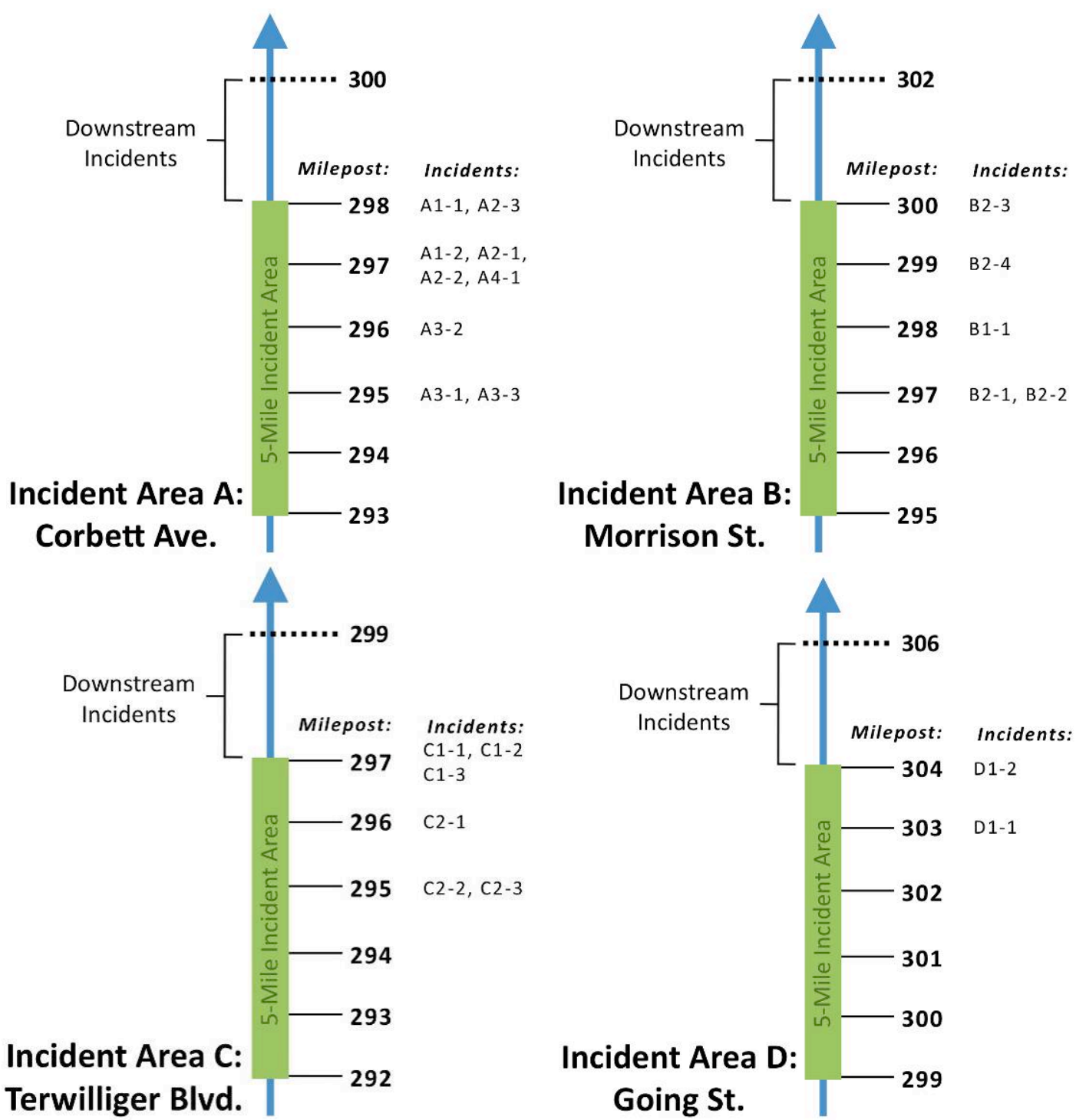

Figure 21: Diagrams of I-5 northbound incident areas A, B, C and D, showing incident locations.

\subsubsection{Impact of an Incident on Freight Movements}

Incident areas A-C presented in Table 4 were used to study the impact of an incident on freight movements in terms of travel time. To quantify the impact of incidents on cost and emission rates, four individual incident periods were studied: incidents C1-1, A1-2, B2-3 and A4-1 (see Table 5). These results are presented later in this section. 


\subsubsection{Effect of Including Partial Through/Local Trucks}

Incident area D presented in Table 4 was used to study the effect of including partial through and partial local trucks in the analysis of freight movements. These results are presented later in this section.

\subsection{Travel Time and Incident Delay}

As previously mentioned, the non-recurring congestion study was designed to analyze congestion during several incident periods, and for one incident period, investigate the effect of including partial through and partial local truck types in the analysis of freight movements.

\subsubsection{Impact of an Incident on Freight Movements}

Figure 22 through Figure 25 present the results for through-incident truck travel times through the five-mile incident areas A, B and C. In each figure, loop sensor travel times are shown for the day the incidents occurred (to show the impact of the incident), and for an aggregated period from June to August 2007 (to represent average day-to-day travel time through incident area). As shown in Figure 22 through Figure 25, there are obvious differences in the loop sensor data when comparing the incident day travel times to the average day-to-day travel times, as indicated by increases in travel time around the time of incidents within the incident area, or downstream of the incident area. Incidents are labeled along the $\mathrm{x}$-axis in Figure 22 through Figure 25 to show the time and duration of the incidents; downstream incidents are labeled with “d".

Only a small number of through-incident trucks were identified following Filter Process 1 and 2 for incident areas A, B and C. Therefore it was not 
possible to obtain averages for through-incident truck data, as there were not multiple through-incident trucks identified in any given time bin. However, as shown in Figure 22 through Figure 25, the through-incident truck travel times for incident areas A, B and C followed closely to the loop sensor data on each incident day, during periods where incidents occurred, as well as periods before and following incidents.

In general, the through-incident trucks passing the incident area during the beginning of an incident period show equal or greater travel time compared to loop sensor travel time- -this means that the initial impact to freight vehicles resulting from incidents may be underestimated by loop sensor data.

Through-incident trucks passing the incident area towards the end of incident periods or after the incident period often show shorter travel time compared to loop sensor travel time (see incidents B1-1, B2-1 and B2-4 in Figure 24 or incidents C2-2 and C2-3 in Figure 25). As discussed earlier in Section 5.5.2, this effect is likely the result of how loop sensor travel time data through the incident area are derived from the data archive. The methods used to obtain travel time from loop sensors may produce slower travel time following a queue; GPS data are more dynamic and show that the queue is dispersing more quickly than indicated by the static representation of travel time from loop sensors. 
Through-Incident Truck Average Travel Time Crossing Incident Area A

*Results following filter process 2

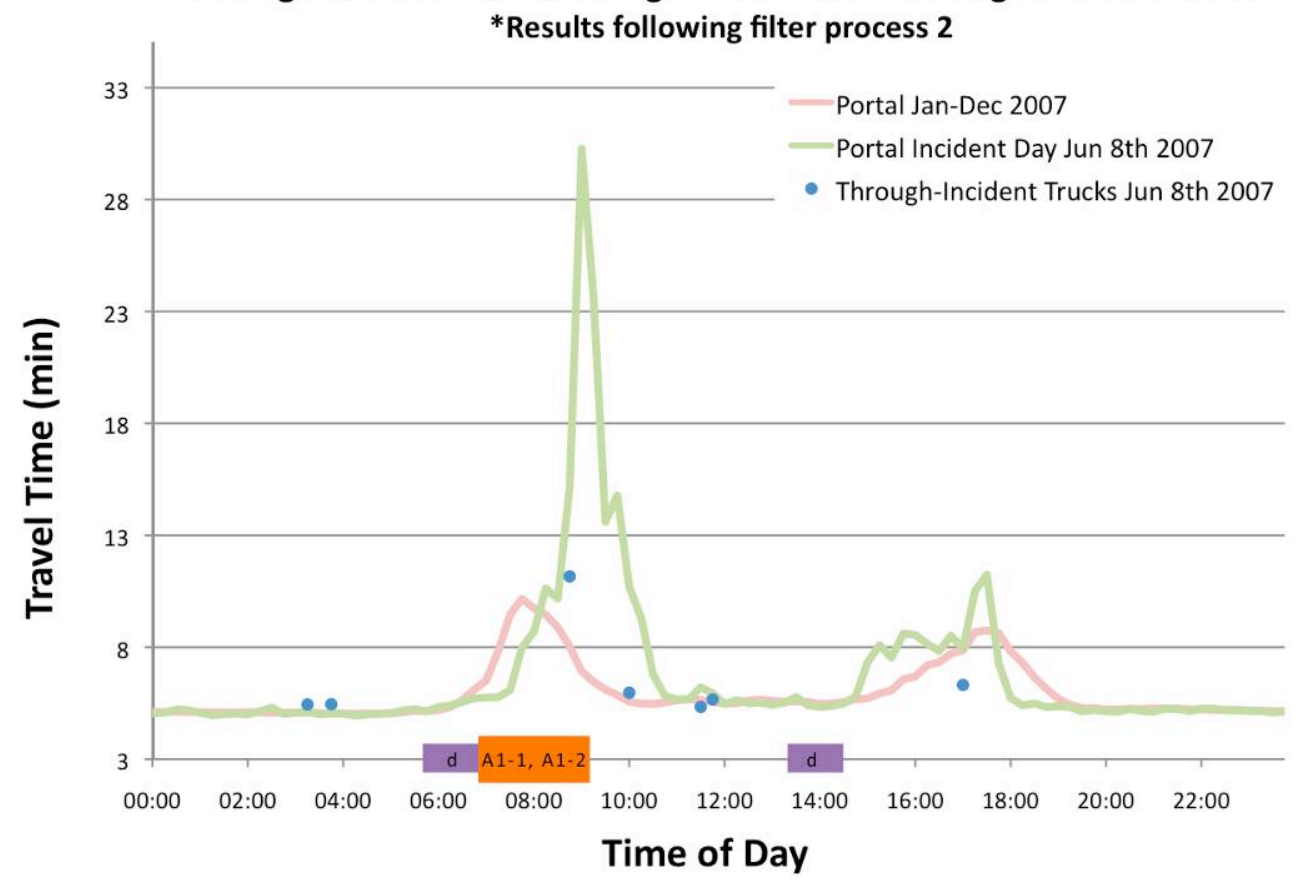

Through-Incident Truck Average Travel Time Crossing Incident Area A

*Results following filter process 2

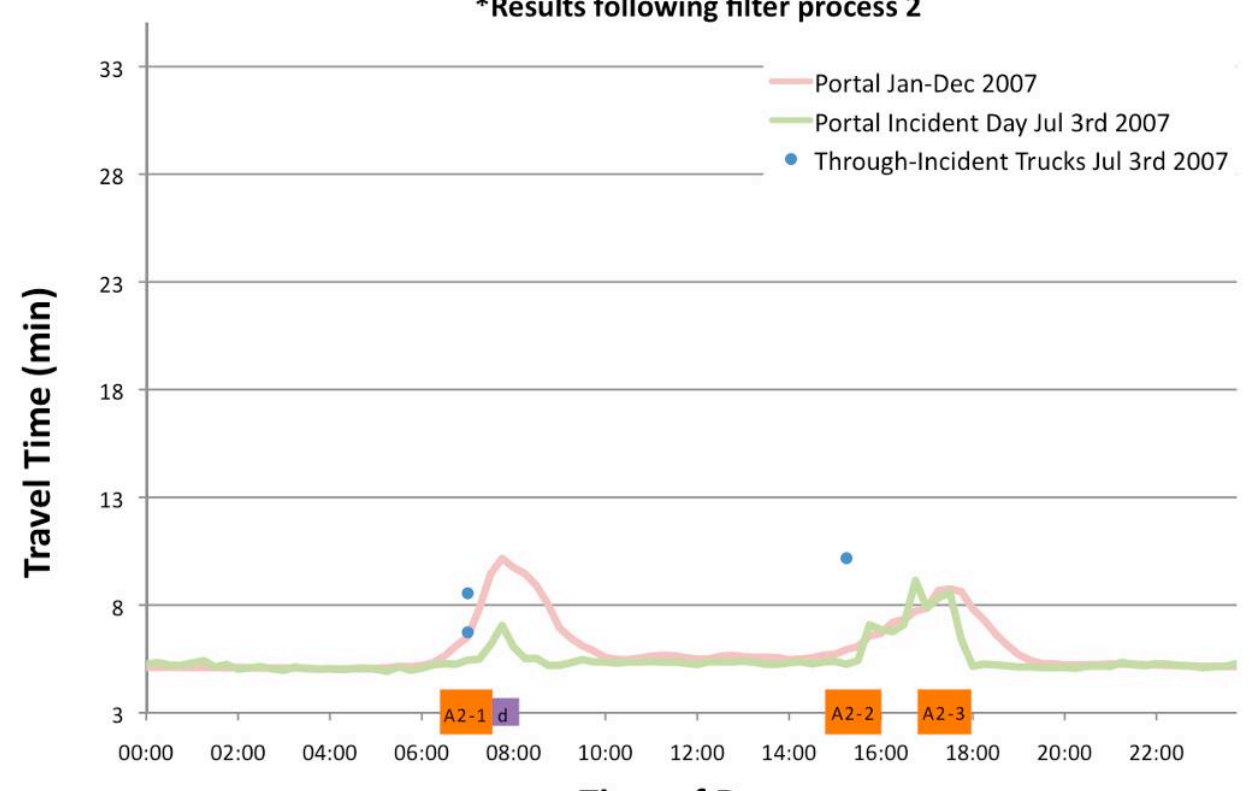

Time of Day

Figure 22: From top to bottom, a) Incident area A northbound I-5 through-incident truck travel time results following Filter Process 2-June 8, 2007; b) Incident area A northbound I-5 through-incident truck travel time results following Filter Process 2-July 3, 2007. 


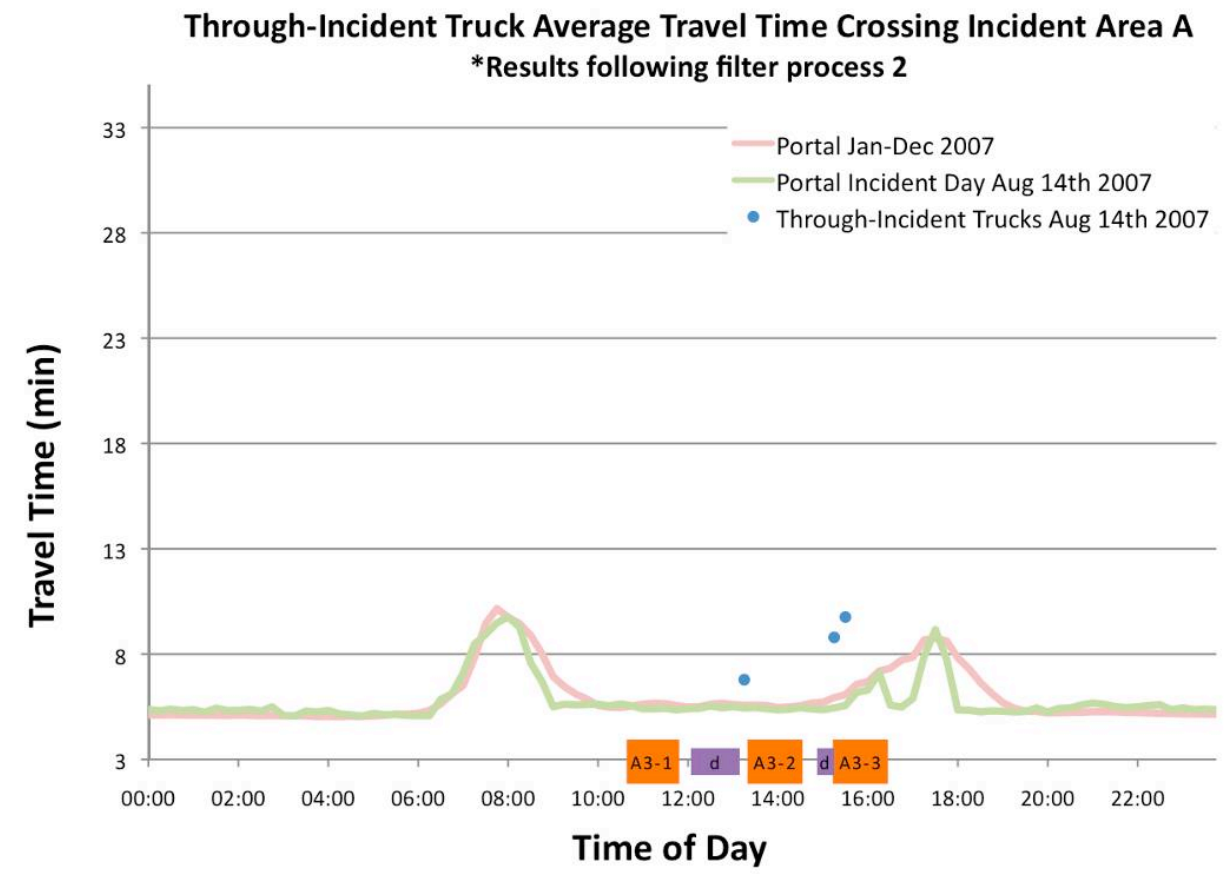

Through-Incident Truck Average Travel Time Crossing Incident Area A *Results following filter process 2

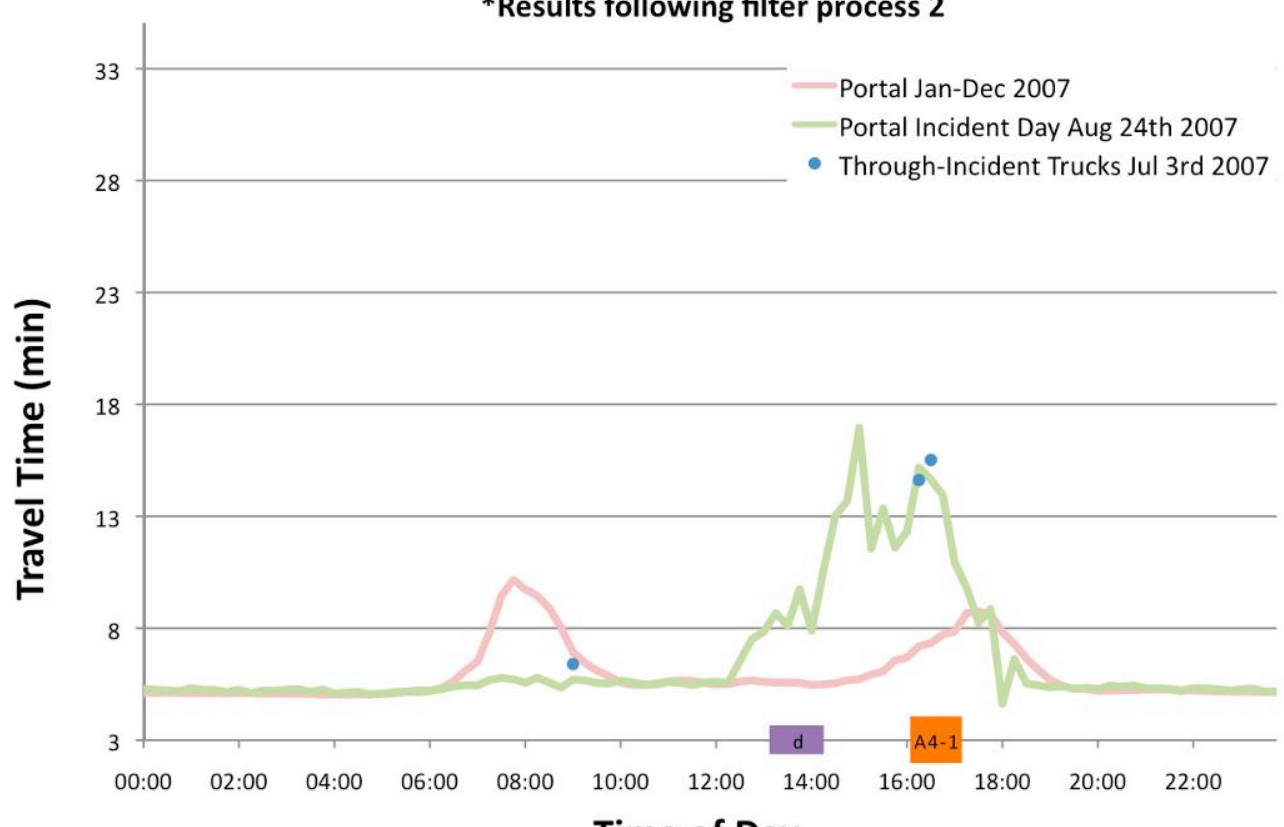

Time of Day

Figure 23: From top to bottom, a) Incident area A northbound I-5 through-incident truck travel time results following Filter Process 2-August 14, 2007; b) Incident area A northbound I-5 through-incident truck travel time results following Filter Process 2-August 24, 2007. 


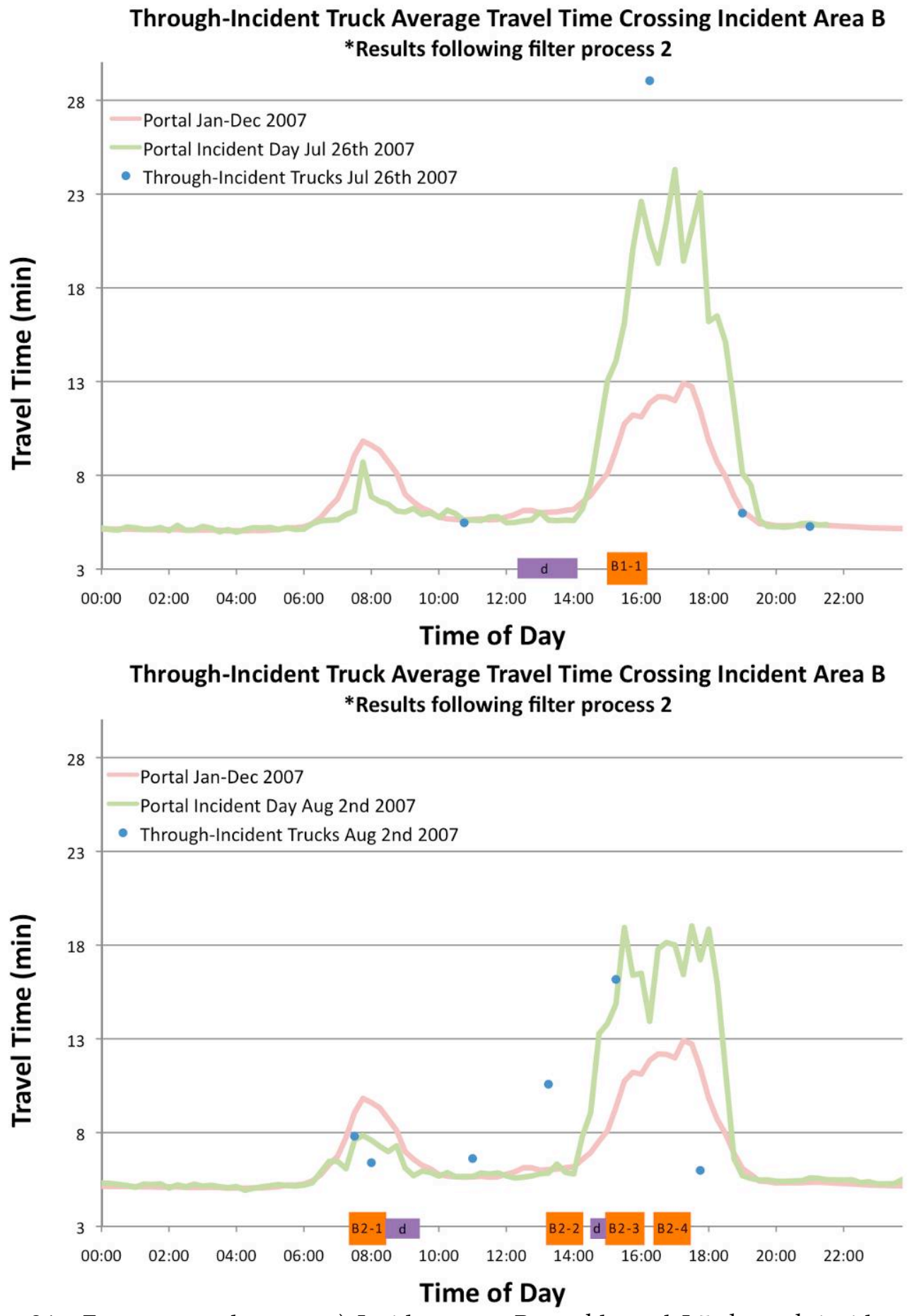

Figure 24: From top to bottom, a) Incident area B northbound I-5 through-incident truck travel time results following Filter Process 2-July 26, 2007; b) Incident area B northbound I-5 through-incident truck travel time results following Filter Process 2-August 2, 2007. 


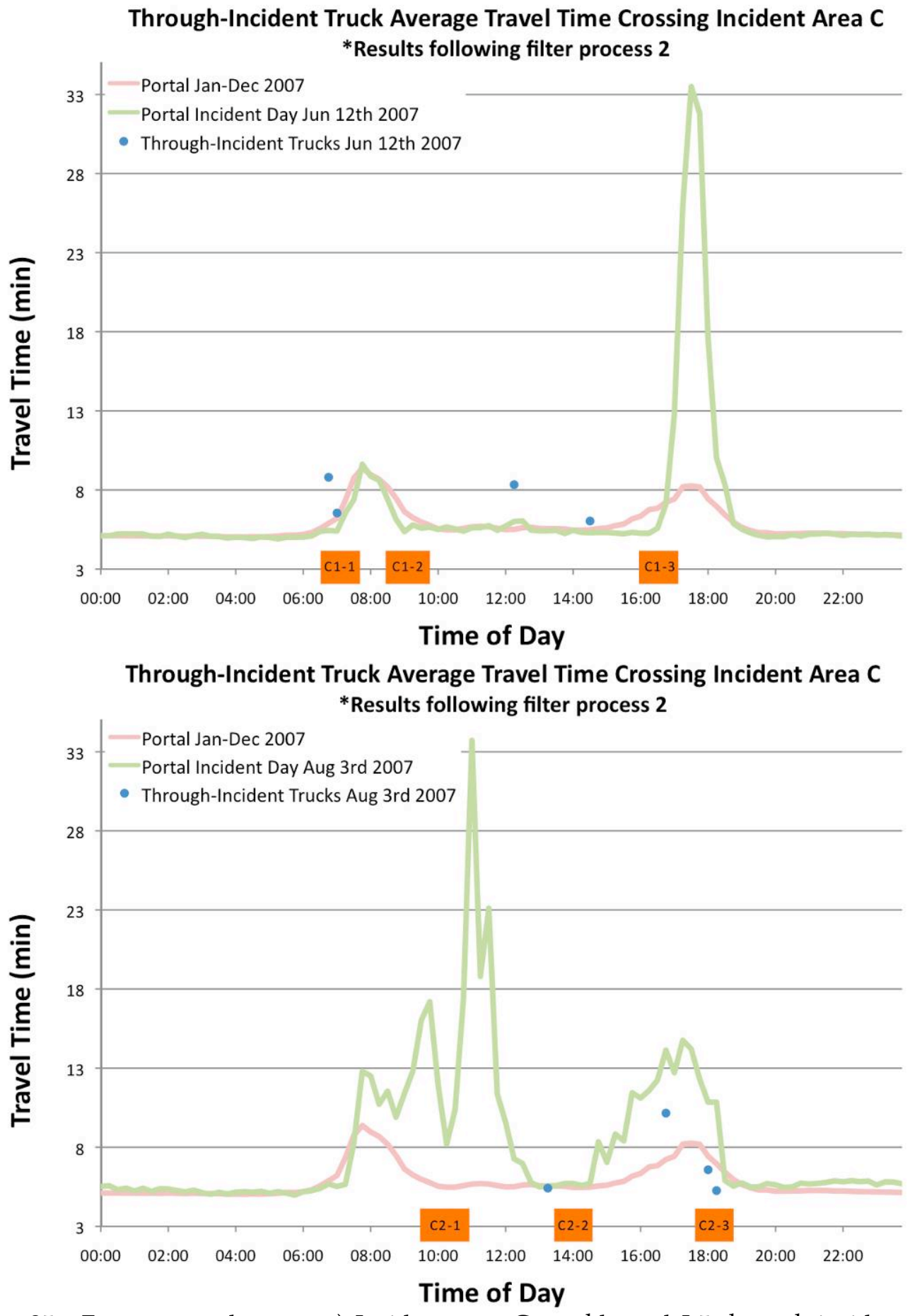

Figure 25: From top to bottom, a) Incident area $C$ northbound I-5 through-incident truck travel time results following Filter Process 2-June 12, 2007; b) Incident area C northbound I-5 through-incident truck travel time results following Filter Process 2-August 3, 2007. 


\subsubsection{Effect of Including Partial Through/Local Trucks}

As with incident areas A, B, and C, the through-incident travel time results for incident area $\mathrm{D}$ followed closely to the loop sensor data; Figure 26a presents the results for through-incident truck travel times. Several through-incident trucks were identified for incident area $\mathrm{D}$, with multiple through-incident trucks identified for four time bins. For these four time bins, an average travel time through the incident area is shown in Figure 26a, along with the standard error for each average.

Similar to the through-incident truck analysis, Figure $26 \mathrm{~b}$ presents results when only partial through and partial local incident trucks were included. For the aggregated data in time bins with multiple readings, it can be seen that the standard error of the mean for partial through/local truck data varies more so than when only through-incident trucks were averaged. This finding points to the effectiveness of through only trucks serving as the best indicator of performance estimations.

When trucks making partial through or partial local movements are included in the estimation there is likely to be some bias. Partial local trucks may underestimate speeds, while partial through trucks may not have traveled completely through the incident area (or corridor) and therefore avoided part or all congestion. For instance, a partial through truck with a reading south of the incident area and one reading just inside the incident area may have exited the corridor several miles before the incident site; the speed estimation for this vehicle may not reflect the full impact of the incident. 
Alternatively, through-incident vehicles provide the best estimation of performance measures because they must travel the length of the incident area (or corridor) and fully experience incident congestion. 

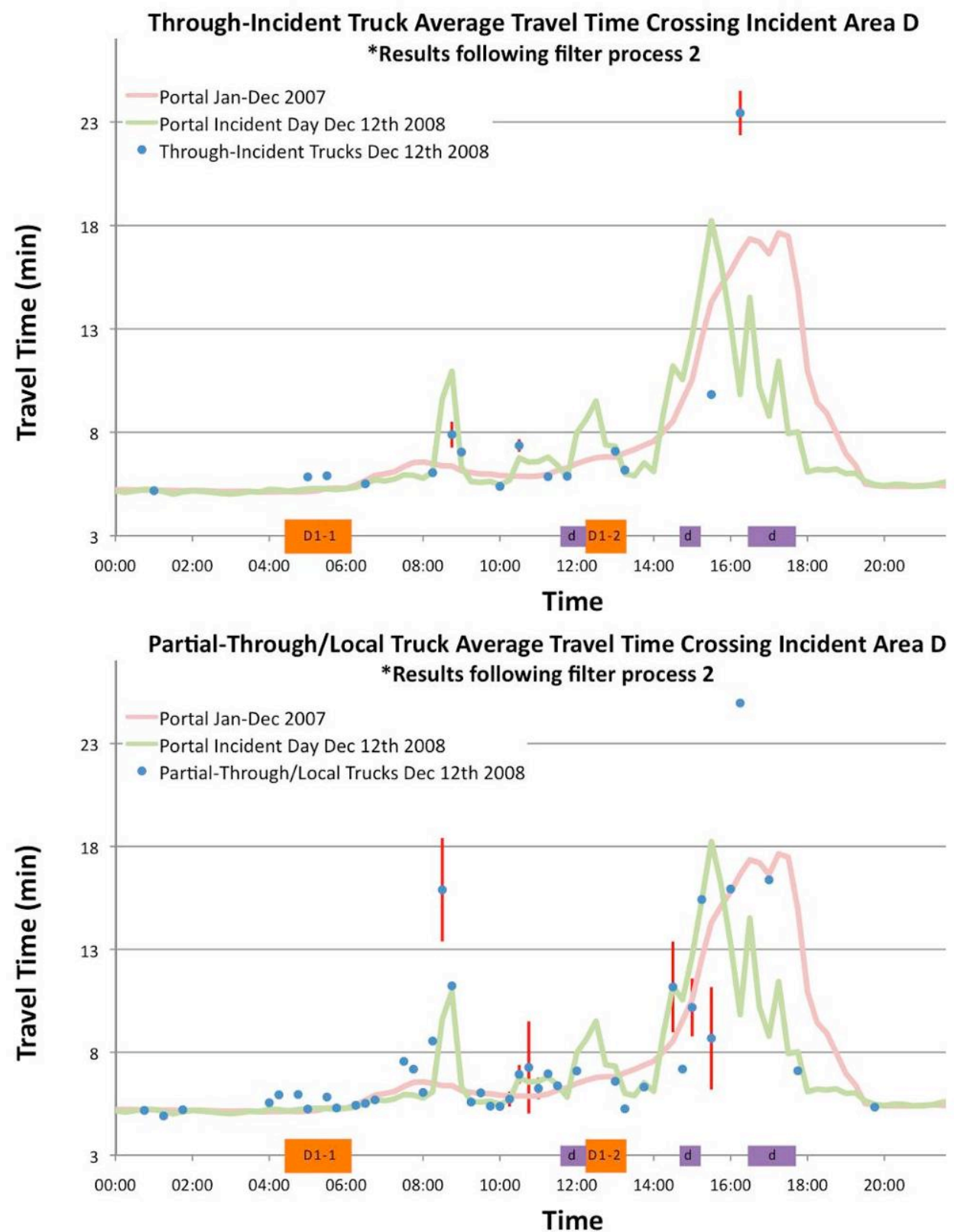

Figure 26: From top to bottom, a) Incident area D northbound I-5 through-incident truck travel time results following Filter Process 2-December 12, 2008 (with standard error of mean noted for multiple readings in a time bin); b) Incident area D northbound I-5 partial through and partial local incident truck travel time results following Filter Process 2-December 12, 2008 (with standard error of mean noted for multiple readings in a time bin). 


\subsection{The Cost of Non-Recurring Congestion}

Four incident periods were used to quantify the impact of non-recurring congestion in terms of cost: incident C1-1, A1-2, B2-3 and A4-1. These incidents were chosen because they represent a range of AM and PM peak hour incidents, incident type and number of lanes affected. These incident periods all had at least one through-incident truck crossing the incident area during the duration (one hour) of the incident. The methods for estimating cost for non-recurring congestion were similar to the methods used for the recurring congestion analysis, however the focus was on the hour that the incident occurred. Because of a lack of data, it was not possible to obtain costs for scenarios that incorporated a term for reliability; only cost formulation A was used.

The cost of non-recurring congestion was compared to the cost of free-flow travel (at $52.05 \mathrm{mph}$ ) to assess cost above ideal travel conditions. Additionally, recurring congestion travel time for through trucks traveling each incident area were used as a comparison to average day-to-day cost of congestion. Table 6 presents the travel times obtained from through-incident trucks in the non-recurring study, through truck recurring congestion travel times obtained at each incident area (averaged over June-August 2007), and free-flow travel time at $52.05 \mathrm{mph}$ for a five-mile segment. 
Table 6: Non-Recurring, Recurring and Free-Flow travel times through five-mile incident areas

\begin{tabular}{|c|c|c|c|c|c|}
\hline $\begin{array}{c}\text { Incident } \\
\text { Label }\end{array}$ & $\begin{array}{c}\text { Incident } \\
\text { Hour }\end{array}$ & $\begin{array}{c}\text { Non- } \\
\text { Recurring } \\
\text { Congestion } \\
\text { Travel Time } \\
\text { (min) }\end{array}$ & $\begin{array}{c}\text { Recurring } \\
\text { Congestion } \\
\text { Travel Time } \\
\text { (min) }\end{array}$ & $\begin{array}{c}\text { Free-Flow } \\
\text { Travel Time } \\
\text { (min) }\end{array}$ & $\begin{array}{c}\text { Hourly Truck } \\
\text { Volume }\end{array}$ \\
\hline C1-1 & $7: 00-8: 00$ & 6.54 & 6.47 & 5.76 & 322 \\
A1-2 & $8: 00-9: 00$ & 11.16 & 6.43 & 5.76 & 333 \\
B2-3 & $15: 00-16: 00$ & 16.17 & 14.04 & 5.76 & 289 \\
A4-1 & $16: 00-17: 00$ & 15.07 & 14.66 & 5.76 & 242 \\
\hline
\end{tabular}

Figure 27 presents the percent increase in freight vehicle cost during each incident period-percent increase is shown relative to free-flow travel time at $52.05 \mathrm{mph}$, and relative to recurring congestion travel time (see Table 6). As shown, the incidents had a wide range of impact in terms of cost. The PM peak hour incidents happening between 15:00-17:00 (B2-3 and A4-1), show the greatest impact in cost from free-flow congestion conditions, however smaller impact relative to average recurring congestion conditions. It is important to note that average recurring congestion conditions do reflect conditions at each incident area, however, the aggregation period between June-August 2007 did not provide a large amount of data-a greater aggregation period may show greater differences between the cost of incident delay in the PM peak hour and cost of delay due to average recurring congestion conditions in the PM hour. 


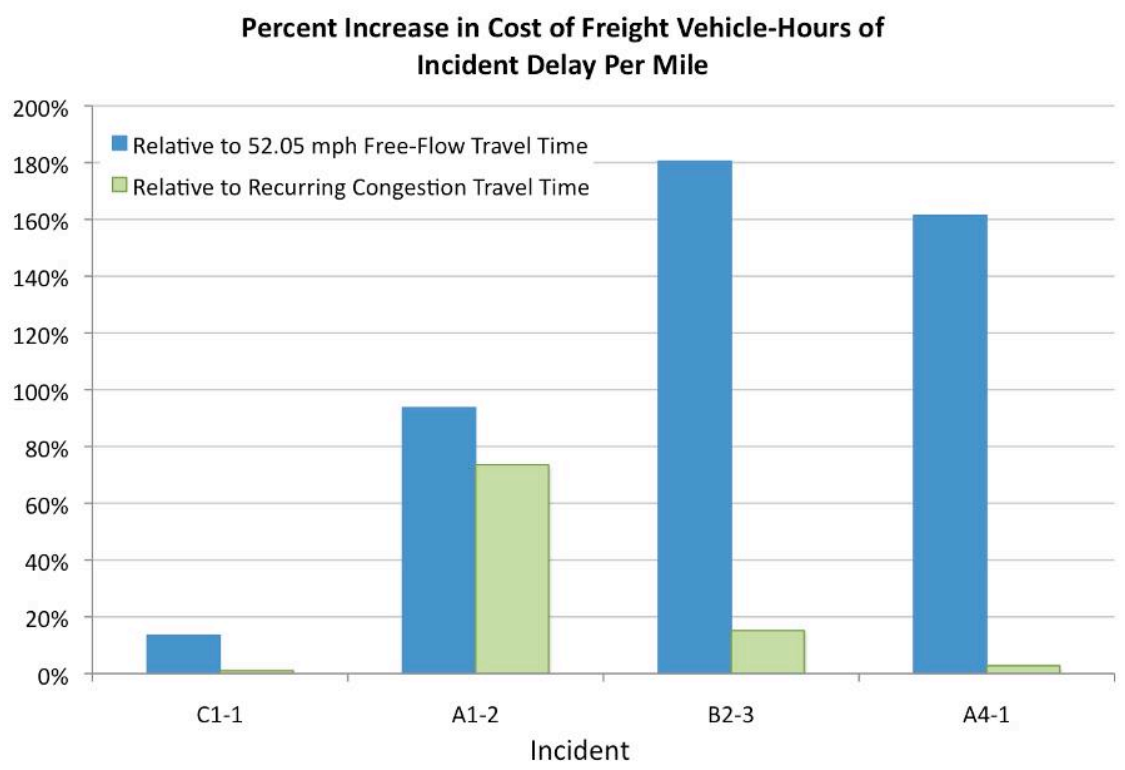

Figure 27: Percent increase in freight vehicle cost of incident delay for northbound I-5, relative to $52.05 \mathrm{mph}$ free-flow travel time and relative to recurring congestion travel times presented in Table 6.

Figure 27 shows that in the AM peak hour incident C1-1 had little impact on costs above free-flow and average recurring congestion travel times, while A1-2 shows greater impact in costs: roughly $90 \%$ increase in cost above costs at free-flow travel time conditions, and $70 \%$ increase in cost above average costs for average recurring congestion travel time conditions. Again, the results for cost above recurring congestion conditions may differ more greatly when a larger aggregation period is used.

Finally, Figure 28a and Figure 28b present the freight vehicle cost per mile above free-flow and recurring congestion conditions. As with the recurring congestion analysis, ten cost scenarios were used to obtain a range of costs for each incident period. Figure 28c presents the cost scenarios used for the incident periods studied; as mentioned earlier, cost scenarios incorporating a 
term for reliability (scenarios 5-8) were not used because there were not a large amount of data to produce average travel times and standard deviations.

Incident A1-2, which appears to have had the greatest impact on both freight vehicle costs above free-flow and recurring congestion conditions, resulted in $\$ 416$ per mile (cost above free-flow conditions) and $\$ 366$ per mile (cost above average recurring conditions) for cost scenario 4-this scenario uses a regional value of time, with a 2.5 congestion markup to reflect congested value of time.

\subsection{Non-Recurring Congestion Emissions Estimation}

The four incident periods used to quantify the impact of non-recurring congestion in terms of cost were also used to estimate emission rates during incident periods: incident $\mathrm{C} 1-1, \mathrm{~A} 1-2, \mathrm{~B} 2-3$ and A4-1. The methods for estimating emissions for non-recurring congestion were similar to the methods used for recurring congestion, however, the focus was on the hour that the incident occurred; the MOVE2010 model was employed for this portion of the analysis. Please refer to Appendix B for a more detailed explanation of user-defined parameters for MOVES2010 and assumptions made during the emissions estimation resulting non-recurring congestion conditions. 

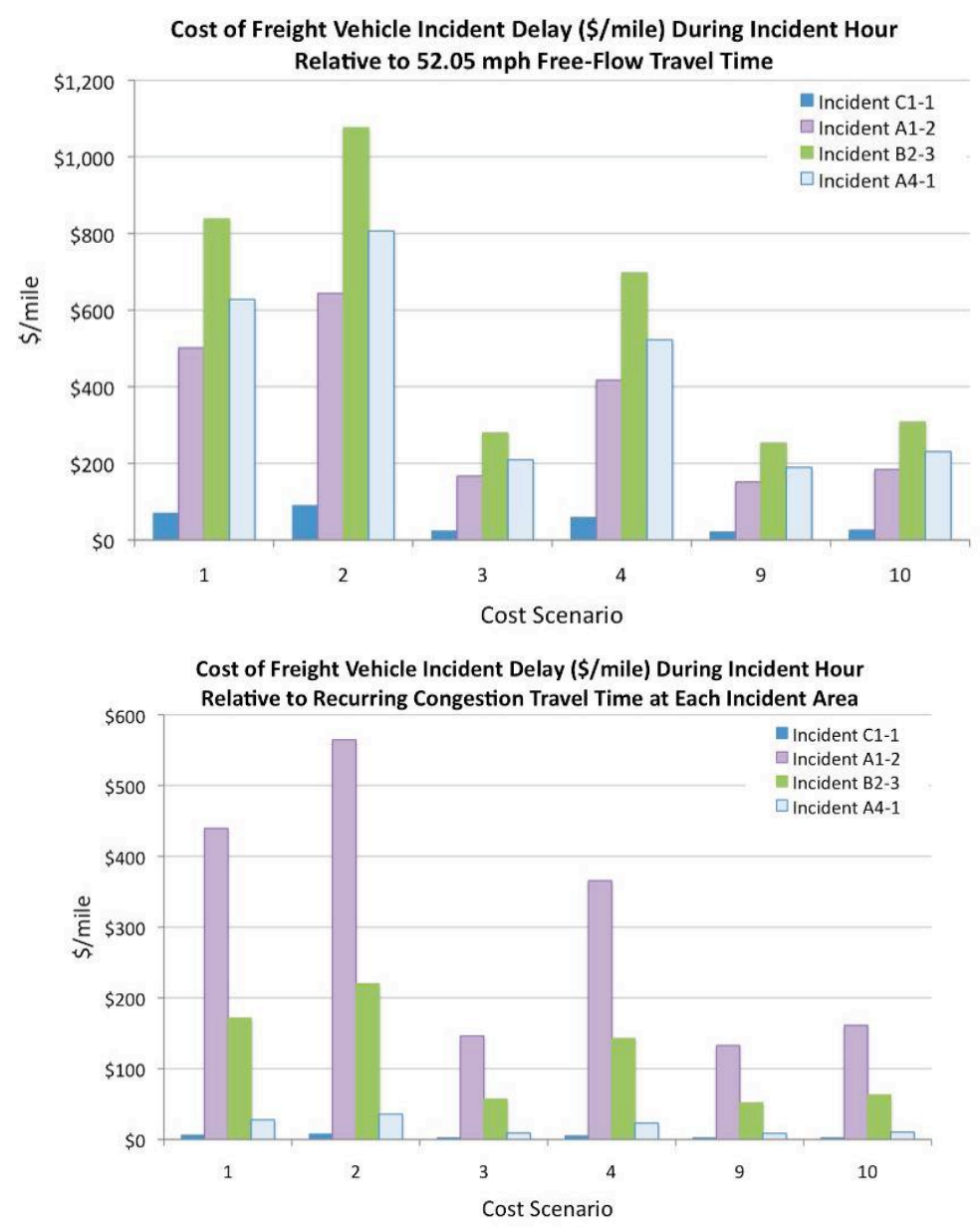

\begin{tabular}{|c|c|c|c|c|c|}
\hline $\begin{array}{c}\text { Cost } \\
\text { Scenario }\end{array}$ & $\begin{array}{l}\text { General Formulation of } \\
\text { Cost Calculation }\end{array}$ & $\begin{array}{l}\text { Factors/Parameters } \\
\text { Represented }\end{array}$ & $\begin{array}{c}\text { Cost Source for } \\
\text { Operating Cost Per Hour (CPH) or } \\
\text { Value of Time (VOT) }\end{array}$ & $\begin{array}{l}\text { Freight } \\
\text { CPH }\end{array}$ & $\begin{array}{l}\text { Factor of } \\
\text { dislike for } \\
\text { variability }\end{array}$ \\
\hline 1 & A : ATRI, 2010 & Marginal Operating Cost & ATRI, 2010 & $\begin{array}{l}\$ \quad 83.26 \\
{ }^{*} \text { Freight } \\
\text { VOT }(\$ / h r)\end{array}$ & \\
\hline 2 & A: TTI, 2009 & National/Urban & TTI, 2009 & $\$ 107.46$ & \\
\hline 3 & A: TTI, 2009 & Regional & ODOT, 2005 Avg Truck & 27.85 & \\
\hline 4 & A : TTI, 2009 & Regional + Congestion & ODOT, 2005 Avg Truck X 2.5 (NCHRP) & 69.61 & \\
\hline 9 & A: TTI, 2009 & Differnce in Operator Type & Kawamura, 2000 Private Carriers & 23.05 & \\
\hline 9 & A : TTI, 2009 & Differnce in Operator Type & Kawamura, 2000 For-Hire Carriers & 36.67 & \\
\hline 10 & A: TTI, 2009 & Differnce in Service Type & Kawamura, 2000 Avg All Carriers & 30.64 & \\
\hline 10 & A : TTI, 2009 & Differnce in Service Type & Kawamura, 2000 Truck Load & 32.74 & \\
\hline 10 & A: TTI, 2009 & Differnce in Service Type & Kawamura, 2000 Less-Than Truck Load & 29.60 & \\
\hline
\end{tabular}

${ }^{\star}$ Freight Value of Time (VOT) have been adjusted for inlation and reflect 2010 prices.

${ }^{*} \mathrm{~A}, \mathrm{~B}$, and $\mathrm{C}$ refer the general formulation:

A: Uses CPH or VOT to obtain costs

C : Incorporates Reliability (high-end estimation)

Figure 28: From top to bottom, cost of incident delay per mile for freight vehicle traveling northbound I-5 during incident periods C1-1, A1-2, B2-3 and A4-1, a) relative to free-flow travel time at $52.05 \mathrm{mph}$; $\mathrm{b}$ ) relative to recurring congestion travel times presented in Table 6; c) cost scenario descriptions, parameters and formulations used for non-recurring analysis. 
The emissions rates estimated during incident periods were compared to the emission rates during free-flow travel (at $52.05 \mathrm{mph}$ ), and emission rates during recurring congestion conditions for each incident area. Table 6 presents the travel times obtained from through-incident trucks in the non-recurring study, through truck recurring congestion travel times obtained at each incident area (averaged over June-August 2007), and free-flow travel time at $52.05 \mathrm{mph}$ for a five-mile segment.

Figure 29 through Figure 31 present the percent increase in freight vehicle emission rates ( $\mathrm{g} / \mathrm{mile}$ ) relative to emission rates during free-flow conditions and relative to emission rates during average recurring congestion conditions. Figure 29 presents GHG emission rates, Figure 30 presents MSAT emission rates, and Figure 31 presents criteria pollutant emission rates.

As shown in the figures indicated above, incident B2-3 appears to have the greatest impact on freight vehicle emission rates above emission rates during free-flow, while incident A1-2 appears to have had the greatest impact relative to recurring congestion conditions. During this incident period, there was a $97-188 \%$ increase above free-flow emission rates, and roughly $25 \%$ increase above recurring congestion emission rates. Relative to emissions during freeflow conditions, the incident periods each produced an additional 1800-3500 grams per mile of $\mathrm{CO} 2$ emitted from freight vehicles as the result of incident congestion. Similarly, the incident periods each produced an additional 9-23 grams per mile of $\mathrm{N} 2 \mathrm{O}, 0.23-0.68$ grams per mile of particulate matter, and 0.05-0.11 grams per mile of $\mathrm{SO} 2$. 
Percent Increase in GHG Emission Rates (g/mile) for Freight Vehicles Relative to 52.05 mph Free-Flow Emissions

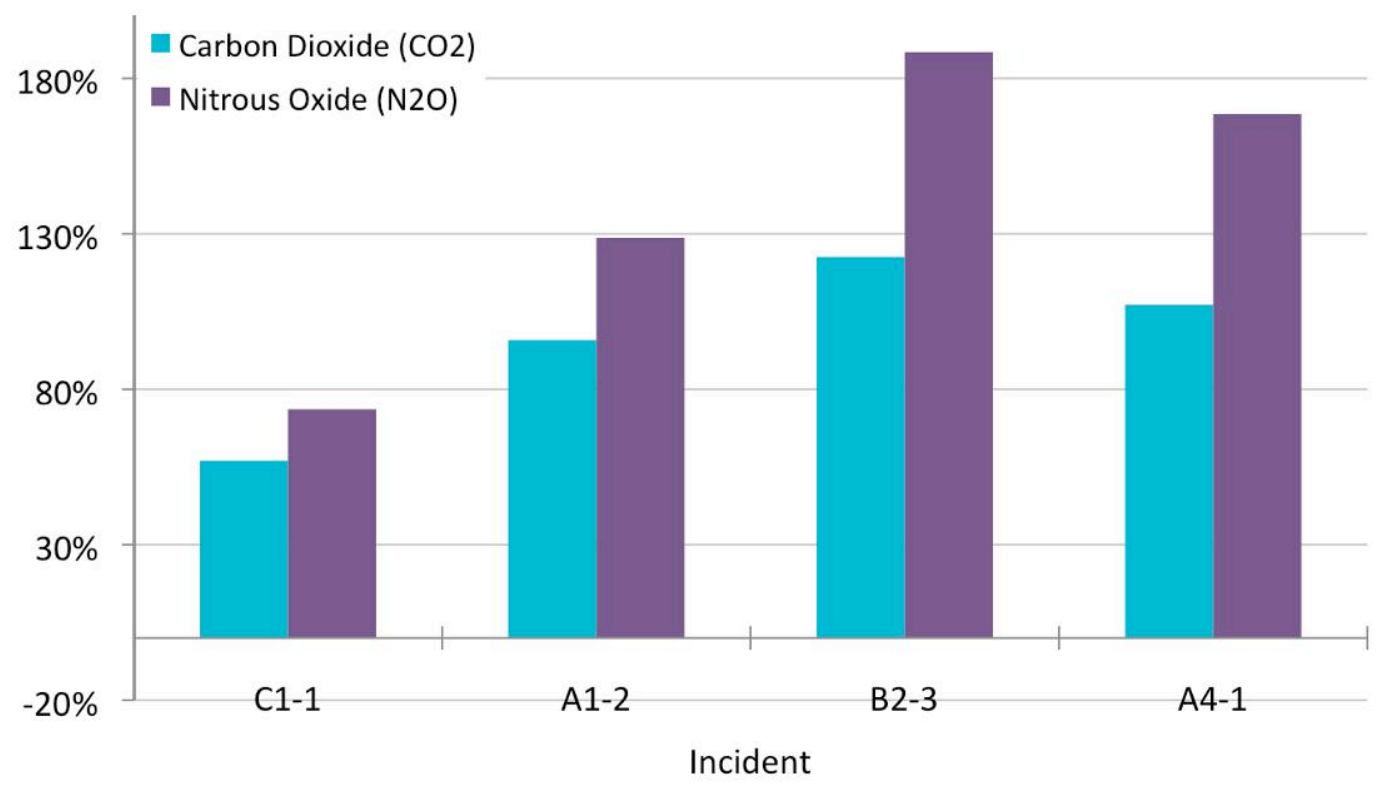

Percent Increase in GHG Emission Rates (g/mile) for Freight Vehicles Relative to Recurring Congestion Emissions

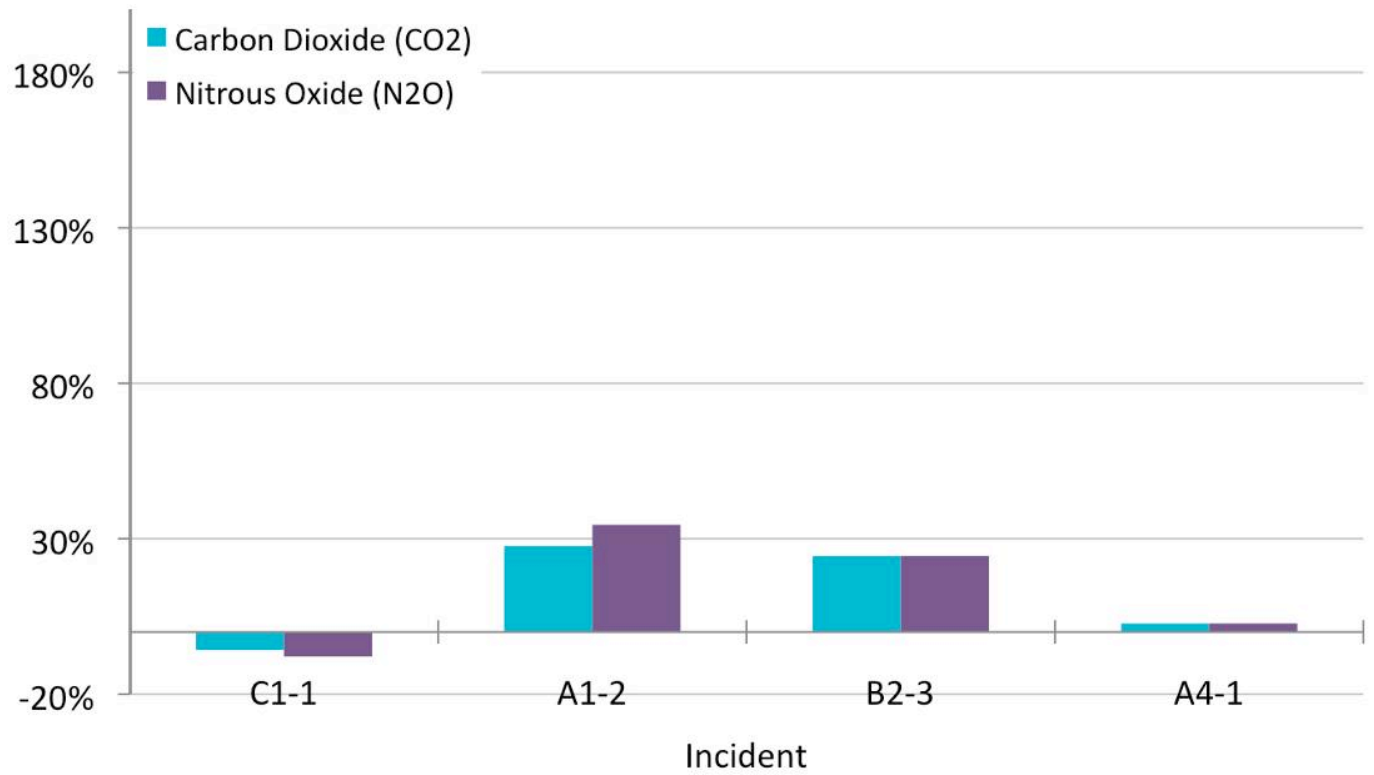

Figure 29: From top to bottom, percent increase in freight vehicle Greenhouse Gas (GHG emissions from freight vehicle traveling northbound I-5 during incident periods C1-1, A1-2, B2-3 and A4-1, a) relative to $52.05 \mathrm{mph}$ free-flow emission rates; b) relative to recurring congestion travel times presented in Table 6. 
Percent Increase in MSAT Emission Rates (g/mile) for Freight Vehicles Relative to $52.05 \mathrm{mph}$ Free-Flow Emissions

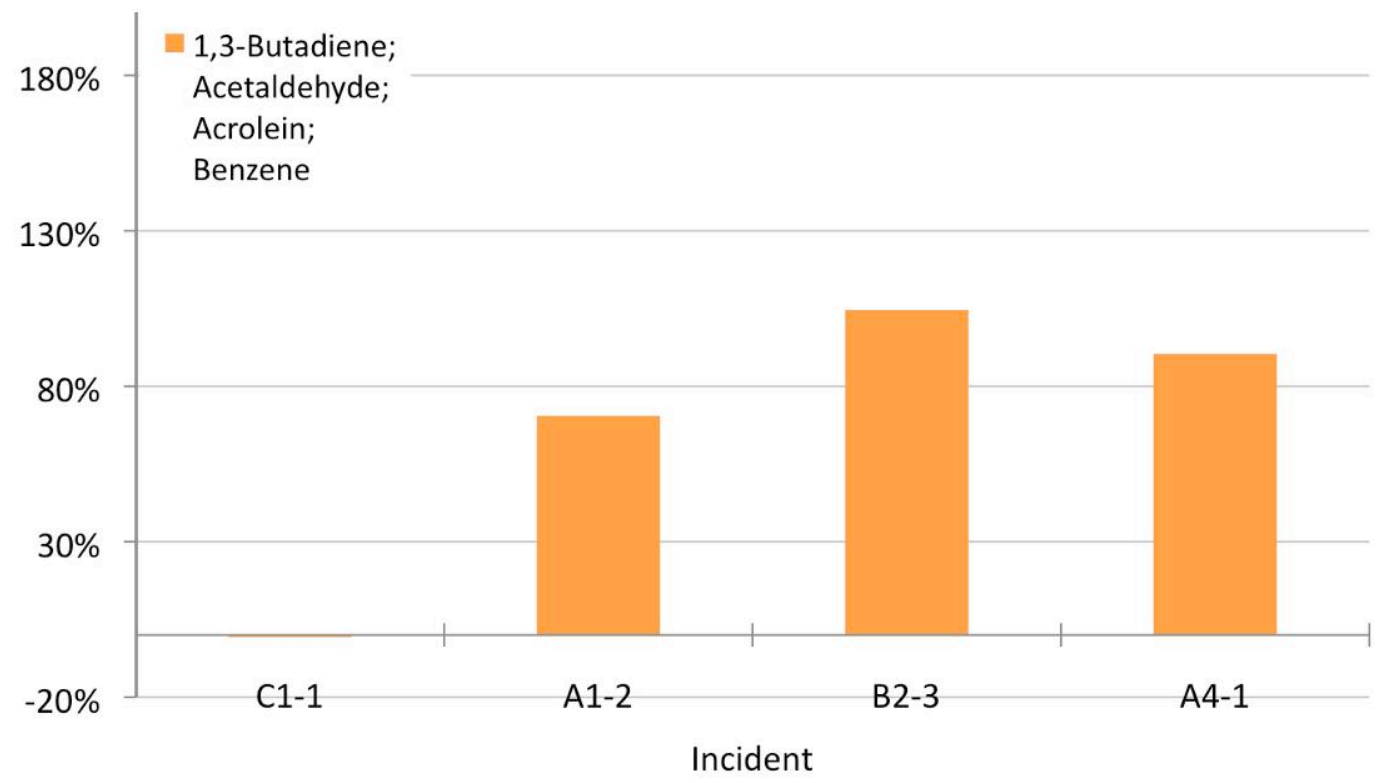

Percent Increase in MSAT Emission Rates (g/mile) for Freight Vehicles Relative to Recurring Congestion Emissions

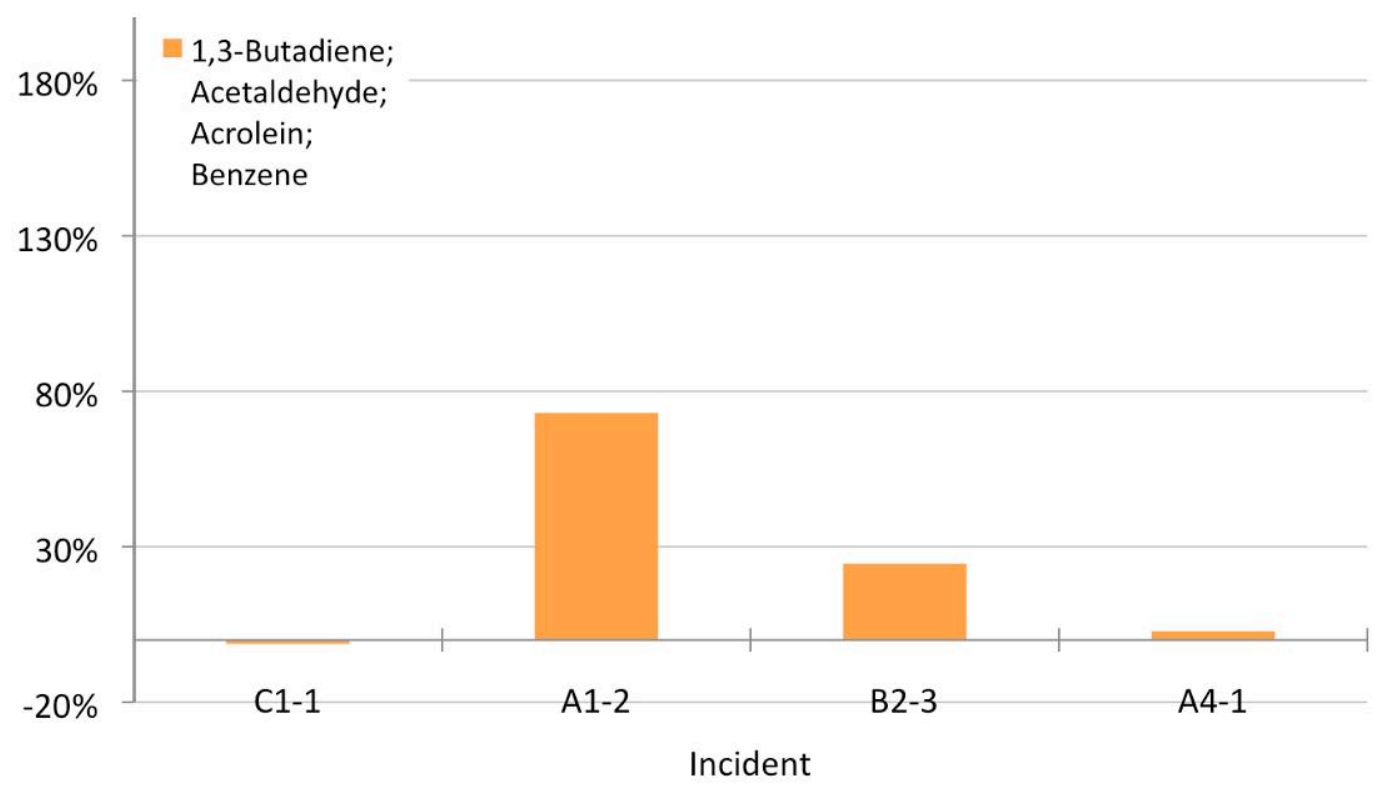

Figure 30: From top to bottom, percent increase in freight vehicle Mobile Source Air Toxic (MSAT) emissions from freight vehicle traveling northbound I-5 during incident periods C1-1, A1-2, B2-3 and A4-1, a) relative to $52.05 \mathrm{mph}$ free-flow emission rates; b) relative to recurring congestion travel times presented Table 6 . 
Percent Increase in CP Emission Rates (g/mile) for Freight Vehicles Relative to $52.05 \mathrm{mph}$ Free-Flow Emissions

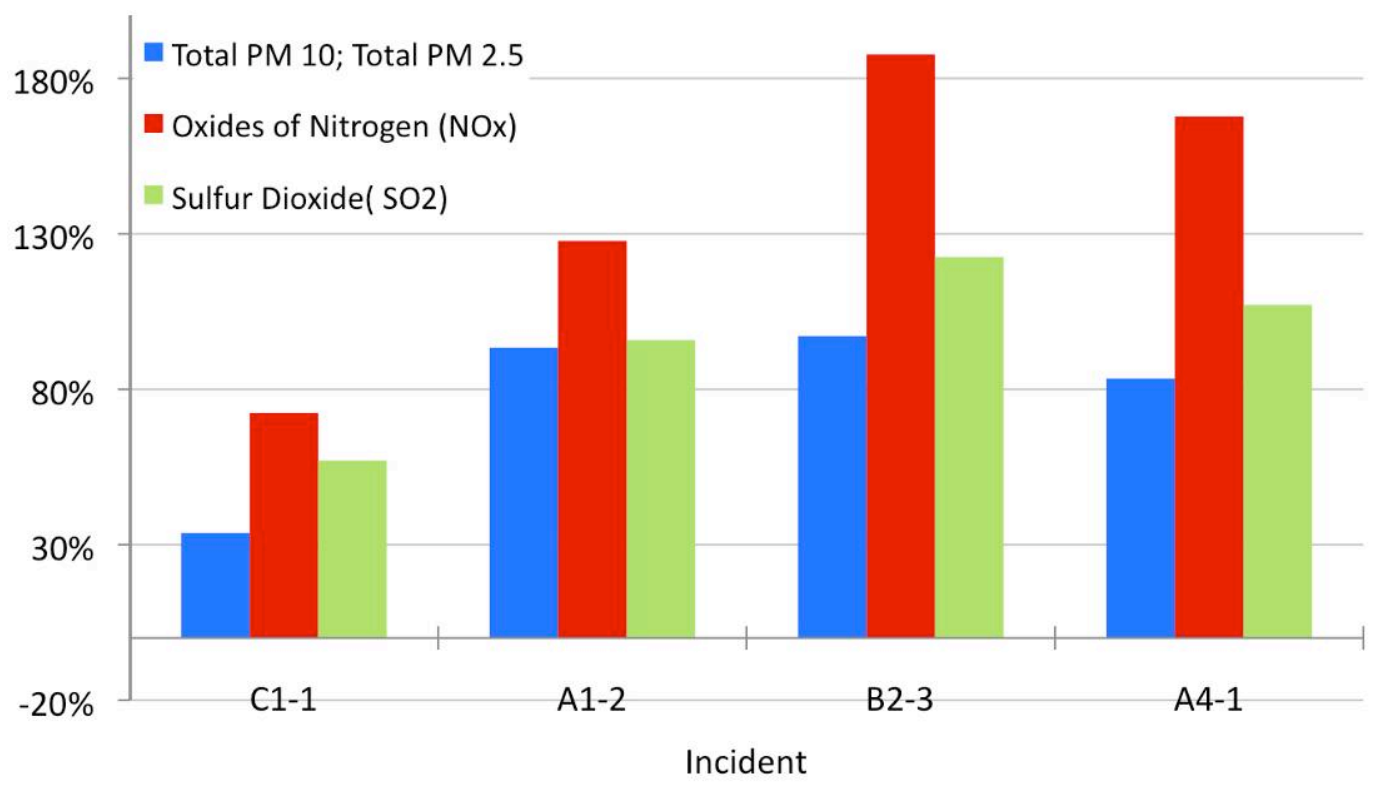

Percent Increase in CP Emission Rates (g/mile) for Freight Vehicles Relative to Recurring Congestion Emissions

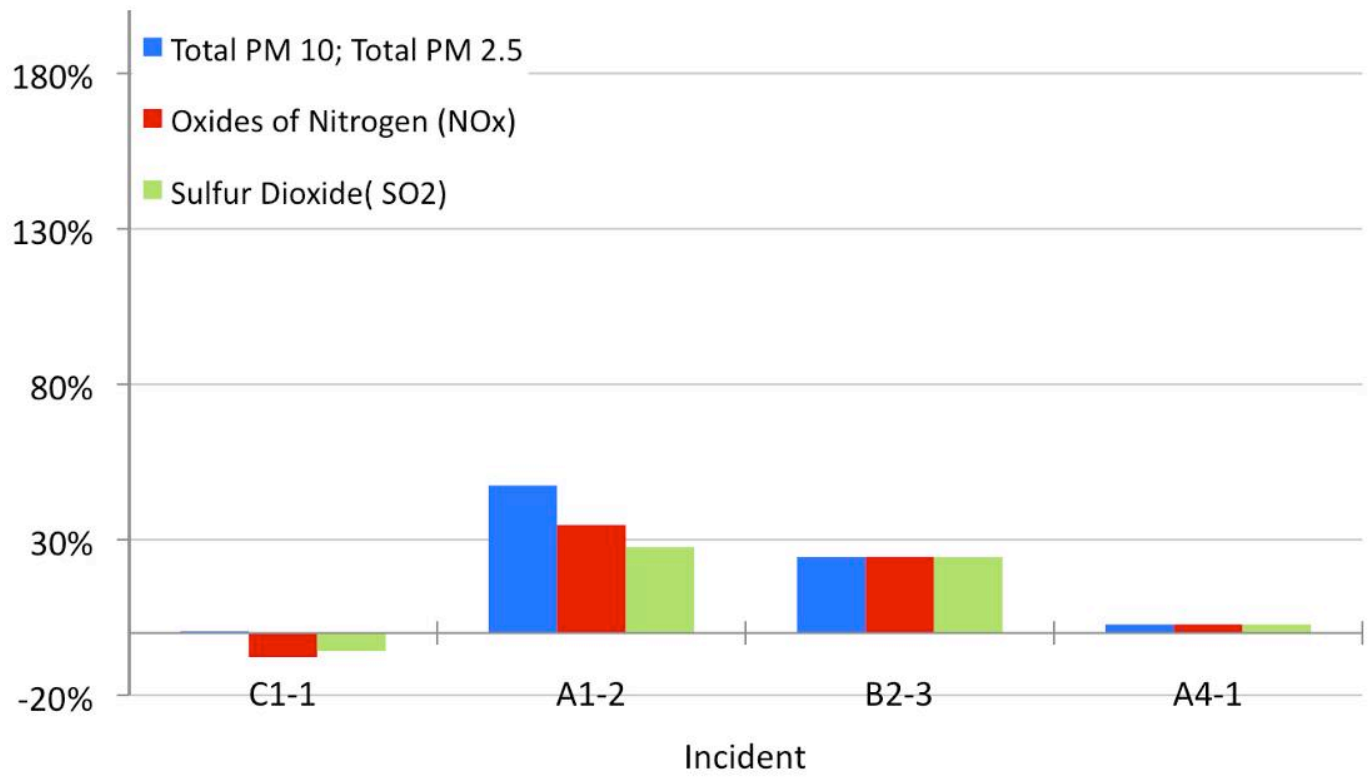

Figure 31: From top to bottom, percent increase in freight vehicle Criteria Pollutant (CP) emission emissions from freight vehicle traveling northbound I-5 during incident periods C11, A1-2, B2-3 and A4-1, a) relative to $52.05 \mathrm{mph}$ free-flow emission rates; b) relative to recurring congestion travel times presented in Table 6. 


\subsection{Non-Recurring Congestion Summary}

This section provides a synopsis of the results from the non-recurring congestion analysis and relates the findings and methods used to engineering, planning and freight industry practice.

\subsubsection{Summary of Key Findings}

Travel Time and Incident Delay

- Analysis of nine individual incident days found through-incident truck travel time to be consistently equal or greater than travel time derived by loop sensor data, indicating that loop sensor data may underestimate the impact of incident congestion on freight performance.

- Analysis of travel time of partial through/local incident trucks, versus travel time from only through-incident revealed greater variation in travel time when partial through/local incident trucks are used. This finding demonstrates the potential bias that can be incorporated if partial or local truck data is included when estimating freight performance measures.

\section{The Cost of Non-Recurring Congestion}

- Incident periods studied for this analysis occurred at different times of day, through different incident areas, and various incident types-the resulting impact of each incident on freight industry cost varied greatly. This shows that the cost of incident depends on a variety of factors, particularly the severity and duration of the incident, but also the period of time in which it occurs. 
- Incident A1-2 appears to have had the greatest impact on freight industry cost compared to both free-flow and recurring congestion conditions: $\$ 416 /$ mile (above free-flow costs) and $\$ 366$ (above recurring congestion costs).

- Incident B2-3 had the greatest impact on freight industry cost relative to free-flow conditions.

- A1-2 had the greatest impact relative to recurring congestion conditions.

\section{Non-Recurring Congestion Emission Estimation}

- The impact of the incidents on freight vehicle emission rates varied greatly from incident to incident. Again, this shows that the impact of the incident depends on the severity and duration of the incident, but also the period of time in which it occurs.

- Incident B2-3 appears to have had the greatest impact on freight vehicle emissions above free-flow conditions, while A1-2 appears to have had the greatest impact on freight vehicle emissions above recurring congestion conditions.

Table 7 presents the multi-criteria performance measures resulting from an average incident-average percent increase in delay, cost and emissions are relative to free-flow and recurring congestion conditions through the incident area. As shown, MSAT emissions resulting from the average incident show the greatest increases in emission rates relative to recurring congestion conditions compared to other emission types. In comparison to free-flow 
conditions, NOx, SO2 and the GHG emissions show the greatest increases in emission rates.

Table 7: Average impact of an incident; average percent increase in delay, cost and emission relative to free-flow, and recurring congestion conditions. Averages are based on data obtained for incidents C1-1, A1-2, B2-3 and A4-1.

\begin{tabular}{|c|c|c|c|c|c|c|c|c|}
\cline { 2 - 9 } \multicolumn{1}{c|}{} & \multicolumn{6}{c|}{ Multi-Criteria Performance Measure } \\
\cline { 2 - 9 } & Delay & $\begin{array}{c}\text { Freight } \\
\text { Vehicle } \\
\text { Cost }\end{array}$ & $\begin{array}{c}\text { MSAT } \\
\text { Emissions }\end{array}$ & \multicolumn{2}{|c|}{$\begin{array}{c}\text { GHG } \\
\text { Emissions }\end{array}$} & \multicolumn{3}{c|}{$\begin{array}{c}\text { CP } \\
\text { Emissions }\end{array}$} \\
\cline { 2 - 9 } & Form. A & $\begin{array}{c}1,3-\text {-Butadiene } \\
\text { Acetaldehyde } \\
\text { Acrolei } \\
\text { Benzene }\end{array}$ & CO2 & N2O & $\begin{array}{c}\text { PM } \\
10 \& \\
2.5\end{array}$ & NOx & SO2 \\
\hline $\begin{array}{c}\text { Above } \\
\text { Free-Flow }\end{array}$ & $112 \%$ & $112 \%$ & $66 \%$ & $96 \%$ & $140 \%$ & $77 \%$ & $139 \%$ & $96 \%$ \\
\hline $\begin{array}{c}\text { Above } \\
\text { Recurring } \\
\text { Condition }\end{array}$ & $23 \%$ & $23 \%$ & $25 \%$ & $12 \%$ & $13 \%$ & $19 \%$ & $14 \%$ & $12 \%$ \\
\hline
\end{tabular}

\subsubsection{Applying Techniques for Deriving Multi-Criteria FPM in Practice}

The findings from the non-recurring congestion analysis are of value particularly to public agencies-although indirectly, the freight industry will likely benefit from decisions made by public agencies regarding non-recurring congestion. The methods used to study freight vehicles in congestion and results from the analysis can be used to inform decisions made regarding intelligent transportation system infrastructure improvements, as well as incident response strategies.

Understanding the monetary and environmental impacts of non-recurring congestion may motivate and justify the need for public agencies to provide system wide improvements-technologies such as variable message signs located along freeways would be beneficial in communicating to passenger and freight vehicles of an upcoming incident. Communicating this 
information well in advance of the incident area provides drivers with ample opportunity to divert to an alternative route in order to avoid incident congestion. The research here has shown that incidents greatly effect travel time, cost and emissions through incident areas; the multi-criteria performance measures would allow agencies to quantify these impacts.

Additionally, multi-criteria performance measures may also justify the need for increased incident response by ATMS. The incidents studied in the non-recurring congestion analysis each lasted roughly one hour. Because of a lack of data, it was not possible to study congestion prior or following incident periods, as a limited amount of through-incident trucks were available. However, further analysis of a larger quantity of data may show that costs and emissions continue to rise even after the incident period, as queues propagate upstream; this effect is evident in the loop sensor data following incident durations. The quicker an incident is cleared, quicker the queue will disperse following the incident duration, decreasing costs and emissions following incident periods. 


\section{$7 \quad$ Conclusions}

A unique contribution of this research is the integration of GPS with loop sensor and incident data to study multi-criteria trucking performance measures. The integration of diverse data sources has validated the accuracy of the raw GPS data and allowed for a new methodology to filter and identify through trips.

The new methodology presented in this work was effective to identify through trucks using a two-step filtering process. The first process finds all potential through trucks, while the second process integrates loop sensor data in order to eliminate any remaining through trucks that may have stopped midway through the corridor. It is shown that the separation of through trucks from partial through, partial local and local trips removes bias from the estimation of performance measures. Otherwise, the results have shown that corridor travel time and reliability can be under/overestimated.

Findings show that in general, the GPS truck data have greater travel times than the expected loop sensor average in the PM peak period. The GPS data more accurately portray the roadway conditions experienced by a freight truck and the comparison with loop sensor data indicates that traditional loop-detector congestion estimates tend to underestimate increases in both truck travel times and travel time variability.

Variability in particular is critical to the freight industry as carriers must meet customer demands and adhere to strict delivery schedules. Without a reliable transportation network, carriers are forced to increase buffer time in 
case of delay. This work has shown that by eliminating variability in the PM peak, a cost savings of $6-27 \%$ can be made.

This research also shows that congestion is not only detrimental for carriers costs and shippers' just-in-time operations but also for the environment due to major increases in GHG emissions and for the local community due to increases in NOx, PM, and other harmful pollutants. Freeway congestion management strategies that can maintain moderate speeds will benefit people living near transportation systems by minimizing freight vehicle emissions such as NOx, and PM, which are closely link to respiratory heath issues.

\subsection{Practical Application}

The methodology developed throughout this work has the potential to provide valuable freight operation and performance data for transportation decision makers to incorporate freight performance measures into the planning process.

From a planning and engineering perspective, the methodology developed to identify through trucks and produce corridor level multi-criteria performance measures will allow for the consideration of the freight industry in transportation improvement projects. This is a significant step in being able to study and address the needs of all users of the transportation system, as current freeway performance measures are not freight specific.

The methodology can be modified to identify and study bottlenecks throughout the corridor and allow for comparisons to be made between target 
areas, in order to prioritize the areas most in need of transportation improvements. Being able to quantify the impact of congestion on freight vehicles creates transparency in the transportation planning process, holding agencies accountable to the public for the decisions that are made.

Additionally, the research presented here can help inform decisions made regarding congestion management strategies, infrastructure improvements, and incident response strategies. Here the multi-criteria performance measures would allow decision makers to study the benefits of such improvements or strategies to the freight industry by using performance data that reflect the current impact of congestion on freight vehicles.

Understanding the monetary and environmental impacts of non-recurring congestion may also motivate and justify the need for public agencies to provide system wide improvements-technologies such as variable message signs located along freeways would be beneficial in communicating to passenger and freight vehicles of an upcoming incident. Additionally, multicriteria performance measures may also justify the need for increased incident response by ATMS.

From a freight industry perspective, the methodology developed to identify through trucks and produce corridor level multi-criteria performance measures will allow carriers to improve routing and scheduling logistics. Freight carriers could use the multi-criteria performance measures to identify periods of time when travel time delay and variability increase on a given freeway-examining the region wide system of freeways, carriers would be 
able to identify the optimal route for a given time of day that would reduce travel time delay and improve reliability. By modifying scheduling and routing in this way, carriers would see a reduction in transportation costs, and improvement in reliability, allowing carriers to more easily adhere to strict scheduling.

\subsection{Future Work}

Researchers should continue to develop and build upon the methodologies outlined in this research. Parameters used in Filter Process 1 and $2\left(r, t_{c}, t_{b}, m\right)$ should be studied further to determine optimum user-input values for differing corridor lengths. Because of large gaps between readings, it was difficult to obtain a large quantity of through trucks crossing smaller segments. Further analysis may reveal user-defined parameters that are more fruitful in the number of through trucks identified.

Although loop sensor data used in this research represented a static view of the corridor conditions, it was appropriate for use in Filter Process 2. When loop sensor data were collected dynamically some differences were found between the static and dynamic loop sensor travel time. However, through truck average corridor travel time remained consistently greater in the PM peak hour, with some time bins showing statistically significant difference between dynamic loop sensor and through truck travel time. Future methods should seek to develop algorithms that can determine dynamic travel time from loop sensor data. Dynamic travel time from loop sensors would provide 
a better comparison to GPS through truck data, however static loop sensor data appears to be adequate for use in Filter Process 2.

One of the challenges regarding commercial GPS data is that freight carriers do not require a high frequency of readings to track trucks along routes. The gap times between readings in the data set obtained for this research varied, among carriers, and often among sequential readings for a given trucks. When narrow corridors are defined to obtain realistic data for small segments, as with the non-recurring congestion analysis, very few through trucks (or through-incident trucks) are obtained on a given day. Future work seeking to study non-recurring congestion should identify data sources (i.e., data vendors) that can provide truck data at a higher resolutionthis would increase the number of through-incident trucks that can be identified using the filtering methods defined in this research.

Finally, to improve accessibility of multi-criteria freight performance measure to public and private sector users, this research could be incorporated into a web interface. This would provide freight carriers and public agencies with a user-friendly interface to interpret and compile multi-criteria freight performance measures. The online tools would help justify routing and scheduling decisions, as well as decisions made at a project or regional level. 


\section{References}

1. EDRG. The Cost of Congestion to the Economy of the Portland Region. Economic Development Research Group, November 25, 2005. http://www.portofportland.com/Trade_Trans_Studies.aspx.

2. EDRG. The Cost of Highway Limitations and Traffic Delay to Oregon's Economy. Economic Development Research Group, March 20, 2007. http://www.portofportland.com/Trade_Trans_Studies_CostHwy_Lmtns.pdf.

3. Harrison, Robert, and Mike Schofield. Developing Appropriate Freight Performance Measures for Emerging Users. Publication SWUTC/07/47370000073-1. Southwest Region University Transportation Center Texas Transportation Institute, 2007.

4. Harrison, R., M. Schofield, L. Loftus-Otway, D. Middleton, and J. West. Freight Performance Measures Guide. Publication 0-5410-P3. Center for Transportation Research The University of Texas at Austin, 2006.

5. Cambridge Systematics, Inc., PB Consult, Inc., and Texas Transportation Institute. Performance Measures and Targets for Transportation Asset Management. NCHRP 551. Transportation Research Board of National Academies, 2006.

6. Cambridge Systematics, Inc., Dowling Associates, Inc., System Metrics Group, Inc., and Texas Transportation Institute. Cost-Effective Performance Measures for Travel Time Delay, Variation, and Reliability. NCHRP 618. Transportation Research Board of National Academies, 2009.

7. Bertini, R., S. Hansen, A. Byrd, and T. Yin. Experience Implementing the ITS Archived Data User Service in Portland, Oregon. Transportation Research Record: Journal of the Transportation Research Board, No. 1917, Transportation Research Board of the National Academies, Washington, D.C., 2005, pp. 90-99.

8. Wieczorek, J., L. Huan, R. Fernandez-Moctezuma, and R. Bertini. Integrating an Automated Bottleneck Detection Tool into an Online Freeway Data Archive. In 88th Annual Meeting of Transportation Research Board. CD-ROM. Transportation Research Board of the National Academies, Washington, D.C., 2009.

9. Nihan, N. L., X. Zhang, Y. Wang, and P. Briglia. Evaluation of Dual-Loop Data Accuracy Using Video Ground Truth Data. Publication T1803.38. Washington State Transportation Commission and Transportation Northwest, March 2002.

10. Wang, Y., N. Nihan, R. Avery, and G. Zhang. Improving Truck and Speed Data Using Paired Video and Single-Loop Sensors. Publication T2695.61. Washington State Transportation Commission and Transportation Northwest, December 2006.

11. Monsere, C., M. Wolfe, H. Alawakiel, and M. Stephens. Developing Corridor Level Truck Travel Time Estimates and Other Freight Performance Measures from Archived ITS Data. Oregon Department of Transportation, Oregon Transportation Research and Education Consortium, August 2009.

12. Hallenbeck, M., E. McCormack, J. Nee, and D. Wright. Freight Data From Intelligent Transportation System Devices. Washington State Transportation Center and Washington State Department of Transportation, July 2003. 
13. McCormack, E., and M. Hallenbeck. ITS Devices Used to Collect Truck Data for Performance Benchmarks. Transportation Research Record: Journal of the Transportation Research Board, No. 1957, Transportation Research Board of the National Academies, Washington, D.C., 2006, pp. 43-50.

14. Murray, D., C. Jones, and J. Short. Methods of Travel Time Measurement in Freight-Significant Corridors. American Transportation Research Institute, 2005.

15. Short, J., R. Pickett, and J. Christianson. Freight Performance Measures Analysis of 30 Freight Bottlenecks. American Transportation Research Institute, 2009.

16. Federal Highway Administration and American Transportation Research Institute. FPMweb. May 31, 2010. http://www.freightperformance.org/fpmweb. Accessed June 6, 2010.

17. McCormack, E., X. Ma, C. Klowcow, A. Currarei, and D. Wright. Developing a GPS-Based Truck Freight Performance Measure Platform. Transportation Northwest Regional Center X, Washington State Transportation Center and Washington State Department of Transportation, April 2010.

18. Trego, T., and D. Murray. An Analysis of the Operational Costs of Trucking. In 89th Annual Meeting of Transportation Research Board. CD-ROM. Transportation Research Board of the National Academies, Washington, D.C., 2010.

19. Small, K., R. Noland, X. Chu, and D. Lewis. Valuation of Travel-Time Savings and Predictability in Congested Conditions for Highway User-Cost Estimation. NCHRP 431. National Cooperative Highway Research Program, Transportation Research Board, 1999.

20. Smalkoski, B., and D. Levinson. Value of Time for Commercial Vehicle Operators. Journal of the Transportation Research Forum, Vol. 44, No. 1, 2005 , pp. 89-102.

21. ODOT. The Value of Travel Time: Estimates for the Hourly Value of Time for Vehicles in Oregon 2005. Oregon Department of Transportation Economics \& Policy Analysis Unit, 2006.

22. Schrank, D., and T. Lomax. 2009 Urban Mobility Report. Texas Transportation Institute, July 2009.

23. Kawamura, K. Perceived Value of Time for Truck Operators. Transportation Research Record: Journal of the Transportation Research Board, No. 1725, Transportation Research Board of the National Academies, Washington, D.C., 2000, pp. 31-36.

24. Cohen, H., and F. Southworth. On the Measurement and Valuation of Travel Time Variability Due to Incidents on Freeways. Journal of Transportation and Statistics, 1999, pp. 123-131.

25. Short, J., T. Trego, and R. White. Developing a Methodology for Deriving Cost Impacts to the Trucking Industry that Generate from Freight Bottlenecks. In 89th Annual Meeting of Transportation Research Board. CD-ROM. Transportation Research Board of the National Academies, Washington, D.C., 2010.

26. U.S. Department of Transportation. Facts and Figures: Tables 2-1 and 2-1M. 
Weight of Shipments by Transportation Mode: 2002, 2007, and 2035. February 18, 2009.

http://www.ops.fhwa.dot.gov/freight/freight_analysis/nat_freight_stats/docs/08fact sfigures/table2_1.htm. Accessed July 15, 2010.

27. U.S. Environmental Protection Agency and Federal Highway Administration. SmartWay Transport: Basic Information. April 19, 2010. http://www.epa.gov/otaq/smartway/transport/basic-information/index.htm. Accessed July 15, 2010.

28. United States Department of State. U.S. Climate Action Report 2010. Global Publishing Services, Washington, June 2010.

29. U.S. Environmental Protection Agency. Inventory of U.S. Greenhouse Gas Emissions and Sinks: 1990-2008. EPA 430-R-10-006. U.S. Environmental Protection Agency, April 15, 2010.

30. U.S. Environmental Protection Agency. Expanding and Updating the Master List of Compounds Emitted by Mobile Sources - Phase III. EPA420-R-06-005. U.S. Environmental Protection Agency, February 2006.

31. Federal Highway Administration. Interim Guidance Update on Mobile Source Air Toxic Analysis in NEPA Documents. September 30, 2009. http://www.fhwa.dot.gov/environment/airtoxic/100109guidmem.htm. Accessed July 15, 2010.

32. U.S. Environmental Protection Agency and Federal Highway Administration. Six Common Air Pollutants. July 1, 2010. http://www.epa.gov/air/urbanair/. Accessed July 15, 2010.

33. Scora, G., K. Boriboonsomin, and M. Barth. Effects of Operational Variability on Heavy-Duty Truck Greenhouse Gas Emissions. In 89th Annual Meeting of Transportation Research Board. CD-ROM. Transportation Research Board of the National Academies, Washington, D.C., 2010.

34. U.S. Environmental Protection Agency. Nitrogen Dioxide. January 25, 2010. http://www.epa.gov/air/nitrogenoxides/. Accessed July 12, 2010.

35. ICF Consulting. Assessment of Greenhouse Gas Analysis Techniques for Transportation Projects. NCHRP Project 25-25 Task 17. National Cooperative Highway Research Program, Transportation Research Board, 2006.

36. Barth, M., and K. Boriboonsomin. Real-World Carbon Dioxide Impacts of Traffic Congestion. Transportation Research Record: Journal of the Transportation Research Board, No. 2058, Transportation Research Board of the National Academies, Washington, D.C., 2008, pp. 163-171.

37. Barth, M., and K. Boriboonsomin. Access: Transportation Research at the University of California. 35. University of California Transportation Center, Fall 2009.

http://www.uctc.net/access/35/access35_Traffic_Congestion_and_Grenhouse_Gas es.shtml. Accessed August 16, 2010.

38. Brodrick, C., E. Laca, A. Burke, M. Farshchi, L. Li, and M. Deaton. Effect of Vehicle Operation, Weight, and Accessory Use on Emissions from a Modern 
Heavy-Duty Diesel Truck. Transportation Research Record: Journal of the Transportation Research Board, No. 1880, Transportation Research Board of the National Academies, Washington, D.C., 2004, pp. 119-125.

39. Timoshek, A., D. Eisinger, S. Bai, and D. Niemeier. Mobile Source Air Toxics Emissions: Sensitivity to Traffic Volumes, Fleet Composition, and Average Speeds. In 89th Annual Meeting of Transportation Research Board. CD-ROM. Transportation Research Board of the National Academies, Washington, D.C., 2010.

40. Gajendran, P, and N. Clark. Effect of Truck Operating Weight on Heavy-Duty Diesel Emissions. Environmental Science and Technology, Vol. 37, 2003, pp. 4309-4317.

41. Pierson, W. R., A. W. Gertler, and N. F. Robinson. Real-world Automotive Emission-Summary of Studies in the Fort McHenry and Tuscarora Mountain Tunnels. Atmospheric Environment, Vol. 30, 1996, pp. 2233-2256.

42. Barth, M., G. Scora, and T. Younglove. Modal Emissions Model for Heavy-Duty Diesel Vehicles. Transportation Research Record: Journal of the Transportation Research Board, No. 1880, Transportation Research Board of the National Academies, Washington, D.C., 2004, pp. 10-20.

43. Federal Highway Administration. Emission Models. January 7, 2010. http://www.fhwa.dot.gov/environment/models.htm. Accessed July 16, 2010.

44. Cambridge Systematics, Inc. Portland Freight Data Collection Phase II. Portland Freight Data Collection Team, March 2007.

45. Bureau of Labor Statistics. CPI Inflation Calculator. http://www.bls.gov/data/inflation_calculator.htm. Accessed July 22, 2010.

46. U.S. Census Bureau. Oregon 2002 Economic Census Vehicle Inventory and Use Survey: Geographic Area Series. EC02TV-OR(RV). U.S. Department of Commerce, Economics and Statistics Administration, U.S. Census Bureau, December 2004. 


\section{Appendix A: Cost Estimation Parameters for Recurring and Non-Recurring Congestion Analysis}

This section presents the assumptions and input parameters used to estimate freight transportation cost under recurring and non-recurring congestion conditions. This section will begin with recurring congestion, then highlight differences in assumptions used for non-recurring congestion. Where applicable, input data are provided in tabular or graphic form.

\section{Recurring Congestion Analysis Assumptions and Parameters Hourly Truck Travel Time and Speed Distributions}

The hourly truck average travel time and speed distributions were obtained through the methodologies defined in this research. The average hourly travel time was used in cost calculations to derive cost per hour; see Figure 34 and Figure 35 for the average hourly travel time and speed distributions used in cost estimations for recurring and non-recurring conditions. During off-peak periods (where few through truck observations were made), free-flow speeds of $52.05 \mathrm{mph}$ were assumed.

\section{Northbound I-5 Average Truck Counts}

The hourly truck count distributions used to produce recurring and nonrecurring costs were estimated from data on northbound I-5 as part of a collection effort for the Port of Portland (44). Data were collected at eight northbound I-5 count stations covering the study area used in this research. 
Trucks passing each station were classified into eight different vehicle classes per FHWA standard. Figure 32a provides an example of the truck count distribution by vehicle class for one northbound I-5 count station. The eight stations (each with three days of count data) were averaged to provide an estimate of hourly truck counts to be used in cost estimations. Figure 32b presents the final average hourly truck counts used in this research. Additionally, this data helped to provide an estimate of truck count distributions by vehicle class; these values were used as input in the emissions estimation process and are presented in Appendix B.

\section{Value of Time}

Several studies deriving freight vehicle value of time were used in the cost estimation process in order to provide a range of costs resulting from recurring and non-recurring congestion. Figure 33 presents the freight vehicle value of time used in cost scenarios. Here, the values are presented for the source year, with the adjusted 2010 price (used in this research) noted. The consumer price index was used to convert value of time costs to 2010 prices (45).

\section{Truck Counts by Operator and Service Types}

In order to provide cost estimates by operator and service type, truck count distributions by these characteristics were obtained from the Oregon 2002 Economic Census Vehicle Inventory and Use Survey report (46). Given the data available, it was assumed that medium, light-heavy and heavy-heavy 
vehicle types were to be considered commercial freight trucks (while light trucks were considered to be domestic pick-up trucks and SUVs).

Several operator characteristics were used in the Census report. It was assumed that operator characteristics of personal transportation, rental, private and N/A referred to private carrier types, while operator characteristics of motor carrier, and owner operator referred to for-hire carrier types. From the Census report, an estimate of $84 \%$ was used for the percentage of trucks that are private carriers, and $16 \%$ was used for the percentage of trucks that are for-hire carriers.

Additionally, the report was used to estimate the percentage of truckload and less than truckload carriers, which were found to be $6 \%$ and $5 \%$, respectively. The remaining percentage was attributed to the average service type.

\section{Non-Recurring Congestion Analysis Assumptions and Parameters}

Assumptions and parameters used to derive costs for the recurring congestion analysis were the same for non-recurring congestion analysis.

\section{Free-Flow Cost Estimation Comparison for Recurring and Non-Recurring Congestion Analysis}

For the recurring and non-recurring congestion analysis, a comparison to freeflow cost was needed. Here, free-flow speed was assumed to be the accepted industry average operating speed $(52.05 \mathrm{mph})$ used by ATRI $(18,25)$. This is a 
conservative speed for cost calculations when compared to posted freeway speed limits. The methods and parameters used to develop costs for the freeflow scenario were the same as indicated for recurring and non-recurring congestion studies
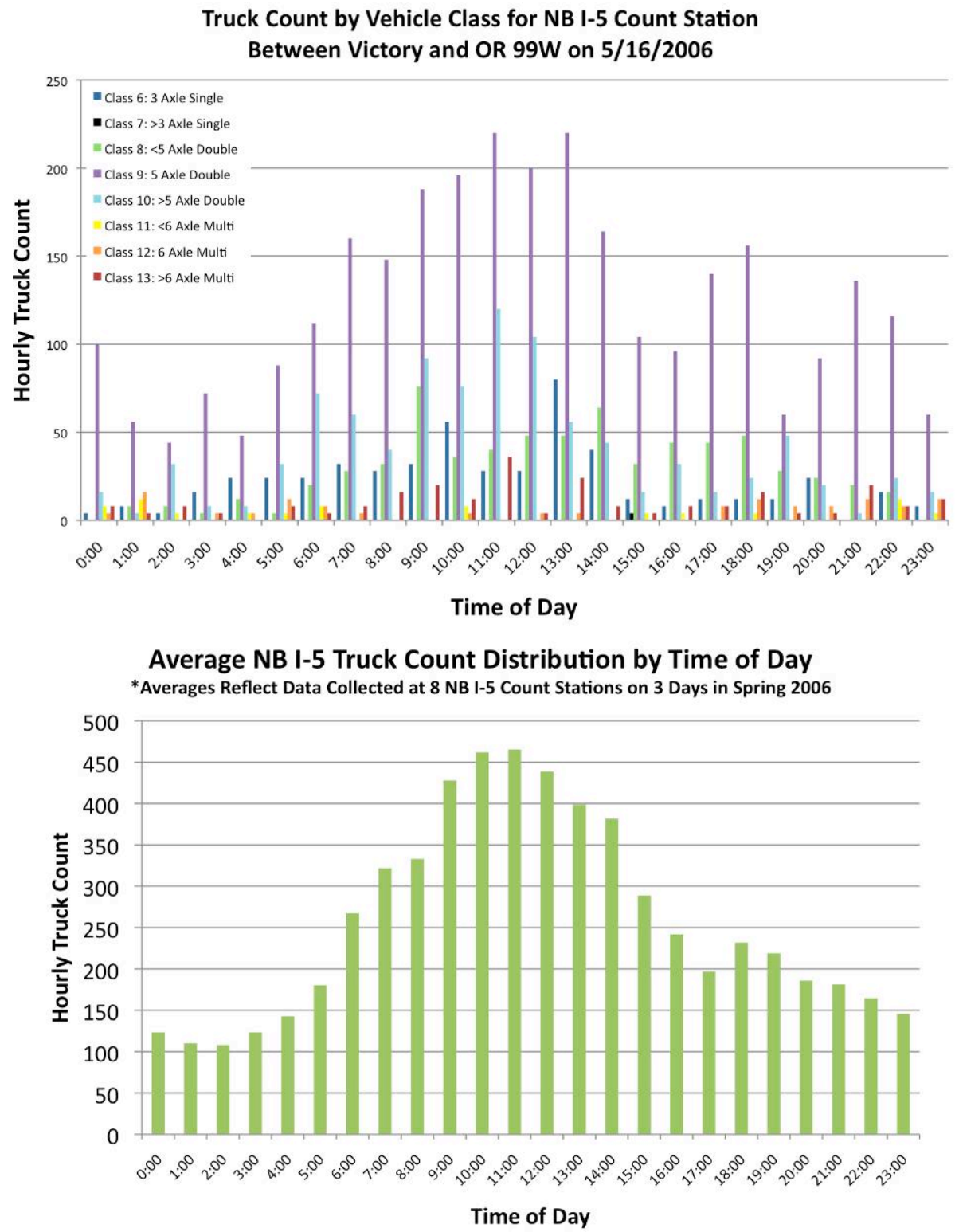

Figure 32: From top to bottom, a) truck count distribution at a northbound I-5 count station between Victory and OR $99 \mathrm{~W}$; b) average hourly northbound I-5 truck counts by time of day (average is was take from 8 count stations, each with 3 days of count data from spring of 2006). 


\begin{tabular}{|l|c|c|c|}
\hline \multicolumn{1}{|c|}{ Value of Time Source } & Cost Year & $\begin{array}{c}\text { Freight VOT } \\
\text { (per hour) }\end{array}$ & $\begin{array}{c}\text { Freight VOT 2010 } \\
\text { (per hour) }\end{array}$ \\
\hline TTI, 2009 Mobility Report & 2007 & $\$ 102.12$ & $\$ 107.46$ \\
Kawamura, 2000 All Carriers & 1999 & $\$ 23.40$ & $\$ 30.64$ \\
Kawamura, 2000 Private Carriers & 1999 & $\$ 17.60$ & $\$ 23.05$ \\
Kawamura, 2000 For-Hire Carriers & 1999 & $\$ 28.00$ & $\$ 36.67$ \\
Kawamura, 2000 Truck Load & 1999 & $\$ 25.00$ & $\$ 32.74$ \\
Kawamura, 2000 Less Than Truck Load & 1999 & $\$ 22.60$ & $\$ 29.60$ \\
Oregon, 2005 Light Trucks & 2005 & $\$ 20.35$ & $\$ 22.73$ \\
Oregon, 2005 Heavy Trucks & 2005 & $\$ 29.50$ & $\$ 32.96$ \\
Oregon, 2005 Average Trucks & 2005 & $\$ 24.93$ & $\$ 27.85$ \\
\hline
\end{tabular}

Figure 33: Freight vehicle value of time used in cost estimations of recurring and nonrecurring congestion; value of time for the source year are shown alongside the 2010 adjusted prices. Costs were adjusted using the consumer price index (45). 


\section{Appendix B: MOVES2010 Emission Estimation Input Parameters for Recurring and Non-Recurring Congestion Analysis}

This section presents the assumptions and input parameters used for MOVES2010, in order to estimation emissions rates under recurring and nonrecurring congestion conditions. This section will begin with recurring congestion, then highlight differences in assumptions used for non-recurring congestion. Where applicable, input data are provided in graphic form.

\section{Recurring Congestion Analysis Assumptions and Parameters}

Analysis Scale

The northbound I-5 corridor emissions estimation was performed using the project-level analysis as the MOVE2010 Domain/Scale. The MOVE2010 Calculation Type used was Emission Rates to provide the grams per mile of emissions each hour.

\section{Time Spans}

The analysis year was chosen to be 2010, for a typical weekday in the month of May.

\section{Geographical Bounds}

The region select for analysis was OREGON-Multnomah County (to reflect the Portland Metropolitan area). 


\section{Vehicle/Equipment}

Five vehicle and fuel source combinations were chosen to represent different trucks that may be present on the freeway (the truck types listed below where the only truck types categories available in the MOVES2010 model):

- Diesel Fuel - Combination Long-haul Truck

- Diesel Fuel - Combination Short-haul Truck

- Diesel Fuel - Light Commercial Truck

- Diesel Fuel - Single Unit Long-haul Truck

- Diesel Fuel - Single Unit Short-haul Truck

\section{Road Type}

The Urban Restricted Access road type was chosen to reflect urban freeway conditions.

\section{Pollutant and Processes}

A variety of GHG, MSAT and criteria pollutants were chosen for analysis; running exhaust process was selected.

\section{Strategies}

No user-defined inputs were selected for this input parameter. 


\section{Output}

MOVES2010 default output settings were selected, and rate output units were chosen to be in grams per mile.

\section{Run Spec Input Data}

Links: One link was needed for this analysis as the study focused on a northbound segment of I-5. The link length was input as 31.75 miles. Figure 35 provides link average speed (estimated from hourly through truck travel time and speed distributions) and hourly truck volumes (obtained from (44)) were used for this analysis.

Link Sources Types: Based on local truck volume data (obtained from (44)), a distribution of truck volume by truck type was estimated and input into the model. Vehicle classes 6 and 7 were assumed to be Light Commercial Trucks, classes 8, 9 and 10 were assumed to be Single Unit Long- and Shorthaul Trucks and classes 11, 12 and 13 were assumed to be Combination Longand Short- haul Trucks. The final distribution of count by truck type are as follows,

- $4 \%$ Combination Long-haul Truck

- $4 \%$ Combination Short-haul Truck

- 10\% Light Commercial Truck

- $41 \%$ Single Unit Long-haul Truck

- $41 \%$ Single Unit Short-haul Truck 
Link Drive Schedules: Fifteen-minute through truck travel time and speed distributions were used to develop Link Drive Schedule data. In fifteen time bins where no fifteen-minute truck data were obtained for through trucks (i.e., no through trucks were found in the time bin), an estimation of speed was used based on the based of previous and subsequent time bins. Figure 34 shows the fifteen-minute speeds used each hour to develop link drive schedules. During off-peak periods (where little truck data were obtained) free-flow travel time and speed conditions were assumed.

Meteorology Data: Default data from MOVES2010 for the OREGONMultnomah County region were used to provide meteorological information about the area; the climate reflects the average weekday in May based on previous input parameters.

Age Distribution, Fuel Supply, and Fuel Formulation: Default data from MOVES2010 were used to provide input information for these categories.

Operating Mode Distribution, Off-Network, and I/M Programs: Input values were not required for these categories in order to perform the analysis. Link and Link Schedule provided necessary speed distribution information (operating mode distribution was not required), and no off-network links existed in the study area. I/M programs were not investigated. 


\section{Non-Recurring Congestion Analysis Assumptions and Parameters}

\section{Run Spec Input Data}

Links: One link was needed for this analysis as the study focused on a northbound segment of I-5. The link length was input as 5 miles. Figure 35 provides the link average speed (estimated from hourly through-incident truck travel time and speed distributions) and average hourly truck volumes (obtained from (44)) used for this analysis. Only four time bins were investigated because only four incident hours were studied.

Link Drive Schedules: Fifteen-minute through-incident truck travel time and speed distributions were used to develop Link Drive Schedule data. A limited number of through-incident trucks were available for each incident period, so in fifteen time bins where no fifteen-minute truck data were obtained (i.e., no through-incident trucks were found in the time bin), an estimation of speed was used based on the previous and subsequent time bins. Figure 35 shows the fifteen-minute speeds used for each incident hour to develop link drive schedules. Only four time bins were investigated because only four incident hours were studied. 
Free-Flow Emission Estimation Comparison for Recurring and NonRecurring Congestion Analysis

For the recurring and non-recurring congestion analysis, a comparison to freeflow emissions was needed. With this analysis, the only changes in input parameters from those used in recurring and non-recurring congestion analysis were those data reflected in the Link and Link Drive Schedule inputs. Here, an average speed of $52.05 \mathrm{mph}$ was used in the Link inputs, and a constant speed of $52.05 \mathrm{mph}$ for each fifteen-minute time bin were used for Link Drive Schedule data. Free-flow speed was assumed to be the accepted industry average operating speed $(52.05 \mathrm{mph})$ used by ATRI $(18,25)$. This is a conservative speed for cost calculations when compared to posted freeway speed limits.

\section{Recurring Emission Estimation Comparison for Non-Recurring Congestion}

For the non-recurring congestion analysis, a comparison to recurring congestion was needed. With this analysis, the only changes in input parameters from those used for non-recurring congestion were data reflected in the Link and Link Drive Schedule inputs. The average speed used in the Link inputs, and fifteen-minute speeds used for Link Drive Schedule for the recurring congestion through incident areas are also shown in Figure 35. 


\begin{tabular}{|c|c|c|c|c|c|c|c|c|c|c|c|}
\hline Time Bin & $\begin{array}{c}\text { Travel } \\
\text { Time } \\
\text { (min) }\end{array}$ & $\begin{array}{l}\text { Speed } \\
(\mathrm{mph})\end{array}$ & $\begin{array}{c}\text { Hourly } \\
\text { Average } \\
\text { Travel Time } \\
\text { (min) }\end{array}$ & $\begin{array}{l}\text { Hourly } \\
\text { Average } \\
\text { Speed } \\
\text { (mph) }\end{array}$ & $\begin{array}{c}\text { Hourly } \\
\text { Truck } \\
\text { Volume } \\
\text { (veh/hr) }\end{array}$ & Time Bin & $\begin{array}{c}\text { Travel } \\
\text { Time } \\
\text { (min) }\end{array}$ & $\begin{array}{l}\text { Speed } \\
(\mathrm{mph})\end{array}$ & $\begin{array}{c}\text { Hourly } \\
\text { Average } \\
\text { Travel Time } \\
\text { (min) }\end{array}$ & $\begin{array}{c}\text { Hourly } \\
\text { Average } \\
\text { Speed } \\
\text { (mph) }\end{array}$ & $\begin{array}{c}\text { Hourly } \\
\text { Truck } \\
\text { Volume } \\
\text { (veh/hr) }\end{array}$ \\
\hline 00:00:00 & $\begin{array}{l}36.60 \\
36.60\end{array}$ & $\begin{array}{l}52.05 \\
52.05\end{array}$ & 36.60 & 52.05 & 123 & 12:00:00 & $\begin{array}{l}38.37 \\
38.67\end{array}$ & $\begin{array}{l}49.64 \\
49.27\end{array}$ & 37.58 & 50.69 & 439 \\
\hline $\begin{array}{l}00: 15: 00 \\
00: 30: 00\end{array}$ & 36.60 & $\begin{array}{l}52.05 \\
52.05\end{array}$ & & & & $12: 30: 00$ & $\begin{array}{l}38.67 \\
37.50\end{array}$ & $\begin{array}{l}49.27 \\
50.79\end{array}$ & & & \\
\hline $00: 45: 00$ & 36.60 & 52.05 & & & & $12: 45: 00$ & 35.81 & 53.19 & & & \\
\hline 01:00:00 & 36.60 & 52.05 & 36.60 & 52.05 & 110 & 13:00:00 & 38.27 & 49.78 & 44.15 & 43.15 & 399 \\
\hline $01: 15: 00$ & 36.60 & 52.05 & & & & $13: 15: 00$ & 38.34 & 49.69 & & & \\
\hline $01: 30: 00$ & 36.60 & 52.05 & & & & $13: 30: 00$ & 47.57 & 40.04 & & & \\
\hline $01: 45: 00$ & 36.60 & 52.05 & & & & $13: 45: 00$ & 47.57 & 40.05 & & & \\
\hline 02:00:00 & 36.60 & 52.05 & 36.60 & 52.05 & 108 & $14: 00: 00$ & 46.33 & 41.12 & 55.39 & 34.39 & 382 \\
\hline $02: 15: 00$ & 36.60 & 52.05 & & & & $14: 15: 00$ & 58.26 & 32.70 & & & \\
\hline $02: 30: 00$ & 36.60 & 52.05 & & & & $14: 30: 00$ & 35.51 & 53.65 & & & \\
\hline $02: 45: 00$ & 36.60 & 52.05 & & & & $14: 45: 00$ & 58.12 & 32.77 & & & \\
\hline 03:00:00 & 36.60 & 52.05 & 36.60 & 52.05 & 123 & 15:00:00 & 61.64 & 30.91 & 71.32 & 26.71 & 289 \\
\hline $03: 15: 00$ & 36.60 & 52.05 & & & & $15: 15: 00$ & 72.59 & 26.24 & & & \\
\hline $03: 30: 00$ & 36.60 & 52.05 & & & & $15: 30: 00$ & 71.14 & 26.78 & & & \\
\hline $03: 45: 00$ & 36.60 & 52.05 & & & & $15: 45: 00$ & 78.72 & 24.20 & & & \\
\hline 04:00:00 & 36.60 & 52.05 & 36.60 & 52.05 & 143 & $16: 00: 00$ & 68.30 & 27.89 & 70.79 & 26.91 & 242 \\
\hline $04: 15: 00$ & 36.60 & 52.05 & & & & $16: 15: 00$ & 69.08 & 27.58 & & & \\
\hline $04: 30: 00$ & 36.60 & 52.05 & & & & $16: 30: 00$ & 78.12 & 24.38 & & & \\
\hline $04: 45: 00$ & 36.60 & 52.05 & & & & $16: 45: 00$ & 70.10 & 27.18 & & & \\
\hline 05:00:00 & 36.60 & 52.05 & 37.93 & 50.22 & 180 & $17: 00: 00$ & 60.40 & 31.54 & 58.58 & 32.52 & 197 \\
\hline $05: 15: 00$ & 36.64 & 51.99 & & & & $17: 15: 00$ & 61.99 & 30.73 & & & \\
\hline $05: 30: 00$ & 36.90 & 51.63 & & & & $17: 30: 00$ & 48.46 & 39.31 & & & \\
\hline $05: 45: 00$ & 41.38 & 46.04 & & & & $17: 45: 00$ & 56.84 & 33.52 & & & \\
\hline 06:00:00 & 41.88 & 45.49 & 40.07 & 47.54 & 267 & 18:00:00 & 56.85 & 33.51 & 48.35 & 39.4 & 232 \\
\hline $06: 15: 00$ & 39.02 & 48.82 & & & & $18: 15: 00$ & 41.35 & 46.08 & & & \\
\hline $06: 30: 00$ & 39.02 & 48.82 & & & & $18: 30: 00$ & 45.36 & 42.00 & & & \\
\hline $06: 45: 00$ & 39.02 & 48.82 & & & & $18: 45: 00$ & 40.84 & 46.65 & & & \\
\hline 07:00:00 & 39.39 & 48.36 & 45.52 & 41.85 & 322 & $19: 00: 00$ & 39.74 & 47.93 & 37.22 & 51.18 & 219 \\
\hline $07: 15: 00$ & 39.39 & 48.36 & & & & $19: 15: 00$ & 36.23 & 52.59 & & & \\
\hline $07: 30: 00$ & 50.31 & 37.86 & & & & $19: 30: 00$ & 35.93 & 53.01 & & & \\
\hline $07: 45: 00$ & 45.08 & 42.25 & & & & $19: 45: 00$ & 35.93 & 53.01 & & & \\
\hline 08:00:00 & 41.84 & 45.53 & 42.12 & 45.23 & 333 & 20:00:00 & 36.60 & 52.05 & 36.60 & 52.05 & 186 \\
\hline $08: 15: 00$ & 42.41 & 44.91 & & & & $20: 15: 00$ & 36.60 & 52.05 & & & \\
\hline $08: 30: 00$ & 43.51 & 43.78 & & & & $20: 30: 00$ & 36.60 & 52.05 & & & \\
\hline $08: 45: 00$ & 40.35 & 47.21 & & & & $20: 45: 00$ & 36.60 & 52.05 & & & \\
\hline 09:00:00 & 37.06 & 51.40 & 39.29 & 48.48 & 428 & 21:00:00 & 36.60 & 52.05 & 36.60 & 52.05 & 181 \\
\hline $09: 15: 00$ & 41.02 & 46.44 & & & & $21: 15: 00$ & 36.60 & 52.05 & & & \\
\hline $09: 30: 00$ & 40.03 & 47.59 & & & & $21: 30: 00$ & 36.60 & 52.05 & & & \\
\hline $09: 45: 00$ & 39.26 & 48.52 & & & & $21: 45: 00$ & 36.60 & 52.05 & & & \\
\hline $10: 00: 00$ & 36.60 & 52.05 & 36.60 & 52.05 & 462 & 22:00:00 & 36.60 & 52.05 & 36.60 & 52.05 & 165 \\
\hline $10: 15: 00$ & 36.60 & 52.05 & & & & $22: 15: 00$ & 36.60 & 52.05 & & & \\
\hline $10: 30: 00$ & 36.60 & 52.05 & & & & $22: 30: 00$ & 36.60 & 52.05 & & & \\
\hline $10: 45: 00$ & 36.60 & 52.05 & & & & $22: 45: 00$ & 36.60 & 52.05 & & & \\
\hline 11:00:00 & 38.24 & 49.82 & 37.31 & 51.06 & 465 & 23:00:00 & 36.60 & 52.05 & 36.60 & 52.05 & 146 \\
\hline $11: 15: 00$ & 37.86 & 50.32 & & & & $23: 15: 00$ & 36.60 & 52.05 & & & \\
\hline $11: 30: 00$ & 36.08 & 52.80 & & & & $23: 30: 00$ & 36.60 & 52.05 & & & \\
\hline $11: 45: 00$ & 36.44 & 52.27 & & & & $23: 45: 00$ & 36.60 & 52.05 & & & \\
\hline
\end{tabular}

Figure 34: Link and Link Drive Schedule travel time and speed distributions for recurring congestion analysis. For of-peak periods (where little through truck data was observed) 52.04 mph free-flow conditions were assumed. 

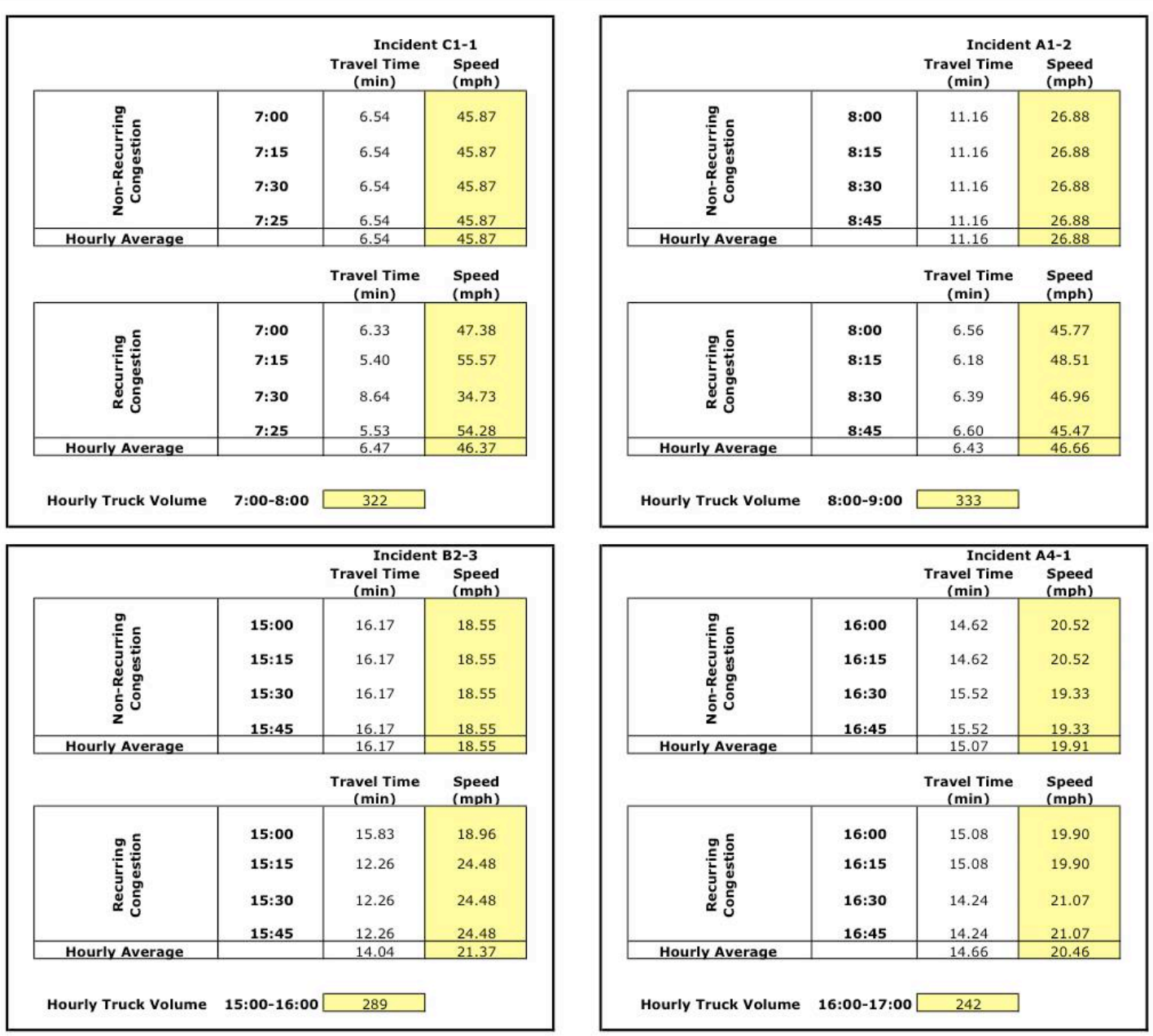

Figure 35: Link and Link Drive Schedule travel time and speed distributions for nonrecurring analysis; non-recurring and recurring congestion conditions provided for each incident areas and incident period studied. 